\title{
Welding and Repair of Single Crystal Ni-based Superalloys
}

by

\author{
Sizhao Wang \\ B. Eng. Beijing Polytechnic University
}

\begin{abstract}
A thesis submitted to the Faculty of Graduate Studies and Research in partial fulfillment of the requirements for the degree of

\section{Master of Applied Science}

\author{
Ottawa-Carleton Institute for Mechanical and Aerospace Enginecring \\ Department of Mechanical and Aerospace Engineering \\ Carleton University \\ Ottawa, Ontario \\ Canada
}

January 2005 


$\begin{array}{ll}\begin{array}{l}\text { Library and } \\ \text { Archives Canada }\end{array} & \begin{array}{l}\text { Bibliothèque et } \\ \text { Archives Canada }\end{array} \\ \begin{array}{l}\text { Published Heritage } \\ \text { Branch }\end{array} & \begin{array}{l}\text { Direction du } \\ \text { Patrimoine de l'édition }\end{array} \\ \begin{array}{l}\text { 395 Wellington Street } \\ \text { Ottawa ONK1A ON4 } \\ \text { Canada }\end{array} & \begin{array}{l}\text { 395, rue Wellington } \\ \text { Ottawa ON K1A ON4 } \\ \text { Canada }\end{array}\end{array}$

Your file Votre référence ISBN:

Ourfile Notre reterence ISBN:

NOTICE:

The author has granted a nonexclusive license allowing Library and Archives Canada to reproduce, publish, archive, preserve, conserve, communicate to the public by telecommunication or on the Internet, loan, distribute and sell theses worldwide, for commercial or noncommercial purposes, in microform, paper, electronic and/or any other formats.

The author retains copyright ownership and moral rights in this thesis. Neither the thesis nor substantial extracts from it may be printed or otherwise reproduced without the author's permission.
AVIS:

L'auteur a accordé une licence non exilusive permettant à la Bibliothèque et Archives Canada de reproduire, publier, archiver, sauvegarder, conserver, transmettre au public par lélécommunication ou par l'Internet, prêter, distribuer et vendre des thèses partout dans le monde, à des fins commerciales ou autres, sur support microforme, papier, électronique et/ou autres formats.

L'auteur conserve la proprièté du droit d'auteur et des droits moraux qui protège cette thèse. $\mathrm{Ni}$ la thèse ni des extraits substantiels de celle-ci ne doivent être imprimés ou autrement reproduits sans son autorisation.
In compliance with the Canadian

Privacy Act some supporting forms may have been removed from this thesis.

While these forms may be included in the document page count, their removal does not represent any loss of content from the thesis.
Conformément à la loi canadienne sur la protection de la vie privée, quelques formulaires secondaires ont été enlevés de cette thèse.

Bien que ces formulaires aient inclus dans la pagination, il n'y aura aucun contenu manquant. 
The undersigned recommend to the

Faculty of Graduate Studies and Research acceptance of the thesis

\title{
Welding and Repair of Single Crystal Ni-based Superalloys
}

by

\author{
Sizhao Wang \\ B. Eng Beijing Polytechnic University
}

in partial fulfillment of the requirements

for the degree of Master of Applied Science

Dr. J.C.Beddoes

Chair, Department of Mechanical and Acrospace Engineering

Dr. H. Saari, Thesis Supervisor

Carleton University

January 2005

ii 


\begin{abstract}
Single crystal nickel-base superalloys such as PWA 1484 exhibit superior performance compared to conventional superalloys, and are used extensively in turbine blade applications requiring high temperature mechanical strength and good hot corrosion resistance. The life of these blades is typically limited by cracks and crosion. Due to the high cost of these blades, welding techniques are being considered to weld/repair worn components, extending their useful lives and delaying the need for expensive replacement components. However, the sensitivities for solidification cracking and post weld heat treatment cracking are relatively high in these alloys. Electron Beam Welding (EBW) can deliver the most concentrated heat sources and has the potential to address these issues. Numerous welding trials and structural tests must be conducted to identify the optimum method and welding parameters.
\end{abstract}

In this thesis, welding and weldability are studied over a range of material conditions, welding parameters and directions. The influence of welding parameters on the fusion zone microstructure, and resultant weldability is investigated using combination of microscopic examination and micro-hardness testing. The effects of welding parameters on localized microstructural features, solidification cracking sensitivity, and mechanical propertics of electron beam autogenously welded coupons of single crystal PWA 1484 are discussed as well. 


\section{Acknowledgments}

Among all the ones who gave me generous and kind support throughout my thesis composing, I would like to firstly thank my thesis supervisor, Professor Henry Saari for offering me this valuable opportunity to work on this project and for his continued guidance. I would also like to express my appreciation to Dr. Ali Merati for his helpful supervision and mentoring on profound knowledge of welding fundamentals.

I would like to acknowledge the Institute of Aerospace Research, National Research Council Canada and Mick J. Pates from Nu-tech Precision Metals Inc. for their facilitics support.

Many thanks to the material lab's staff, especially Rick Kersey and Scott Yandt, for their help and advice.

Finally, I owe the thanks to the love and encouragement of my parents and my fiance Mare Genest, who gave me the motivation for finishing this thesis. 


\section{Table of Contents}

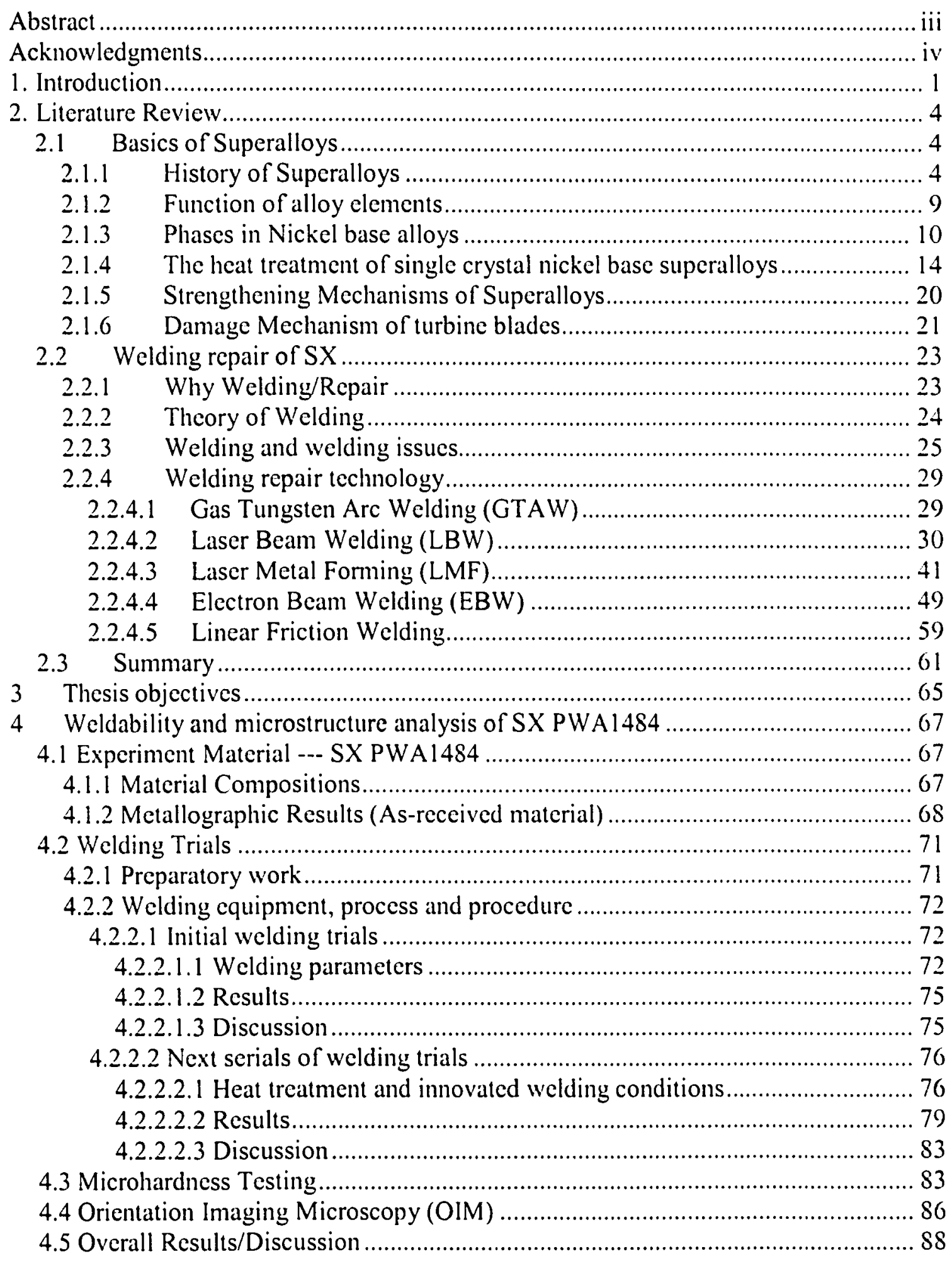


4.5.1 Welding direction vs. crack tendency ................................................. 88

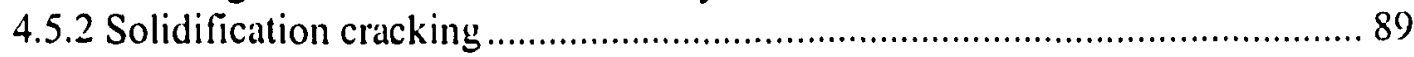

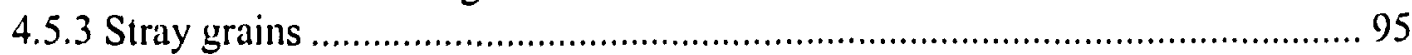

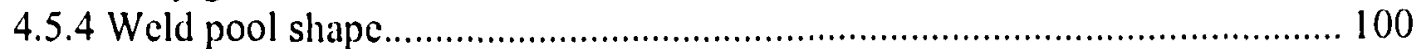

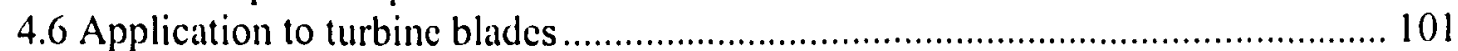

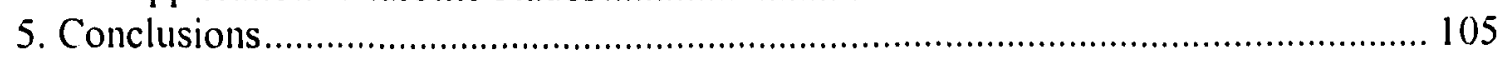

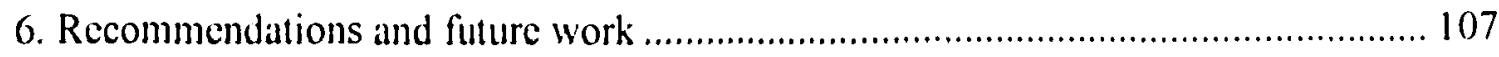

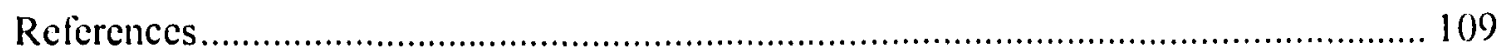




\section{List of Figures}

Figure 1 Cutaway illustration of a Pratt \& Whitney PW4000 high-bypass ratio turbofan engine illustrating the arrangement of the main engine components [1] .................. 2

Figure 2 Turbine engine efficiency in term of the increase of turbine inlet temperature [2]

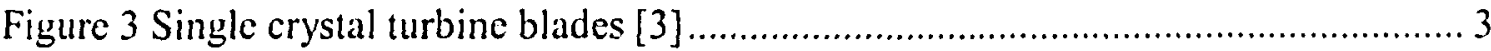

Figure 4 Conventionally cast, DS, and SX superalloys [11] ......................................

Figure 5 Nickel base superalloys phases, developed over the years [5] ..................... 11

Figure 6. Transmission electron micrograph showing a large fraction of cubical $\gamma$

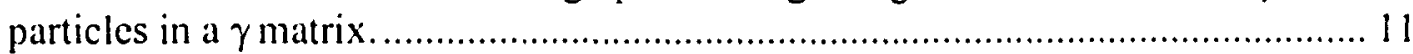

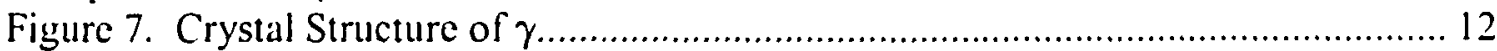

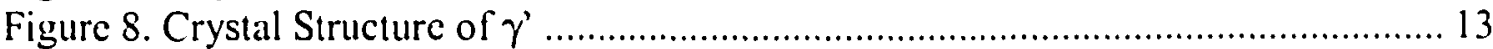

Figure 9 Time-temperature curves for CMSX-2 alloy, corresponding to different cooling rates between 150 and $0.002^{\circ} \mathrm{C} / \mathrm{s}$ from $1300^{\circ} \mathrm{C}$ (after a 20 min hold at $1305^{\prime \prime C}$ )

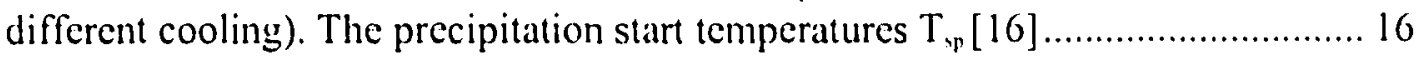

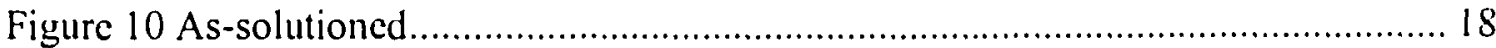

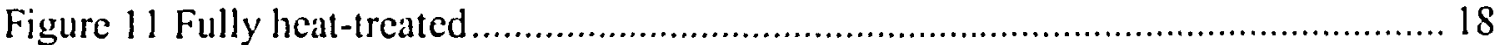

Figure 12 Second step HT is to get optimum $\gamma$................................................. 18

Figure 13 Ultra fine $\gamma^{\prime}$ is attained after aging ........................................................ 19

Figure 14. Ni-base superalloy strength (hardness) with respect to precipitate size [5] ... 21

Figure 15 Components of typical turbine blade [23] ............................................... 22

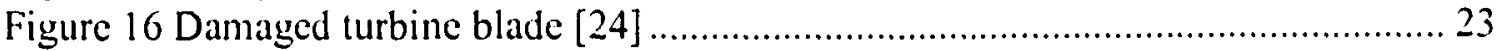

Figure 17. A schematic diagram showing the interaction between heat source and the base metal. Three distinct welding regions are fusion zone, the heat effected zone,

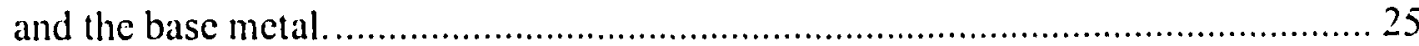

Figure 18 Relationship between estimated weldability and $\mathrm{Al}, \mathrm{Ti} \mathrm{Cr}$ and Co content [29]

Figure 19 Schematic diagram illustrating the mechanism of solidification cracking [30]

Figure 20 Epitaxial growth at the edge of welds and high-angle equiaxed grains in welds

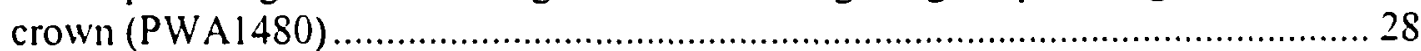

Figure 21 Laser beam welding system diagram [42] .......................................... 31

Figure 22 Microstructure of pulsed laser welded PWA1480 showing dendrite growth pattern within weld and presence of stray grains in centre of weld ....................... 37

Figure 23 Single crystal nature was maintained in welded $\mathrm{Fe}-15 \mathrm{Cr}-15 \mathrm{Ni} \ldots \ldots \ldots \ldots \ldots \ldots . . . . . . . .37$

Figure 24 Stray grains exist on only one side of the welds during high speed and high

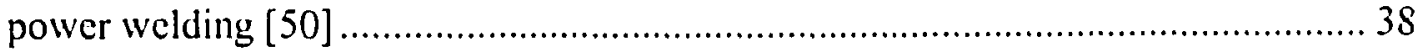

Figure 25. Schematic representation of .......................................................... 41

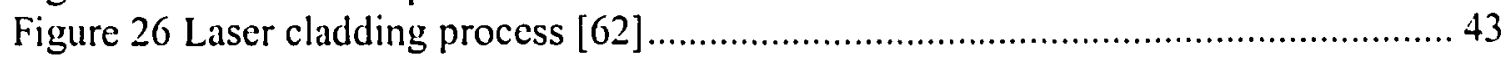

Figure 27 Principle of the laser powder welding process [63] ................................. 43

Figure 28 Laser metal forming process and the evolution of the solidification velocity $V$ and temperature gradient $G$ along the solid/liquid interface [64] ......................... 44 
Figure 29 columnar-to-equiaxed transitions [65]

Figure $30 \mathrm{CET}$ can be controlled by choosing the processing parameters [67] .............. 47

Figure 31 Electron Beam welding facility [77] ..........................................................5 50

Figure 32. Electron Beam Welding joining process diagram, EBW gun target a weld joint by impinging a beam of high-energy electrons to heat it [78] ...............................51

Figure 33 Post weld heat crack in Udimet $700 \mathrm{LC}$ welded in the fully heat treated

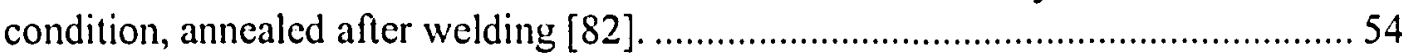

Figure 34 SX PWA1480 is susceptible to hot cracking [85] ........................................57

Figure $35 \mathrm{~A}$ geometrical model was developed to predict the dendrite microstructure in single crystal welds [88]

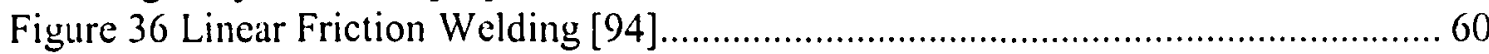

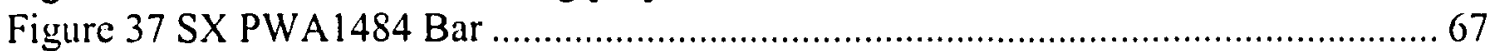

Figure 38 A longitudinal section showing the SX growth direction oriented vertically 69 Figure 39 A transverse section shows the dendrite from the top with the SX growth direction oriented perpendicularly to the plane of the paper.

Figure 40 A high magnification SEM image demonstrates the morphology of $\gamma / \gamma$ 'cutectic phases and $\gamma^{\prime}$ 70

Figure 41 Large amounts of exhibited eutectic phases reveal the microstructure of asreceived material in detail 70

Figure 42 A SEM micrograph of the as-received single crystal PWA1484 bar clearly illustrates the cuboidal nature of the $\gamma$ ' precipitates in the $\gamma$ matrix

Figure 43 Orientation of the longitudinal and transverse EB welding coupons cut from the as-received SX PWA1484 bars. Also shown are the EB welding directions .... 72

Figure 44 Welding coupon showing the longitudinal and transverse EB welds. The longitudinal weld, in the SX growth direction, is oriented horizontally.................. 73

Figure 45 Fine gamma prime is the outcome of solution heat treatment, showing the material is softened

Figure 46 Low speed tends to maintain the epitaxial growth ........................................ 81

Figure 47 High-speed results in more misoriented grains ............................................ 82

Figure 48 AMH43 automatic Micro/Macro-indentation hardness testing system............ 84

Figure 49 microhardness tester ............................................................................... 84

Figure 50 Microhardness result indicates no apparent HAZ in EB welded PWA1484... 85

Figure 51 Sample 02-Orientation map (Sample Normal direction). A grain size

distribution plot and a misorientation angle distribution plot are also shown. Heat

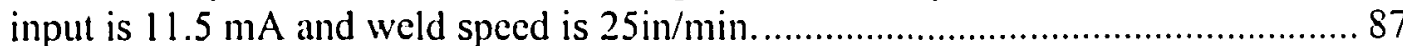

Figure 52 Sample 04-Orientation map (beam current $11 \mathrm{~mA}$, travel specd 20in/min).... 87

Figure $53 \mathrm{~W}$ elding direction does not have an impact on crack tendency ..................... 89

Figure 54 Scanning electron micrographs showing dendritic features on weld crack surface

Figure 55 Detailed SEM image reveals the dendrite-solidificd laycrs on crack surface. 93 Figure 56 Microstructure of FZ showing cracks are surrounded by $\gamma / \gamma^{\prime}$ eutectic phases. 94 Figure 57 Shrinkage porosities in interdendritic region promote the presence of solidification cracking

Figure 58 Cracks propagate along the grain boundaries

Figure 59 stray grains is defined as misorientated grain with high angle grain boundaries,

revealing the loss of single crystallinality 96 
Figure 60 Stray grain are more common in the crown and the center of the welds than at the fusion zone edge.................................................................................... 98

Figure 61 Crack travels along the high angle grain boundaries...................................... 98

Figure 62 The using of oscillation complicates the occurrence of stray grains............... 99

Figure 63 Pool shape vs. welding conditions........................................................... 100

Figure 64 Typical gas turbine repair welds [103] ................................................... 101

Figure 65 Stress in typical blade repair [103] ..................................................... 103 


\section{List of Tables}

Table 1 Relationship of composition (major elements) and strength as temperature capability for wrought and cast nickel-base superalloys [5]................................... 7

Table 2 Characteristic comparison of conventional fusion welding, LBW and EBW .... 53

Table 3 Welding parameters regarding to crack tendency, first patch of specimen .........74

Table 4 Welding parameters related to crack tendency, second patch of specimen......... 77 


\section{Introduction}

The gas turbine engine [Figure 1] has been used in aircraft over the past 50 years. Because of its critical nature, materials for gas turbine components are required to meet a wide range of temperature resistance and stress application requirements. At high temperatures [Figure 2] and severe environments or operating conditions, turbine blades are vulnerable to fatigue and creep. Thus, how to efficiently extend their life cycle is a significant issue that needs to be solved. These drawbacks have been reduced by specific alloy additions, heat treatments and advances in processing techniques. Nickel base single crystal superalloys have been intensively used in turbine blades [Figure 3] for their outstanding strength and oxidation resistance over the high temperature encountered. These alloys exhibit a combination of creep resistance, yield and tensile strength, thermal fatigue resistance and metallurgical stability. High costs of blade replacement makes welding and repair an alternative to extending the blades' lives as it delays the need for the replacement of expensive components. However, there are various challenges associated with the welding of these alloys, which involve cracking during welding and post weld heat treatments, and microstructural changes in welds and strength in the heataffected zone. The successful application of a weld is largely dectemined by choosing proper trial that fits in the material and optimizes the welding procedures. 


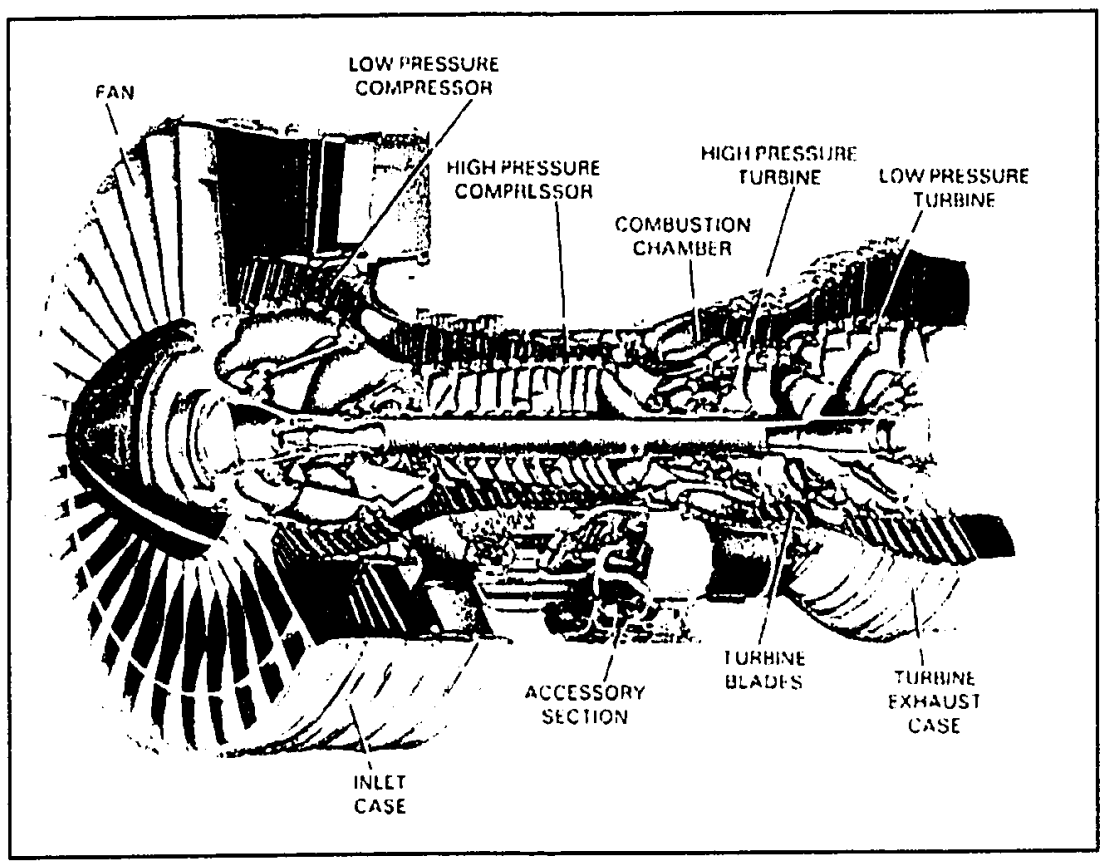

Figure 1 Cutaway illustration of a Pratt \&. Whitney PW 4000 high-bypass ratio turbofan engine illustrating the arrangement of the main engine components [1]
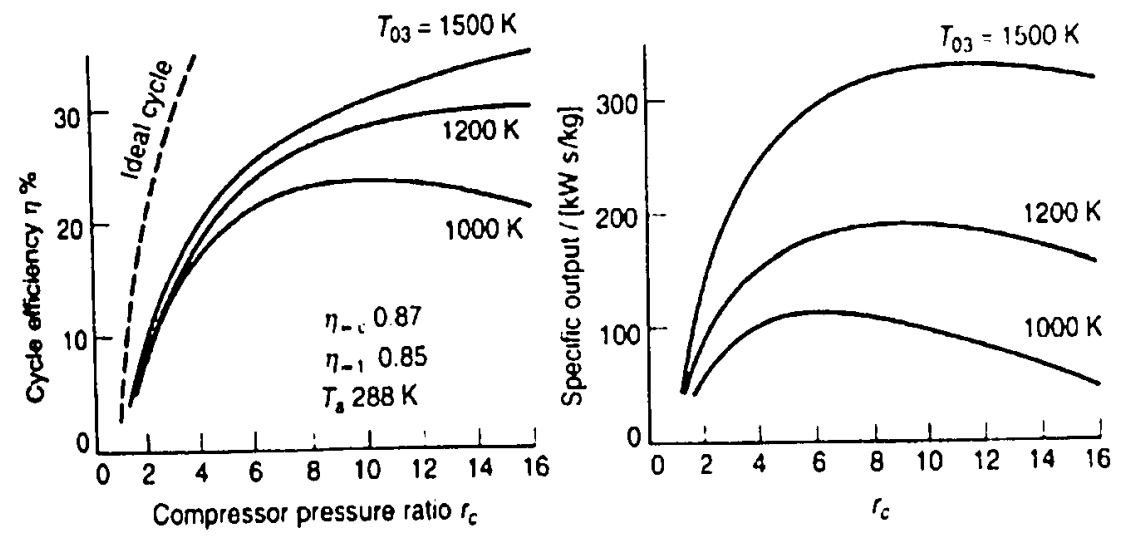

Figure 2 Turbine engine efficiency in term of the increase of turbine inlet temperature [2] 


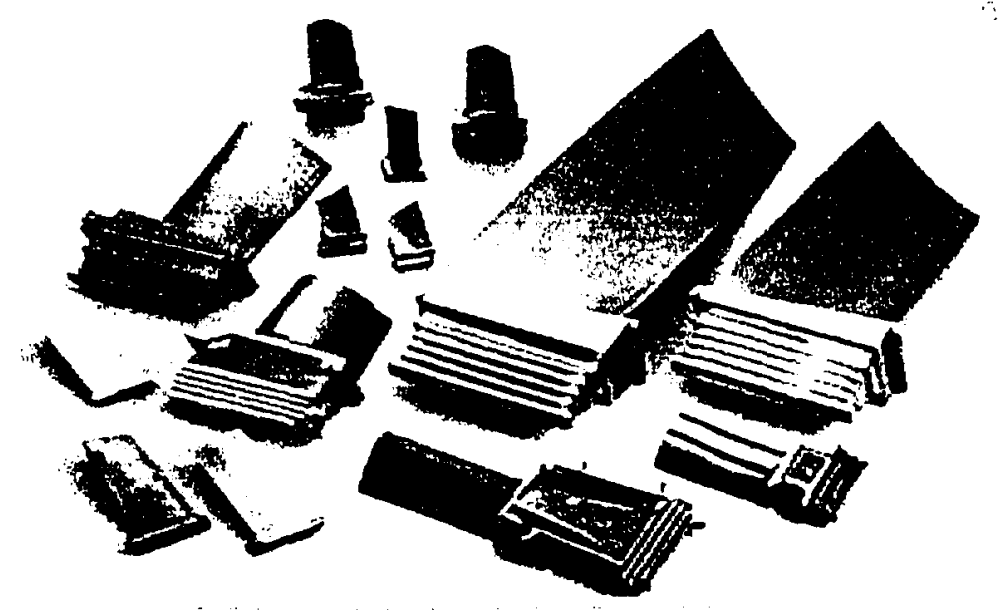

Figure 3 Single crystal lurbine blades [3]

In the following chapter, the fundamentals to support this project are developed through a broad literature review. The review covers the basics of superalloys and various welding technologies using for repairing gas turbine blades. The specific thesis objectives are given in chapter 3 . In chapter 4 , the material, welding trials and microstructure development are presented in detail. Chapter 5 summarizes the work accomplished and conclusion made. The last chapter suggests the future research. 


\section{Literature Review}

The following is the literature review of superalloy and welding background. Section 2.1 focuses on superalloys theory, starting with the development history of superalloys. Then fundamentals of superalloy are reviewed, covering the function of alloy elements, phases in Ni-base alloys, heat treatment of superalloys (especially single crystal PWA1484), and strengthening mechanisms of superalloys. This is followed by a brief introduction on damage mechanisms of turbine blades. In section 2.2, welding and repair of single crystal is reviewed from the welding theory to several welding techniques, including electron beam welding, laser beam welding, laser metal forming and lincar friction welding. The advantages and drawback of each welding procedure are presented. A number of industrial examples are illustrated in this section as well. The last section 2.3 summarizes the current status of repairing single crystal turbine blades and highlights future growth in this area.

\subsection{Basics of Superalloys}

\subsubsection{History of Superalloys}

Supcralloys developments have experienced vast improvement since their introduction. Nickel-base superalloy were first developed in the 1930s in France, Germany, England and United States, prompted by the need for more heat-resistant materials in aircraft engines [4]. The following sequence of material stages briefly covers the development of superalloys. 
The first superalloy turbine blades were developed as wrought alloys. Nimonic alloy 74 (Nickel-20\%Cr) was produced by Mond Nickel Company, England in late 1941[5]. A series of nickel-chromium-iron alloys were developed at Huntington Alloy Products Division of International Nickel Company. Inconel alloy 600, as a representative of those alloys, was based on solid-solution treatment with addition of aluminum and titanium to obtain $\gamma^{\prime}$ hardening.

During the late 1940s, disk alloy was produced by Pratt and Whitney Aircraft and the General Electric [6], and for severe corrosive environments they were soon selected for rotor blades. $10 \%$ cobalt is added to slabilize the F.C.C. phase; $7.5 \%$ tungsten for solid solution strengthening; $25 \%-35 \%$ chromium for solid solution strengthening and oxidation resistance by forming a $\mathrm{Cr}_{2} \mathrm{O}_{3}$ protective oxide; and up to $0.5 \%$ carbon to form a carbide dispersion.

Later on, the $\mathrm{Ni}$-base alloys developed into a broad class of what are now called nickelbase superalloys. Nickel has high melting point $\left(1+52^{\circ} \mathrm{C}, 2646^{\circ} \mathrm{F}\right)$, which contributes to the high temperature resistance for the alloys [7]. Elements such as tantalum, titanium, chromium, tungsten and molybdenum also have very high melting points and retain their hardness and high strength at temperature range between $1000-1200^{\circ} \mathrm{C}[7]$. The initial development was the addition of a small amount of $\mathrm{Al}$ and $\mathrm{Ti}$, originally to act as deoxidizers. Aluminum has a beneficial effect on oxidation resistance as it forms stable $\mathrm{Al}_{2} \mathrm{O}_{3}$ in the oxide scalc during high temperature exposure. The ordered F.C.C. phase, known as $\gamma^{\prime}\left(\mathrm{Ni}_{3}(\mathrm{Al}, \mathrm{Ti})\right)$, strengthens the disordered primary solid solution $\gamma$ by forming 
coherent or semi-coherent phase boundaries. The $\mathrm{Al}$ and $\mathrm{Ti}$ content were increased to increase the volume fraction of $\gamma^{\prime}$ precipitates. At the same time, increased additions of the hardening elements led to an increase in the $\gamma^{\prime}$ solutionizing temperature and a decrease in the incipient melting temperature of the alloy. Since the larger this processing window (defined by the difference between $\gamma$ ' solutionizing temperature and the alloy's incipient melting temperature) is, the easier it is to hot work the material. This was achieved by reducing the chromium content. As a result, the $\gamma$ ' solutionizing temperature was lowered. However, the reduction of chromium had a negative affect on material design because high chromium is important for oxidization and corrosion resistance. The loss in oxidation resistance due to the reduced chromium content has been compensated by the increased addition of aluminum. Then molybdenum, tungsten and tantalum were used primarily to provide solid solution strengthening at high temperatures.

At this stage, forging difficulties were also encountered since an alloy's high temperature strength usually leads to poor forgeability. To avoid this, investment casting was introduced as an alternative way of manufacturing turbine blades. These casting alloys have coarser grains than wrought superalloys and consequently yield better creep and rupture properties. Some of these alloys such as 713C, IN-100, B-1900, Udimet 500, René77, René 80 and IN738 are still widely used today.

Over the years (1941 1972) the capability of superalloys rose from a 100h life at a stress of $140 \mathrm{MPa}$ at $760^{\circ} \mathrm{C}$ to $1040^{\circ} \mathrm{C}$ (Table 1)[5]. Though these alloys were improved in terms of temperature capability, the stress-rupture failure at elevated temperatures happened 
extensively in those conventional superalloys. This failure takes place at grain boundaries transverse to the principal stress; thus, strengthening the grain boundaries became the goal of many researchers focused on. The next paragraph interprets the use of directional solidification and single crystal on turbine engine components as a solution to this problem.

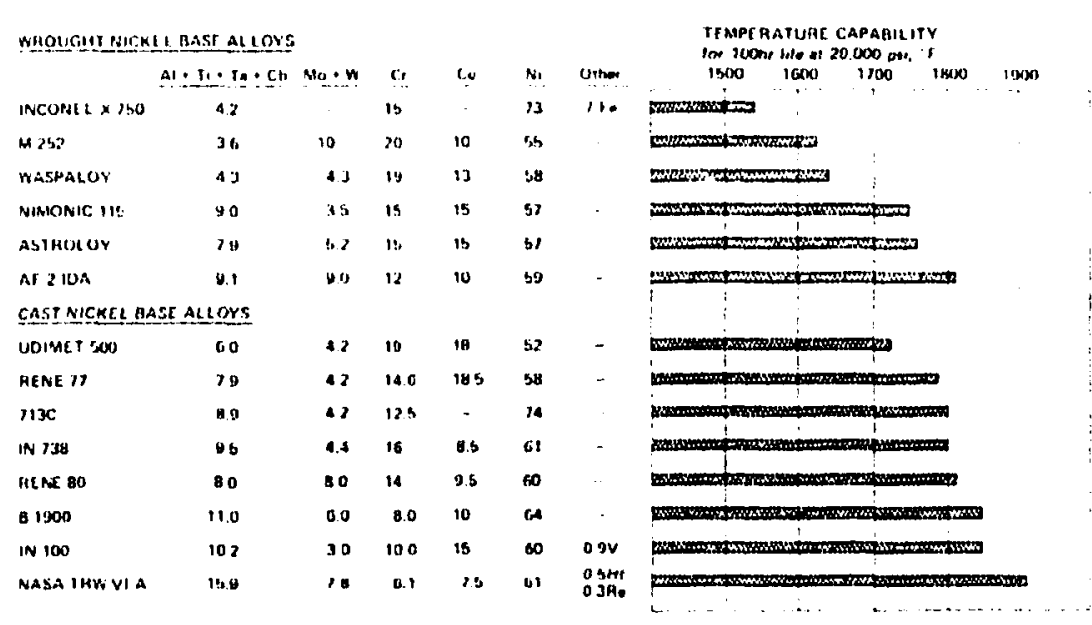

Table 1 Relationship of composition (major elements) and strength as teinperature capability for wrought and cast nickel-base superalloys, data represents creep-rupture [5]

As introduced above, the materials used for hot-section components have been continuously improved. Directional Solidification (DS) and Single Crystal (SX) superalloys are two significant achievements that have resulted in higher temperature capabilities.

The Directional Solidification process was developed by Pratt \& Whitney Aircraft (PWA) in 1969 [8]. By producing columnar grains that were orientated along the growth direction, DS processing eliminated the transverse grain boundaries. This improved the temperature capability, transverse creep rupture strength and ductility compared to conventional investment cast alloys. DS casting also offered a preferred crystallography 
and reduced microporosity, which led to better fatigue life [8]. However, the directionally solidified columnar grain structure still had grain boundaries, but the boundaries are mostly parallel to the major stress axis; so they are much better than the alloys with the equiaxed grain structure that have the worst creep life. Later on, heat treatment studies on DS MAR-M200+Hf showed [9] that increasing the alloy's incipient melting and $\gamma$ solvus were the key to maximizing the $\gamma^{\prime}$ volume fraction $\left(\mathrm{V}_{\mathrm{f}}\right)$, which largely controls the creep strength and high temperature strength. By completely solutioning the as-cast relatively coarse $\gamma$, the material was homogenized and dendrite segregation was significantly reduced.

Based on that research, PWA developed the first generation single crystal alloy PWA1480 in 1980 [10]. Removing the grain boundaries allowed eliminating of the grain boundary strengthening elements $(\mathrm{C}, \mathrm{B}, \mathrm{Zr}, \mathrm{Hf}$ and $\mathrm{Mg}$ ), which led to the introduction of first single crystal (SX) ally. This breakthrough offered special alloys design approaches:

- A high $\gamma^{\prime}$ solvus temperature $\left(1260^{\circ} \mathrm{C}, 2300^{\circ} \mathrm{F}\right)$ enhances the $\gamma^{\prime}$ volume fraction, providing excellent creep strength

- The removal of grain boundary strengthening elements led to an increase of about $100^{\circ} \mathrm{C}$ in the alloy's incipient melting temperature $\left(>1288^{\circ} \mathrm{C}, 2350^{\circ} \mathrm{F}\right)$, allowing a higher solution heat treatment temperatures betiveen the $\gamma^{\prime}$ solvus temperature and incipient melting temperature forming more $\gamma^{\prime}$ precipitate. Therefore, the materials' creep resistance is improved. This also allows for better homogenization of casting segregation. 
- Cast SX's low modulus $<001>$ orientation parallel to the solidification direction responds to low stress, enhancing thermal fatigue resistance

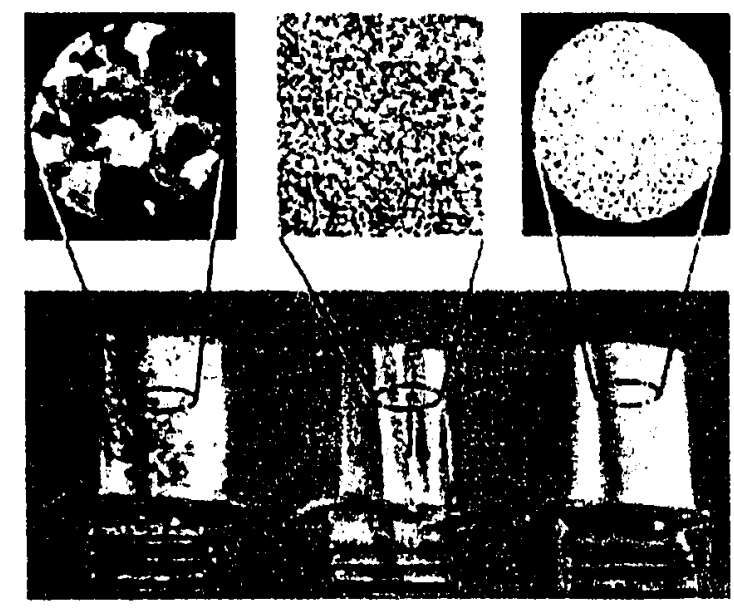

Figure 4 Conventionally cast, DS, and SX superalloys [11]

\subsubsection{Function of alloy elements}

Superalloys are designed with a variety of elements different combinations for desired needs. Table 2[12] lists the effects of alloying elements in superalloys. Some elements are solid solutionized to provide certain properties: oxidation resistance $(\mathrm{Cr}, \mathrm{Al})$, high temperature resistance $(\mathrm{Ni})$, strength $(\mathrm{Mo}, \mathrm{Ta}, \mathrm{W}, \mathrm{Re})$ or increased volume fractions of favorable secondary precipitates (Co). Other elements are added to form hardening precipitates such as gamma prime $\gamma^{\prime}(\mathrm{Al}, \mathrm{Ti})$, and gamma double prime, $\gamma^{\prime \prime}(\mathrm{Nb})$. The $\gamma^{\prime}$ phase is the key factor responsible for the extraordinarily useful high temperature properties of Ni-base superalloys. Minor elements (C, B) are added to form carbides and borides; these elements and others $(\mathrm{Ce}, \mathrm{Mg})$ are added for purposes of tramp element control. Some elements $(\mathrm{B}, \mathrm{Zr}, \mathrm{Hf})$ are also added to promote grain boundary effects other than precipitation or carbide formation, which is mostly for polycrystalline alloys. 
Many elements ( $\mathrm{Co}, \mathrm{Mo}, \mathrm{W}, \mathrm{Cr}$, etc.) although added for their favorable alloying qualities, result in the precipation of undesirable phase formation (sigma, mu, Laves, etc.) in some circumstances.

Table 2. Effects of Several Elements in Ni-Base Superalloys [12]

\begin{tabular}{|c|c|}
\hline Elements & Functions \\
\hline Chromium & $\begin{array}{l}\text { Oxidation and hot corrosion resistance; } \\
\text { solid solution strengthening }\end{array}$ \\
\hline Molybdenum; tungsten & $\begin{array}{l}\text { Solid solution strengthening; form } \mathrm{M}_{0} \mathrm{C} \\
\text { carbides }\end{array}$ \\
\hline Aluminum; titanium & $\begin{array}{l}\text { Form } \gamma^{\prime}, \mathrm{Ni}_{3}(\mathrm{Al}, \mathrm{Ti}) \text {, hardening precipitate; } \\
\text { Ti forms } \mathrm{MC} \text { carbides as well; } \mathrm{Al} \text { enhances } \\
\text { oxidation resistance }\end{array}$ \\
\hline Cobalt & Raises $\gamma^{\prime}$ solvus temperature \\
\hline Boron; zirconium; hafnium & $\begin{array}{l}\text { Improve rupture life through increases in } \\
\text { ductility; B also forms borides; Hf forms } \\
\text { MC carbides and also promotes eutectic } \gamma \text { - } \\
\gamma^{\prime} \text { formation in cast alloys }\end{array}$ \\
\hline Carbon & $\begin{array}{l}\text { Forms } \mathrm{MC}, \quad \mathrm{M}_{7} \mathrm{C}_{3}, \quad \mathrm{M}_{23} \mathrm{C}_{6}, \text { and } \mathrm{M}_{6} \mathrm{C} \\
\text { carbides }\end{array}$ \\
\hline Niobium & $\begin{array}{l}\text { Forms } \gamma^{\prime \prime}, \mathrm{Ni}_{3} \mathrm{Nb} \text {, hardening precipitate; } \\
\text { forms } \mathrm{Ni}_{3} \mathrm{Nb}\end{array}$ \\
\hline Tantalum & $\begin{array}{l}\text { Solid solution strengthening; forms } \mathrm{MC} \\
\text { carbides; enhances oxidation resistance }\end{array}$ \\
\hline
\end{tabular}

\subsubsection{Phases in Nickel base alloys}

Superalloys exposed to high temperatures are chemically dynamic. The phases [see Figure 5] present are unstable and constantly reacting and interacting. Ni-base superalloys consist of a Ni-rich austenite phase, which usually contains a high percentage of solid solution elements, and a high volume fraction of intermetallic precipitates $(\sim 70 \%)$. Figure $6[13]$ shows a large amount of cuboidal $\gamma$ distributed in a $\gamma$ matrix. 


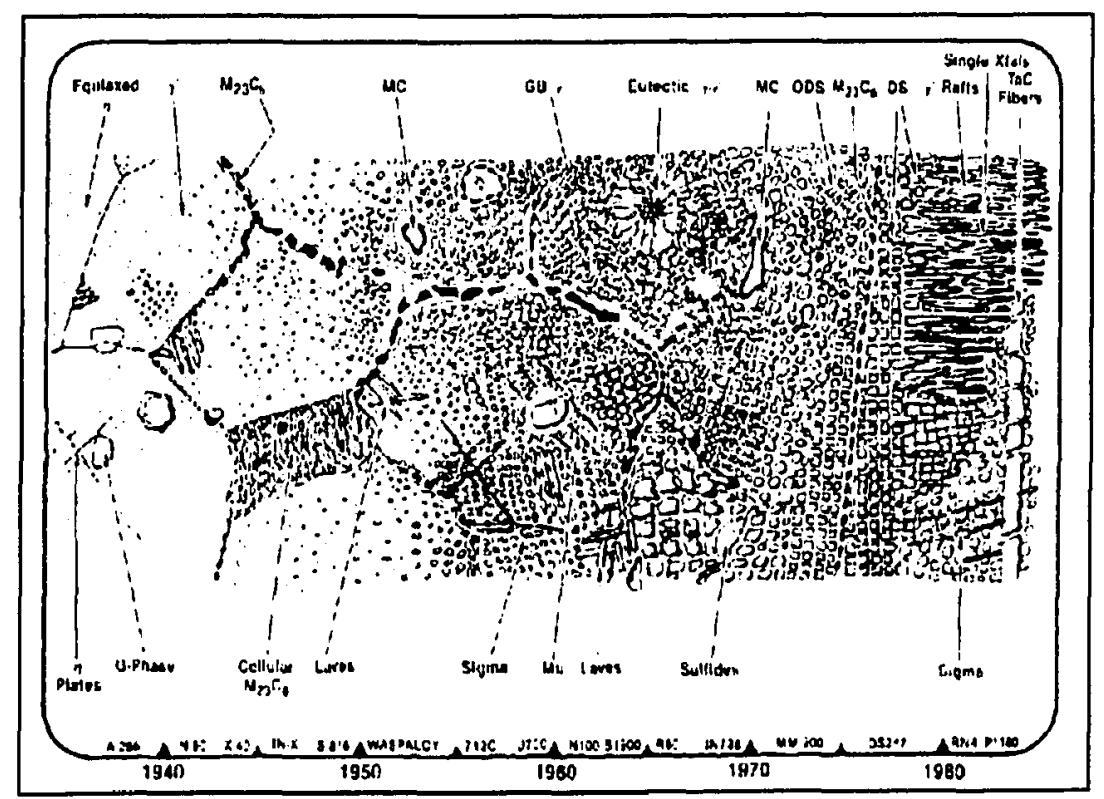

Figure 5 Nickel base superalloys phases, developed over the years [5]

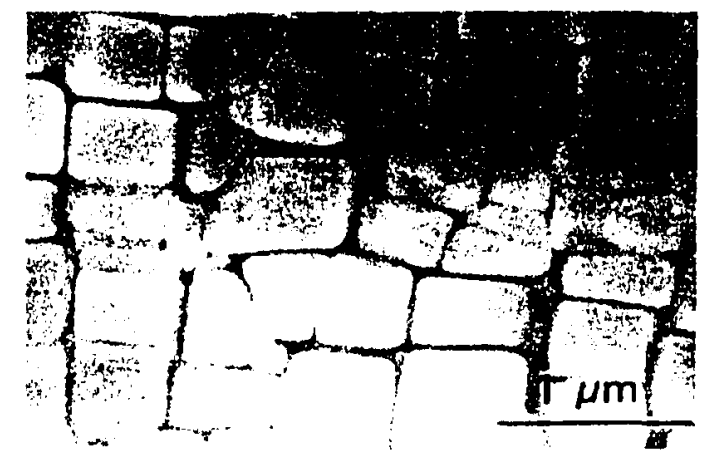

Figure 6. Transmission electron micrograph showing a large fraction of cubical $y^{*}$ particles in a $y$ matrix. Alloy $\mathrm{Ni}-9.7 \mathrm{Al}-1.7 \mathrm{Ti}-17.1 \mathrm{Cr}-6.3 \mathrm{Co}-2.3 \mathrm{~W}$ at $\%$. 
$\mathrm{Ni}$ forms the face-centred cubic (FCC-Al) $\gamma$ matrix. The $\gamma$-phase is a solid solution with a face-centered cubic lattice and a random distribution of the different species of atoms (Figure 7).

The $\gamma$ phase forms the matrix in which the $\gamma$ precipitates. Since both the phases have a cubic lattice with similar lattice parameters, the $\gamma$ precipitates in a cube-cube orientation relationship with the $\gamma$. This means that its cell edges are exactly parallel to corresponding edges of the $\gamma$ phase. Furthermore, because their lattice parameters are similar, the $\gamma$ is coherent with the $\gamma$ when the precipitate size is small. Dislocations in the $\gamma$ nevertheless find it difficult to penetrate $\gamma$, partly because the $\gamma$ is an atomically ordered phase. The order interferes with dislocation motion and hence strengthens the alloy.

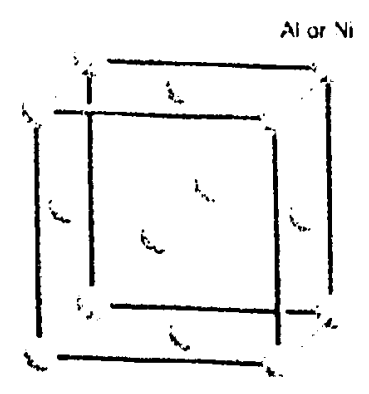

Figure 7. Crystal Structure of $v$ 
$\mathrm{Al}$ and $\mathrm{Ti}$ form the $\mathrm{Ni}_{3}(\mathrm{Al}, \mathrm{Ti}) \gamma$ intermetallic, which precipitates coherently as an ordered cubic face-cantered (FCC) phase in the $\gamma$ matrix [Figure 8]. These precipitates contribute to strengthen the alloy at high temperatures. The nominal composition is $\mathrm{Ni}_{3} \mathrm{Al}$ although it is usually designated $\mathrm{Ni}_{3}(\mathrm{Al}, \mathrm{Ti})$ since as much as $65 \%$ of the aluminum can be replaced by titanium.

During ageing after a solution treatment [14], $\gamma$ ' nucleates initially as a coherent precipitate with its crystallographic orientation identical to that of the $\gamma$ matrix and develops as fine homogeneous particles with a spherical morphology that grow and become cuboidal as coherency is lost. $\gamma^{\prime}$ can also form at grain boundaries and second phase particle interfaces during relatively high temperature ageing treatments or during the partial solution treatment applied to some alloys.

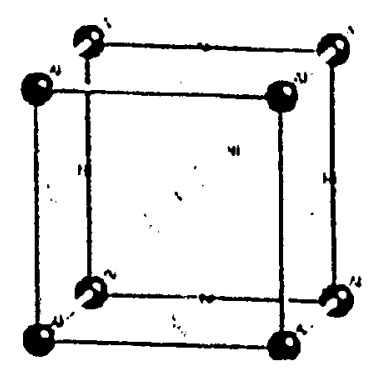

Figure 8. Crystal Structure of $y^{\circ}$ 


\subsubsection{The heat treatment of single crystal nickel base superalloys}

Single crystal superalloys are designed to be microstructurally stable. However, phases as $\sigma, \mu$ or Laves can form in single crystal superalloys as they do in polycrystalline superalloys. In fact, the formation of these Topologically Closed Packed (TCP) phases is somewhat more likely in the as-cast condition due to the greater segregation present in single crystal superalloys than with the more rapidly solidified polycrystalline alloys. Therefore, single crystal superalloys are given a solution heat treatment that homogenizes the alloy, reducing the likelihood of forming any TCP phases.

DS/SX superalloys are generally given three types of heat treatment

- Solution heat treatment --- dissolve the coarse $\gamma^{\prime}$ as well as dissolve the $\gamma / \gamma^{\prime}$ eutectic that forms in the interdendritic regions during the final stage of solidification. The $\gamma^{\prime}$ is subsequently reprecipitated homogeneously to a finer particle in order to strengthen the alloy

- Coating heat treatment -.-- bond the coating onto the alloy substrate

- Aging heat treatment --- Additional $\gamma^{\prime}$ and/or other phases such as carbides and borides are precipitated at the grain boundaries

\section{Solution Heat Treatment}

A solution heat treatment is normally applied on single crystal superalloy castings to achieve the proper microstructure which consists of a fine $\gamma^{\prime}$ precipitate with little or no eutectic and to homogenize the compositional microsegragation that exists between 
dendrite cores and interdendritic areas. Coarse $\gamma^{\prime}$ precipitates due to the slow cooling of the single crystal casting following solidification; $\gamma / \gamma^{\prime}$ eutectic forms in the interdendritic regions during the final stages of solidification, they need to be dissolved to achieve optimum mechanical properties of single crystal.

Ideally, all the $\gamma^{\prime}$ (eutectic and coarse cuboidal) in the as-cast single crystal superalloy should be fully solutionized and the alloy composition should be homogenized. To achieve this, the alloy must be heated above the $\gamma^{\prime}$ solvus to dissolve the as-cast $\gamma^{\prime}$ and below the incipient melting temperature to avoid melting. The temperature between these two points was defined as "solution heat treatment window" [15]. Both solvus and incipient melting temperatures are a function of alloy composition. A successful solution heat treatment depends on there being a large enough difference between the incipient melting and $\gamma^{\prime}$ solvus temperatures. It is easy to understand that the $\gamma^{\prime}$ solvus temperature is which the last precipitates are taken into solution at. In some segregated alloys, the range of solvus temperatures may exceed the corresponding incipient melting temperatures, like the case of PWA-1480 and CMSX-6. Therefore, complete solutioning is impossible, and a small amount of residual $\gamma / \gamma^{\prime}$ in the interdendritic spaces is always retained after solution heat treatment.

Since the size of the $\gamma$ precipitates directly affects the alloy's mechanical properties, controlling the $\gamma^{\prime}$ size is necessary and often implemented by controlling the cooling rate from the solvus to the temperature below which $\gamma$ will not coarsen in a short period. During continuous cooling, the precipitates change their shape, spherical nuclei 
developing into cubes as the precipitates grow. The $\gamma^{\prime}$ size of single crystal can range from 0.2 to $5 \mu \mathrm{m}$, depending on the cooling rate from rapid quenching $\left(100^{\circ} \mathrm{C} / \mathrm{s}\right)$ to slow cooling $\left(0.02^{\circ} \mathrm{C} / \mathrm{s}\right)$ [Figure 9][16]. Usually the SHT temperature is employed in excess of $2200^{\circ} \mathrm{F}\left(1205^{\circ} \mathrm{C}\right)$, and an inert atmosphere sometimes is used to prevent oxidation.

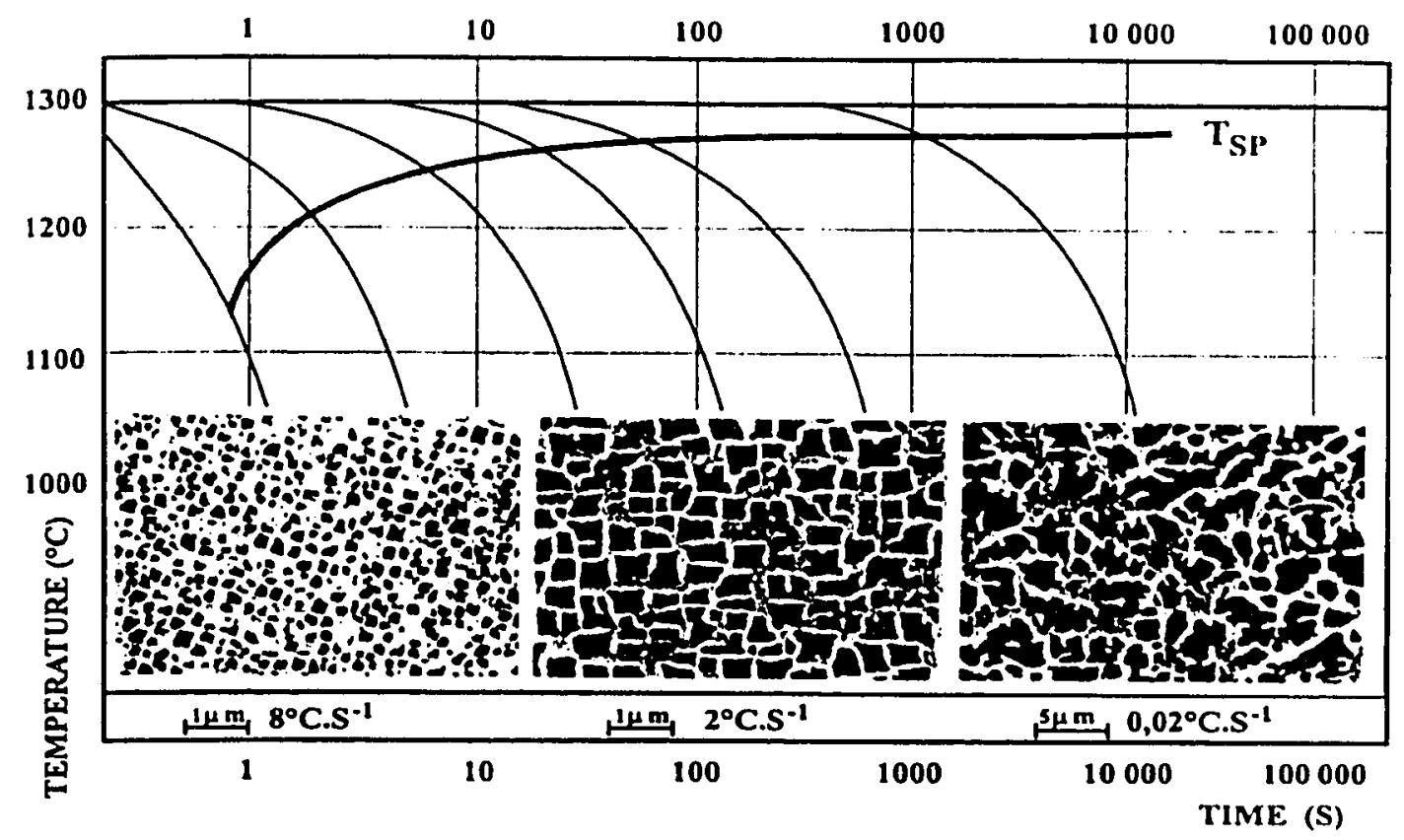

Figure 9 Time-temperature curves for CMSX-2 alloy, corresponding to different cooling rates between 150 and $0.002^{\circ} \mathrm{C} / \mathrm{s}$ from $1300^{\circ} \mathrm{C}$ (after a $20 \mathrm{~min}$ hold at $1305^{\prime \prime} \mathrm{C}$ ) different cooling). The precipitation start temperatures $T_{S p}$ [16] 


\section{Coating Heat Treatment}

The coating heat treatment is the HT that bonds the coating to single crystal and polycrystalline superalloys. Temperatures of 980 to $1120^{\circ} \mathrm{C}$ for times up to 8 hours are commonly used. Since alloy properties are not sensitive to the rate of cooling from the lower coating heat treatment temperatures, it takes fairly long time to attain a significant growth of the $\gamma^{\prime}$ particles. In many single crystal superalloys, the coating heat treatment influences the $\gamma^{\prime}$ size and, thereby, the alloy's strength.

\section{Aging Heat Treatment}

The aging heat treatment is performed at lower temperatures $\left[1300\right.$ to $1650^{\circ} \mathrm{F}(700$ to $\left.\left.900^{\circ} \mathrm{C}\right)\right]$ and for longer time of as much as 32 hours [17]. The objective of it is to precipitate additional hardening phase. Very fine $\gamma^{\prime}$ is precipitated at these lower temperatures resulting in a bimodal size distribution. For low carbon single crystal alloys, where higher temperature creep strength is the primary objective, the aging heat treatment develops maximum strength by precipitation of a dispersed phase throughout the matrix.

\section{Heat treatment for PWA1484}

A standard fully heat treatment of PWA1484 [18] consists of three steps:

$2400^{\circ} \mathrm{F}$ (4hours) $+1975^{\circ} \mathrm{F}$ (4hours) $+1300^{\circ} \mathrm{F}$ (24hours) 
Figure 10 and 11 show the different size of $\gamma$ and $\gamma^{\prime}$ in an as-solutioned and fully heattreated PWA1484. A $2400^{\circ} \mathrm{F}$ for 4 hour solution heat treatment was employed, the coarse as-cast $\gamma^{\prime}$ is reprecipitated to a fine regular array of cuboidal particles $(\leq 0.3 \mu)$.

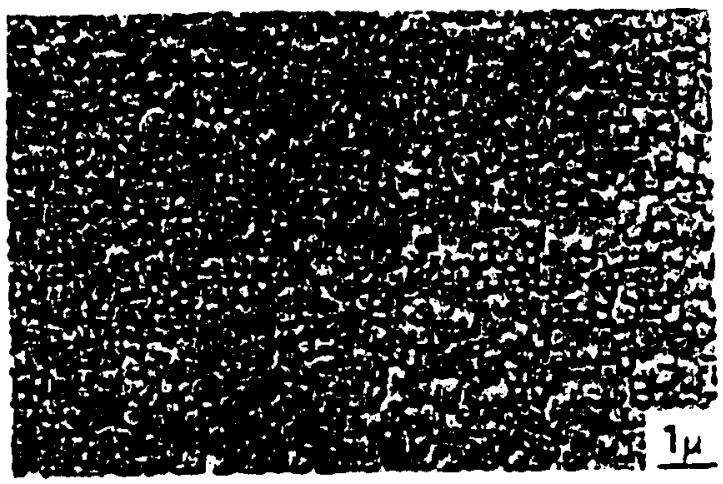

Figure 10 As-solutioned

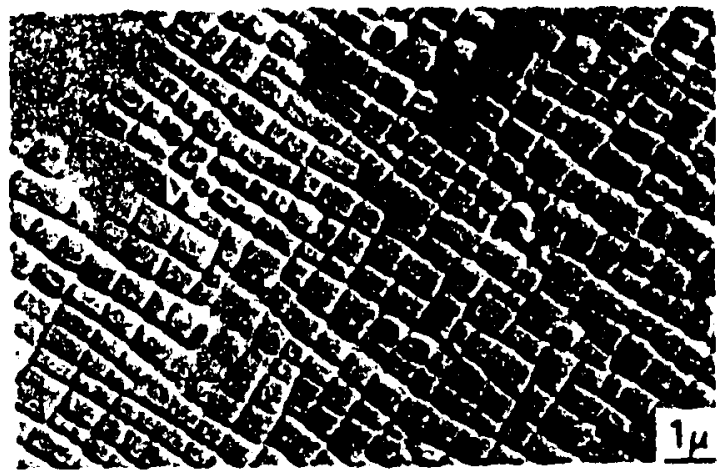

Figure 11 Fully heat-treated

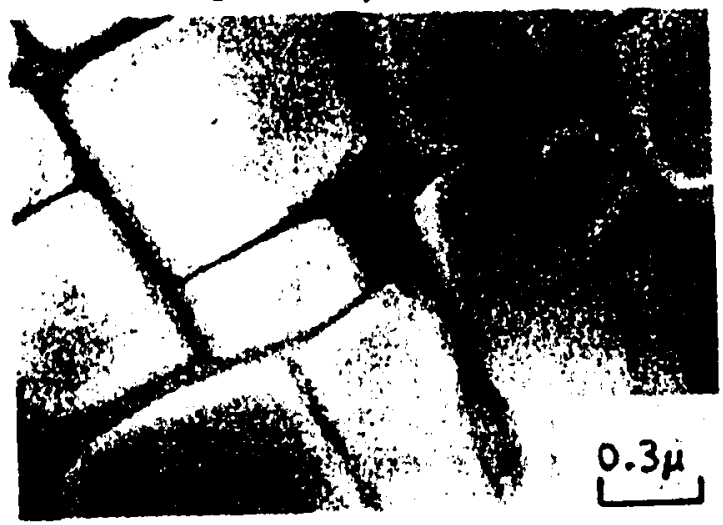

Figure 12 Second step HT is to get optimum $r^{\prime}$ 


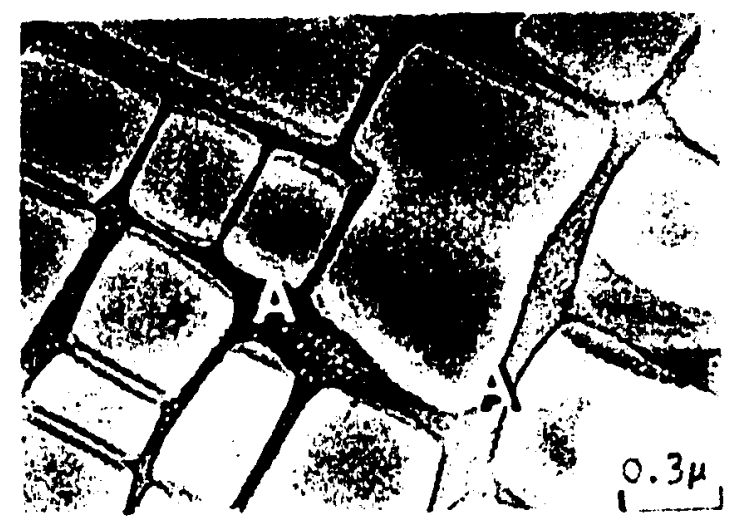

Figure 13 Ultra fine $y^{\prime}$ is attained after aging

A $1975^{\circ} \mathrm{F}$ temperature for 4 hour duration is usually used to bond the coating to the material, as well as to distribute an optimum $\gamma^{\prime}$ size. Figure 12 shows that the microstructure of PWA1484 is well homogenized. Following this, the material is aged at $1300^{\circ} \mathrm{F}$ for 24 hours, thus, ultra fine $\gamma^{\prime}(\leq 0.1 \mu)$ precipitates form between larger particles [Figure 13], which enhances the intermediate temperature yield strength.

The more homogeneous the material composition is, the closer will be the incipient melting temperature to the solidus [15]. In the case of the segregated alloy PWA1484, the $\gamma^{\prime}$ solvus temperature is $1320^{\circ} \mathrm{C}$, and the incipient temperature range varies from $1340^{\circ} \mathrm{C}$ (solidus) to liquidus melting temperatures $\left(1404^{\circ} \mathrm{C}\right)$. Thus, complete solution is impossible, and it explains why PWA1484 always contain a small amount of residual $\gamma^{\prime}$ in the interdendritic region after the standard SHT. 


\subsubsection{Strengthening Mechanisms of Superalloys}

Nickel base superalloys are generally solution heat treated above the $\gamma^{\prime}$ solvus temperature followed by aging to precipitate the $\gamma^{\prime}$ strengthening phase. Proper heat treatment sequences are implemented to optimize the alloy's strengthening mechanism such as solid solution strengthening, precipitation hardening and grain boundary strengthening.

Though a large amount of superalloys can be solid solution strengthened and some polycrystalline superalloys are grain boundary strengthened, single crystal nickel base superalloys attain most of their high temperature strength by precipitation hardening. Two factors mainly influence the degree of precipitation hardening: the volume fraction $\left(V_{f}\right)$ and the size of $\gamma^{\prime}$. Certain amount of $\mathrm{Al}$ and Ti are added to obtain high $\gamma^{\prime}$ volume fraction. For given $\gamma^{\prime}$ volume fraction, the size of $\gamma^{\prime}$ is the critical variant to control the material strength, the actual particle morphology is also vital. The alloy's strength is related to its optimium $\gamma$ size. This optimium size can be explained by the following phenomenon: The interaction of dislocations and precipitates could be various depending on the motion of dislocations within the grains. To get past a precipitate, a dislocation will either cut through it or by-pass it by climbing to another plane or looping around it. The alloy's precipitation strengthening can be expressed by hardness versus particle size. Figure 14 is an example of optimum precipitate size of $\mathrm{Ni}-22 \% \mathrm{Cr}-2.8 \% \mathrm{Ti}-3.1 \% \mathrm{Al}$ regarding to aging temperature. The ascending curve shows that the material strength is increasing with the $\gamma$ ' being cut by dislocation, while after a certain aging temperature peak, the strength starts decreasing due to the dislocation by-passing $\gamma$. This effect can 
be demonstrated for hardness or tensile performance in low $\gamma^{\prime} V_{\mathfrak{f}}$ alloys such as Waspaloy, Inconel 901, but not apparent in high $\gamma^{\prime} \mathrm{V}_{\mathrm{f}}$ alloys like Mar-M246, IN100, PWA1480, etc [19].

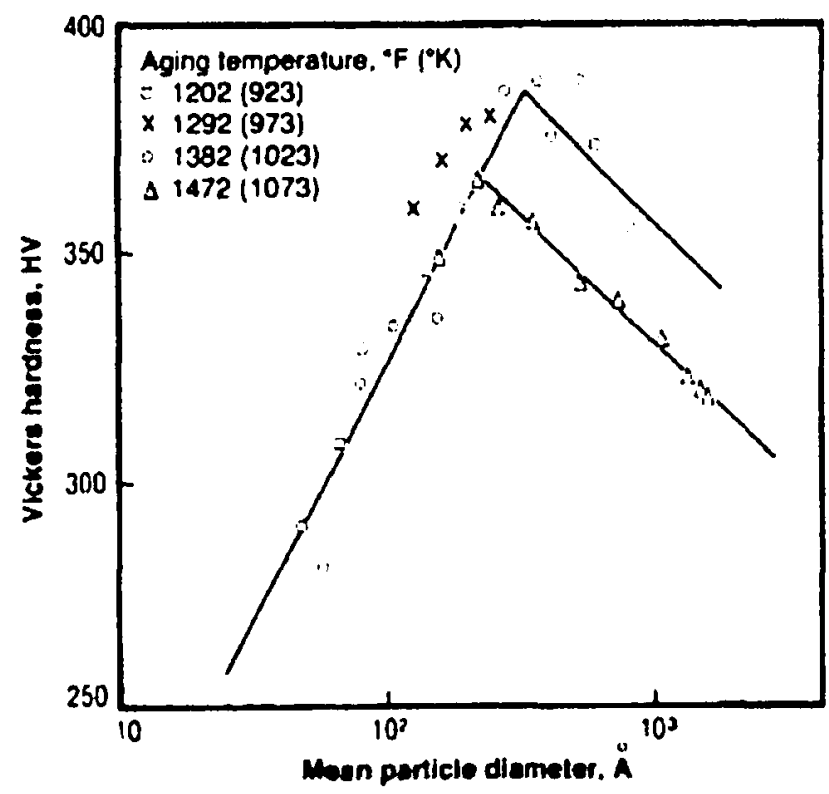

Figure 14. Ni-base superalloy strength (hardness) with respect to precipitate size [5]

\subsubsection{Damage Mechanism of turbine blades}

When gas turbine engines are operated, the hot air (oxidizing gas) is drawn into the engine and compressed. The turbine blades experience the most arduous temperatures, stress conditions and oxidizing gas environments of any component in the engine. A typical conventional turbine blade is shown in Figure 15. 


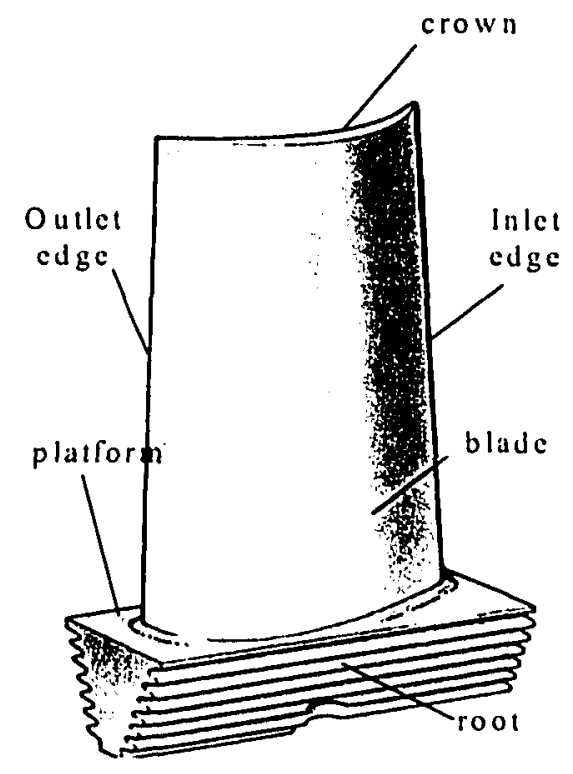

Figure 15 Components of typical turbine blade [23]

Thermal fatigue [20] platform cracks, caused by internal stresses generated by cyclic temperature gradients, is the most common damage occurred on turbine blades. As in the case of compressor blades, high cycle fatigue problems will arise if excitations coincide with the natural frequency of the blade in the flight speed range. Creep caused by constant loading from the root up to the blade body. Sand hitting the blade results in blade tip erosion. All those can lead to final failure of the blade [Figure 16].

The surrounding atmosphere also results in nitridization, carburization, oxidation and sulphidation which lead to the precipitation of low ductility TCP phases, known as sigma, laves phase and intergranular carbide films [21].

All those damages lead to the reduced efficiency of turbine engines, resulting in risk of their tremendous breakdown and shortage of life cycle. Those damaged blades have to be 
removed or repaired. Repair techniques have been developed for application to apply on different location on turbine blades. Formal study [22] has shown that worn blade tips from local erosion and corrosion is usually solved by several repairing techniques. The next chapter will focus on a few types of welding techniques which are mostly used in repairing turbine blade.

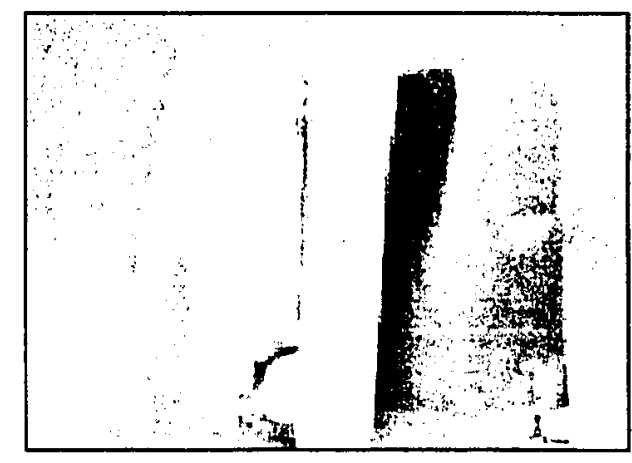

Figure 16 Damaged turbine blade [24]

\subsection{Welding repair of $S X$}

\subsubsection{Why Welding/Repair}

Although gas turbine materials are continuously updated and the newer alloys are more reliable than ever before, they still experience severe environment like high temperaturc and highly oxidized corrosion during the service, where blade damage are unavoidable. Theoretically, turbine blades need to be replaced because of thermal mechanical fatigue cracks formed at the platform or tip erosion that leads to turbine efficiency loss, as discussed in 2.1.6. However, the high cost of replacement (typically $5 \mathrm{~K} \$$ per blade [25]) 
directs the engineers' preference into the gas turbine blade repair technology over simply replacement of damaged blades. Currently $55 \%$ money is spent on the replacement material but only $15 \%$ on component repairs [25]. Therefore, how to develop more efficient and economical repair schemes has drawn peoples' interests as a big challenge. Repair technologies range from coating, brazing, solding and welding. Welding, the most widely used rejuvenating techniques, is basically made by removing the worn or damaged section that form during the service and joining a new piece of component on the blade.

\subsubsection{Theory of Welding}

Weldability is defined as "the capacity of a material to be joined under the imposed fabrication conditions into a specific, suitably designed structure and to perform satisfactorily in the intended service"[26]. Welding processes are generally classified into fusion welding and solid phase welding (also called pressure welding). Fusion welding leads to a welding of the pieces by applying heat at the point of connection, which fuses the pieces together and then joins a material. After the hardening of the mixed components, a solid joint occurs. Such welds comprise three metallurgical zones---the fusion zone (FZ), the unmelted heat-affected zone (HAZ) adjacent to the fusion zone and the unaffected base metal [Figure 17] [27]. Whereas solid-phase welds are proceed by bringing two clean, solid metal surfaces into sufficiently close contact for a metallic bond to be formed between them. 


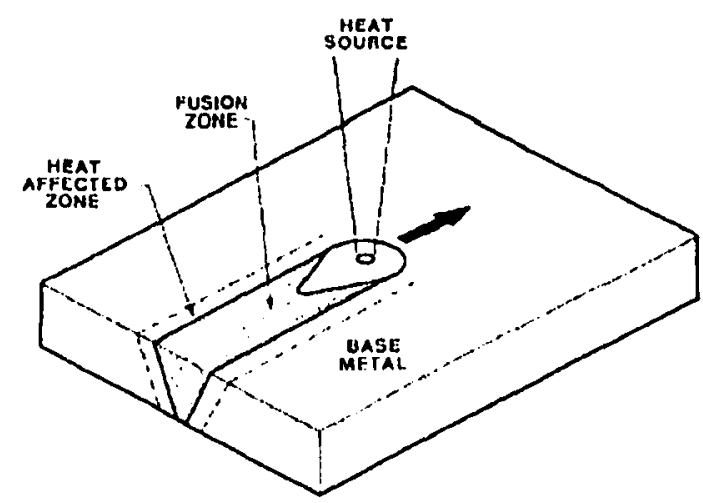

Figure 17. A schematic diagram showing the interaction between heat source and the base metal. Three distinct welding regions are fusion zone, the heat effected zone, and the base metal.

\subsubsection{Welding and welding issues}

Historical work [28] has shown that single crystal nickel base superalloy has relatively poor weldability. Figure 18 [29] illustrates the weldabilities of several superalloys in terms of their element content. PWAI480 and PWA1484 unavoidably falls into this "hard to weld" category base on its composition. 


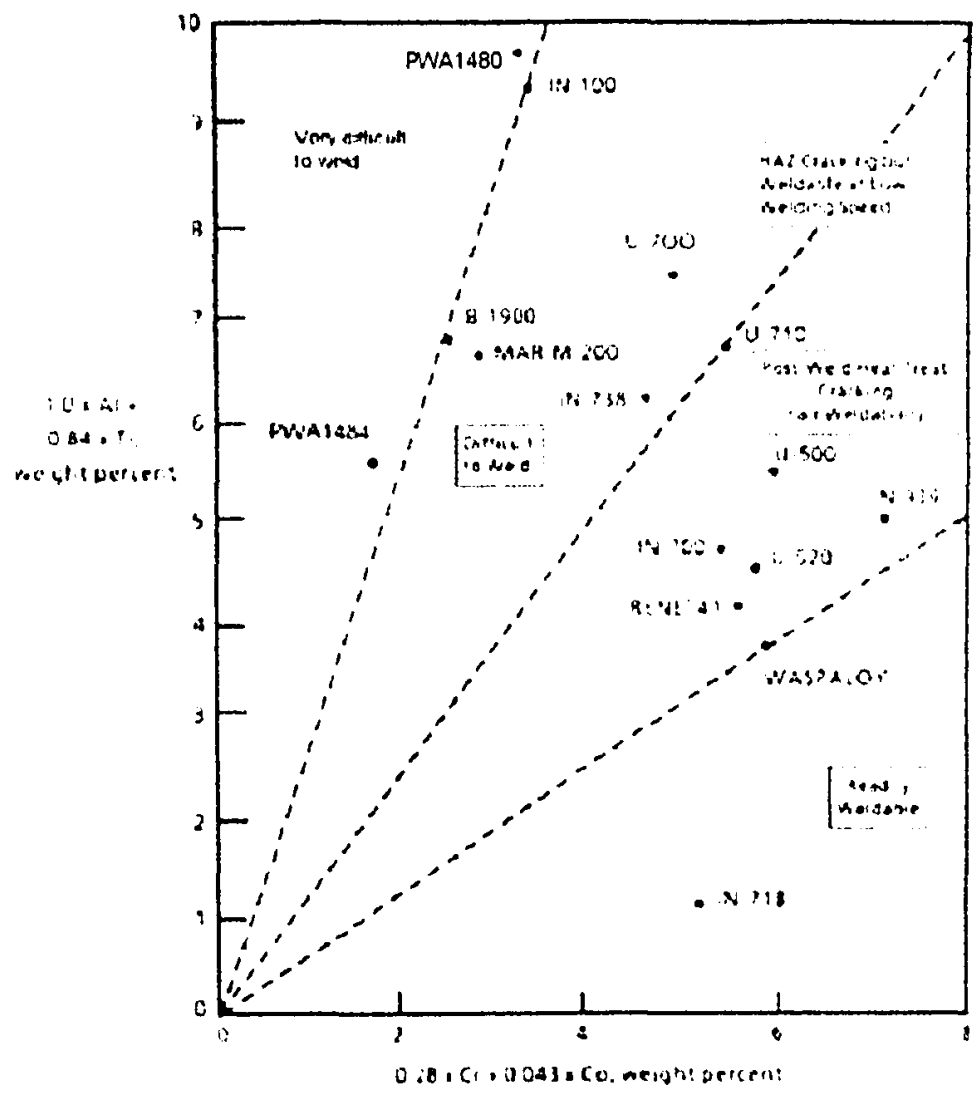

Figure 18 Relationship between estimated weldability and Al, Ti Cr and Co content [29]

Three main concerns of SX welding are: solidification cracking, loss of single crystal nature and strain-age cracking. Solidification cracks, normally known as hot cracking, are the most common welding defect in fusion zone. As a weld travels, the base metal at the front of the weld pool is heated past its melting point, creating thermal expansion and compressive stresses in the base metal ahead of the weld pool. Simultaneously, the rear of the weld pool is solidifying and contracting, thus creating tensile stresses in the base metal and the solidified weld metal. If the tensile stress exceeds the yield stress of the material in an area where the ductility is insufficient, cracking will occur [Figure 19]. 
This type of cracking that occurs during the welding process is called solidification cracking, or hot cracking [30]. Solidification cracking is related to the thermal stresses

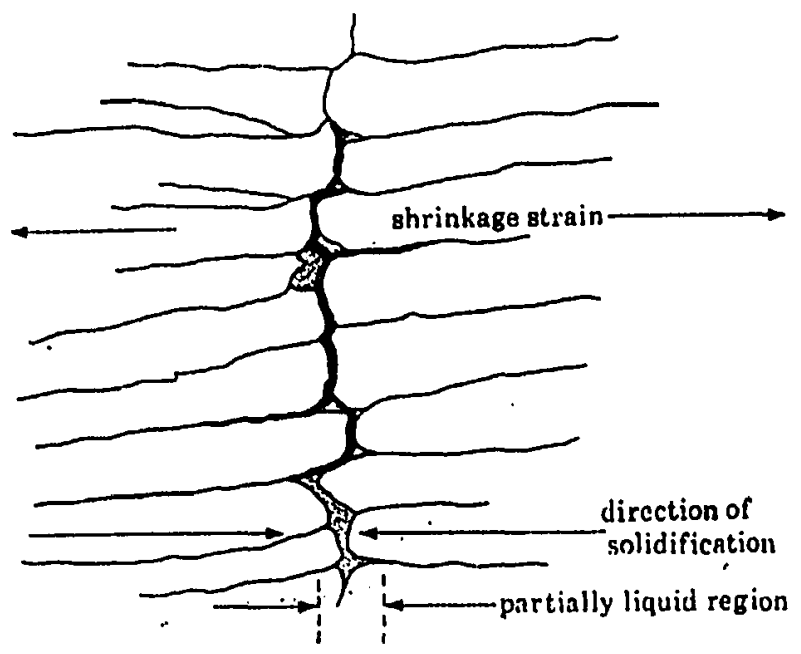

Figure 19 Schematic diagram illustrating the mechanism of solidification cracking [30]

that occur during the welding. According to the heat flow in weld pool theory [27], as the welding speed increases, the cooling rate behind the weld pool increases. It is also predicted that the cooling rate is higher for smaller weld pools than for larger weld pools for similar welding speeds. Higher cooling rates lead, in turn, to higher thermal residual stresses, which are the driving forces for crack formation.

The loss of single crystal nature in the weldment is another issue of concern. The solidification process during welding can be regarded as a casting process. During the solidification, some dendrite tips are broken off and grow in the mushy zone [31]. These dendrite tips act as nuclei for chains of "equiaxed grains"[32,33]. They are some misorientated grain with high-angle grain boundary. This morphology is also known as "stray grain" [Figure 20]. (This terminology is used more often in single crystal welding 
process). Stray grain formation is related to solidification cracking and it may compromise the alloy's creep resistance. Especially in single crystal superalloys, the grain boundary strengthening elements have been removed. Therefore, it is highly desirable to avoid the occurrence of these deleterious stray crystals.

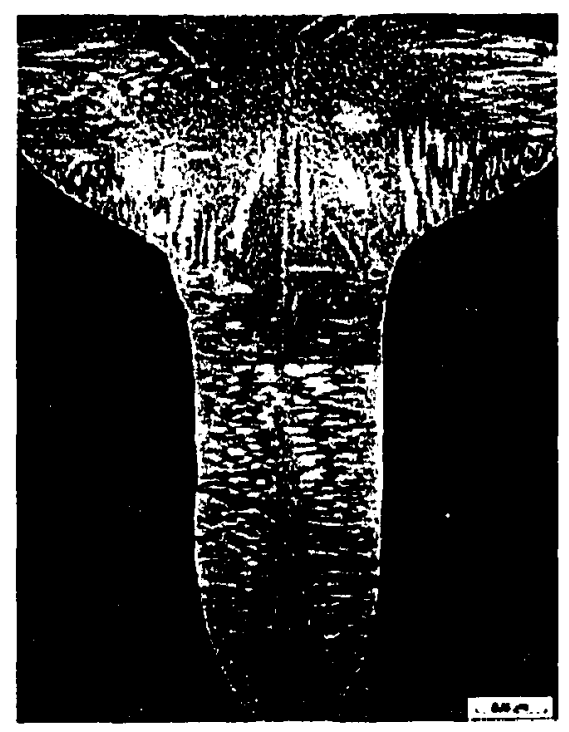

Figure 20 Epitaxial growth at the edge of welds and high-angle equiaxed grains in welds crown (PWA1460)

If a single crystal superalloy is successfully welded without any hot cracks, it usually must be given a post weld heat-treatment to restore properties and relieve residual stresses [34]. During the heat treatment, the material is strengthened by the precipitation of $\gamma^{\prime}$ phase. This precipitation can also be initiated during welding in the unmelted heat affected zone (HAZ) adjacent to the weld metal. The temperature gradient that forms in the HAZ during welding causes the $\gamma^{\prime}$ microstructure be non-homogeneous, which results in variations in strength. If residual stresses resulting from the welding process excced the fracture stress at some location in the material during the aging process, then post weld heat treatment cracking (strain-age cracking) is likely to occur. 


\subsubsection{Welding repair technology}

In this section, several fusion-welding techniques, including gas-tungsten-arc welding, electron-beam welding, laser-beam welding and laser metal forming techniques are studied. Linear friction welding, as a kind of pressure welding, is also briefly discussed below.

\subsubsection{Gas Tungsten Arc Welding (GTAW)}

Gas Tungsten Arc welding is briefly mentioned here. As a conventional welding technique, it has been widely used in aerospace industry as repair for some polycrystalline nickel-based superalloys $[35,36,37,38,39,40]$.

Gas Tungsten Arc Welding (GTAW), also called Tungsten Inert Gas (TIG) welding, is an all-position welding process especially well adapted to weld thin sections which the heat is produced by passing electric current from a non-consumable electrode (tungsten or tungsten alloy) through an inert shielding gas (ionization) and into the workpiece [41]. An initializing spark is required to start the process. In blade repair techniques, it is generated by touching the electrode to the workpiece. The filler material does not pass through the arc; it is inserted into the weld pool directly and melted inside the shiclding gas atmosphere by the heat generated at the workpiece. 
GTAW has been used in aerospace for decades since it can produce low heat inputs and avoid distortion, limit both the size of the brittle layer and the amount of liquation microcracking in the heat affected zone. It is also more readily available and typically relatively affordable.

However, compared to other welding processes, GTAW is a relatively slow welding technique. The main concern of GTAW is the electrode contamination or tungsten contamination in the weld. Contamination of the tungsten electrode can result in discontinuities in the weld and make arc control difficult. The weld pool may become quite contaminated with tungsten by contact with the electrode, and it is very deleterious for the strength and corrosion resistance of the joint.

\subsubsection{Laser Beam Welding (LBW)}

Laser beam welding (LBW) is a technique that utilizes an intense, concentrated and highly parallel beam of light to produce heat in the weld joint. Light beam consists of a stream of photons, which focused and directed by lenses and mirrors as required for the different application. One hundred percent of the laser light will be reflected off the rear mirror and thirty to fifty percent will pass through the front mirror [Figure 21], continuing on through the shutter assembly to the angled mirror and down through the focusing lens to the workpiece. 

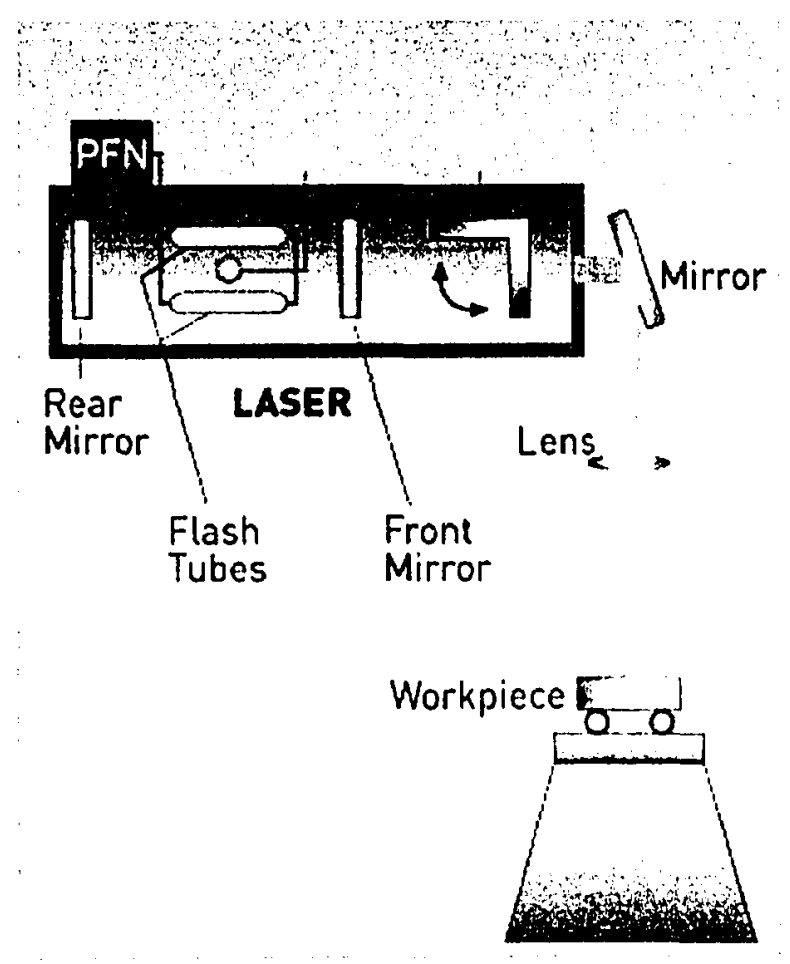

Figure 21 Laser beam welding system diagram [42]

There are two categories of industrial LBW processes: conduction limited and deep penetration [43]. Conduction limited process are performed using solid state or moderated power $\mathrm{CO}_{2}$ lasers at power levels under $1 \mathrm{~kW}$. The heat produced by the laser is concentrated at the surface and the subsurface is heated by thermal conduction. Deep penetration LBW is similar to high power electron beam welding (EBW): The beam energy is intense enough to be distributed through the entire weld joint at impact. It is performed with high power $\mathrm{CO}_{2}$ lasers with the power ratings of $20 \mathrm{~kW}$ or higher. Laser beam system generally consists of three primary parts:

- A laser material or medium in which photons may be generated. Laser welding basically is classified into solid state and $\mathrm{CO}_{2}$ gas. The former lasers use an 
isotropic yttrium-aluminum-garnet crystal $\left(\mathrm{Y}_{3} \mathrm{Al}_{5} \mathrm{O}_{12}\right)$ known by acronym $\mathrm{YAG}$, doped with the ionic impurity neodymium $\left(\mathrm{Nd}^{+++}\right) . \mathrm{Nd}$ is the active medium. They are commonly called Nd:YAG lasers. This single crystal rod has parallel, flat ends [Figure 21]. Both ends have reflective surfaces. While in $\mathrm{CO}_{2}$ lasers, a gas mixture consisting of helium, nitrogen, and carbon dioxide is used, where the carbon dioxide molecule is the active laser medium.

- A means of exciting atoms within the laser medium so that photons are produced. Solid state lasers use white light generated from high-intensity krypton or xenon lamps, this high-intensity light source, or flash tube surround the crystal. When power is supplied by the PFN (pulse-forming network), an intense pulse of light (photons) will be released through one end of the crystal rod. The light being released is of single wavelength, thus allowing for minimum divergence; $\mathrm{CO}_{2}$ gas lasers use an electric discharge as a source for exciting the $\mathrm{CO}_{2}$ medium.

- A collimation or resonance system. The system reflects photon waves back and forth across the longitudinal axis of the laser medium producing standing waves (known as optical resonance). In addition to longitudinal modes of oscillation, transverse modes can also be sustained in the two directions perpendicular to the long axis, known as transverse electric and magnetic $\left(\mathrm{TEM}_{\mathrm{mn}}\right)$ modes.

The photon produced by laser oscillate in monochromatic waves, thus the energy is concentrated in a single wavelength. The output beams are highly directional and collimated so that they can be collected and focused in a lens to very small spot sizes. For solid state Nd:YAG lasers, energy is produced at a wavelength of $1.06 \mathrm{~mm}$; while $\mathrm{CO}_{2}$ 
lasers emit energy at a wavelength of $10.6 \mathrm{~mm}$. The shorter wavelength produced by $\mathrm{Nd}: Y A G$ lasers is absorbed by metals better than the longer wavelength produced in $\mathrm{CO}_{2}$ lasers, so it is better for welding highly reflective metals such as aluminum and nickel alloys. However, they cannot cut or melt transparent materials as glass or plastic that $\mathrm{CO}_{2}$ lasers can do. Besides, the electrical efficiency of gas lasers is considerably higher than solid state lasers---their efficiency can reach up to 15 percent, while Nd:YAG laser efficiency is typically less than 2 percent.

Laser beam welding has some advantages that are important in repairing of gas turbine blades:

1) The beam produces localized heating and melting. Low energy input to the weld joint provides narrow weld widths and heat-affected zones (HAZ).

2) Since LBW is a non-contact process, distortion and other complications associated with contact processes such as blade tips can be reduced or potentially eliminated. Filler metal is not required for most joint preparations.

3) Because of the slightly lower energy density of the focused laser beam when compared to electron beam, the tendencies for spiking, underbead spatter, incomplete fusion, and root porosity are reduced.

4) Well-defined focused beam enable the achievement of very small size weld spot.

5) Laser beams can be focused and directed by relatively simple optical elements; therefore, automation is not much different in complexity with GTAW. Compare with manual GTA welding of blade tips, automated LBW is much faster, requiring less post-weld machining and less rework. 
Some disadvantages must be considered as well. The first issue is the cost. Initial system cost, such as laser mirror, electrode cleaning, replacement of blower bearings, routine optics alignment is higher compare to GTAW; Laser flash lamps must be replaced periodically they are quite expensive; The lasing medium in all lasers (YAG rods or gas charge) tends to degrade over time and must be replaced on a scheduled basis, although longevity is much improved in the more modern systems; Low electrical efficiencies (2 to 15 percent) make power consumption a significant portion of the operating costs. Secondly, safety issue cannot be ignored at the same time. Some lasers produce diffuse reflections, which can result in permanent eye injury.

The first use of LBW in repair of superalloy gas turbine blades started in aero-engine industry about a decade ago [44]. It was used in the restoration of hardfacings at the shrouded blades. By the year 1991, one independent FAA repair vendor reported [45] having repaired over 103,000 aeroengine blades with a first time yield of 98.7 percent using $\mathrm{CO}_{2}$ lasers rated from $600 \mathrm{~W}$ to $8 \mathrm{~kW}$. The heat affected zones were about 0.02 inches and the fusion zones were roughly 0.0001 inches.

However, application of LPW for repair of blade tips and airfoils has gone on at a wary pace due to the following reasons:

1) Cost issue. Lower cost welding process such as GTAW is still largely used and can met certain goals in airfoil and tip repair applications. 
2) The complexity of airfoil shapes and the array of powder fillers, when coupled with the initially small number of welding lasers, slow down the laser introduction for turbine blade repairs.

3) Powder feeding is still a relatively new technique and can be difficult to control the levels required at blade tips. Wire feeding, with the limitation in available filler compositions, also needs more heat to melt than powders and may partially depreciate a key advantage in laser welding (minimal heat input to the joint).

4) Manufacturing makes automation difficult and extends development time. The original equipment reference surfaces, thickness and mass can vary in parts from the same engine. Automated LBW systems must be capable of adjusting the laser position over variable surfaces as well as adjusting the heat input and deposition rate to integrate a variable heat sink [46].

In 1994, the first production repair of industrial turbine airfoils by LBW was introduced [47]. The blown powder used for filler addition was favorable in terms of both weld quality and rework. IN738, INX750 and IN625 were put as the filler materials. Crackfree weldments using IN738 as the filler were achieved yet not on consistent basis. IN625 was utilized only as a baseline to prove that laser welding could be employed for $\gamma^{\prime}$ strengthened alloys.

Oak Ridge National Laboratory $[48,49,50,51,52,53]$ started the weldability and microstructure development of laser welding research on single crystal PWA 1480, 
CMSX4 and Fe-15Cr-15Ni over a range of welding conditions and orientations. A pulsed Nd-YAG laser was used with power of $400 \mathrm{~W}$ by MCD. Laser welding on PWA1480 was applied by the speeds varing from 2.1 to $16.9 \mathrm{mms}^{-1}$ and pulse rate ranging from $20 \mathrm{~s}^{-1}$ to $200 \mathrm{~s}^{-1}$. The welds were axially symmetric overlapping [Figure 22]. With the wide range welding parameters, the weld pool shapes varied from relatively shallow, hemispherical cap shape to deeper welds. This was unlike the case of EBW, where weld pool shape tended to be steady. Consequently, solidification performed from all direction from the center, the initial solidified dendrite pattern does not affect the microstructure of subsequent solidification. The dendritic growth patterns in transverse section micrograph were depended on local longitudinal section, therefore, the microstructure of the weld was varied along its length, periodically repeating related to the pulse rate and travel speed. For all the speeds and pulses investigated, the welds contained centerline cracks with side branches. Compared with electron beam welding, laser welds had more cracking tendency. Minimum cracking was obtained by $500^{\circ} \mathrm{C}$ preheating, low speeds (2.1 to $\left.4.2 \mathrm{mms}^{-1}\right)$ and relatively high pulses rate. Stray crystals were not observed during the welding of Fe-Cr-Ni [Figure 23]. 


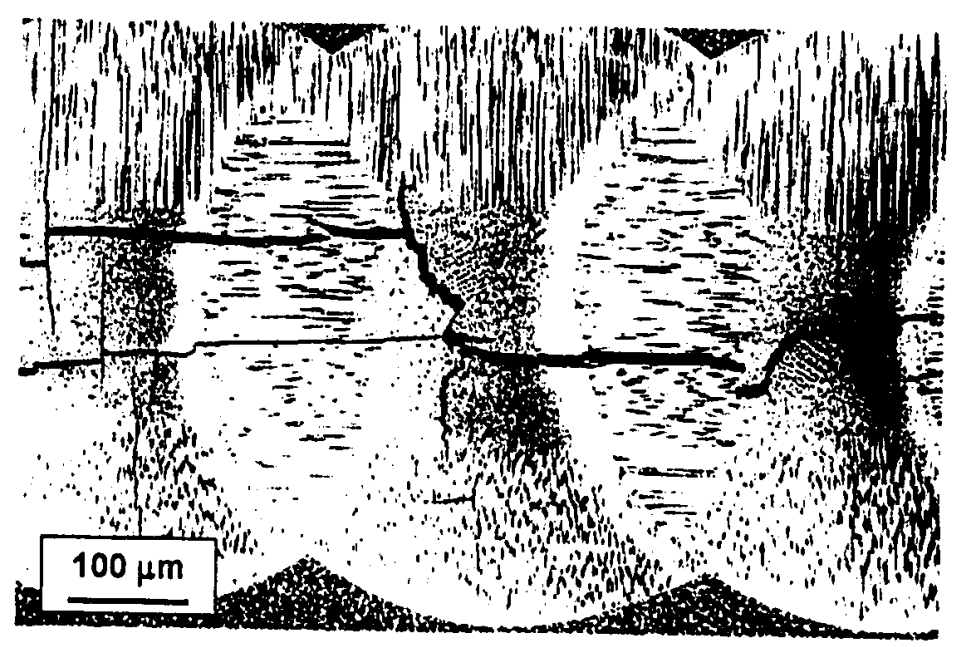

Figure 22 Microstructure of pulsed laser welded PWA1480 showing dendrite growth paltern within weld and presence of stray grains in centre of weld

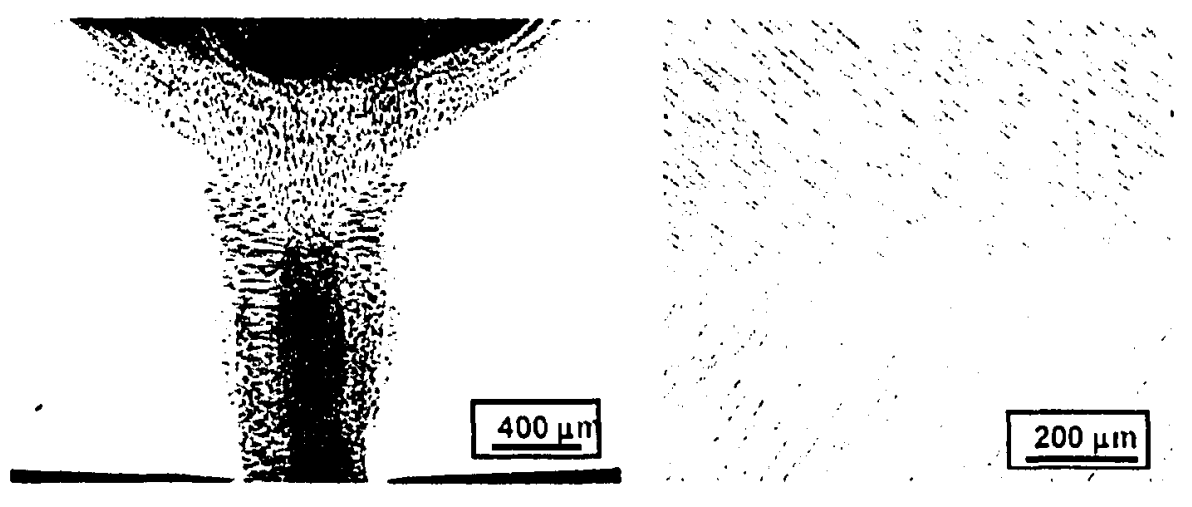

Figure 23 Single crystal nature was maintained in welded $\mathrm{Fe}-15 \mathrm{Cr}-15 \mathrm{Ni}$

However, though slow welding speeds and preheating obviously reduced the weld metal cooling rate, they led to large extent of solute partitioning in the liquid and may promote the formation of large amounts of low-melting eutectics. As illustrated in Figure 22, the welds contain misoriented stray grains that play a critical role in the promotion of hot cracks. Evidence indicated $[48,49]$ extensive stray crystal formation in the center of the weld. For maintaining the single crystal nature, the ideal grain growth direction is $<100>$ 
crystallographic orientation. However, in some regions, the dendrite growth is lost due to stray grain formation, thus, the base metal no longer constituted a perfect single crystal. They particularly studied the effect of crystallographic orientation of dendrites with respect to the solidification front normal on stray grain formation. Results [50] showed that stray grain formation is very sensitive to dendrite growth orientation as well as processing parameters. No stray grains were found in the weld under a low power and low welding speed; while they were extensively occurred only on one side of the weld as increasing the travel speed and power [Figure 24].

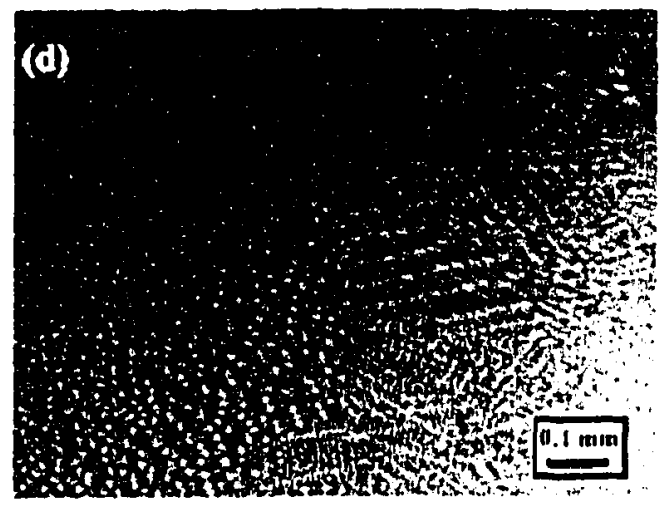

Figure 24 Stray grains exist on only one side of the welds during high speed and high power welding [50]

The formation of the $\gamma / \gamma^{\prime}$ eutectic during the last stages of solidification was identified $[52,53]$. Detailed atom probe field ion microscopy analysis was carried out to determine the $\gamma / \gamma^{\prime}$ compositions and the segregation at the $\gamma / \gamma^{\prime}$ interface, revealing that there is no solute segregation at the interface and the composition of $\gamma / \gamma^{\prime}$ was close to that of the equilibrium composition. Crystallographic orientations were determined by Laue back reflection X-ray analysis. It showed that individual dendrite zones maintained the single crystal nature of the base metal to within $3^{\circ}$, and the stray crystal orientations deviated 
considerably from the base metal orientation. It was also concluded that the stray grain formation seemed to be promoted by conditions which favor constitutional supercooling, characterized by high growth rates and low thermal gradients.

Solidification theory $[54,55]$ interpreted the welding results by the degree of constitutional supercooling (CS), where CS is related to the conditions that lead to planar stability of the solidification front. The criterion for CS for plane front stability can be mathematically stated as:

$$
\frac{G_{L}}{R} \geq \frac{\Delta T_{o}}{D_{l}}
$$

Where $G_{L}$ is the temperature (thermal gradient) in liquid, $\mathrm{R}$ is the solidification growth rate, $\Delta T_{O}$ is the equilibrium solidification temperature range, and $D_{L}$ is the solute diffusion coefficient in liquid. If (1) is met, the plane front will be stable, which means the epitaxial growth will maintain during the solidification. In another word, if

$$
\frac{G_{L}}{R}<\frac{\Delta T_{0}}{D_{L}} \quad \cdot \ldots . . .
$$

the plane stability will be unstable and break down. Along the boundary of welds and base metal, the growth rate $\mathrm{R}$ is the lowest while the thermal gradients are the steepest. As the weld solidification approaches toward the centerline, the growth rate increases while the temperature gradient decreases. As a result, the microstructure develops 
variously from the edge to the center of the welds. Therefore, maintaining the stability can be achieved by either increasing the thermal gradients or reducing the growth rate.

At EPRI Conference in 2000, several organizations [56,57] reported laser welding processes study. EPRI Repair \& Replacement Applications Center (RRAC) [54,55] discussed the results of IN738 repair by using filler materials, IN625, IN738, IN939 Successful welds were achieved using IN625 and IN939, while IN625 was only utilized as a baseline to promote $\gamma^{\prime}$ strengthened alloys, IN939 could be used consistently on IN738 without any cracking. Crack-free welds of IN738 as the filler were obtained but was not on a consistent basis.

S.Katayama, M.Sakamoto [58] presented their newly weldability investigation on $\mathrm{CW}$ YAG laser welded CM247LC and CMSX4. Cracks and crystals with different orientation are developed in pulsed laser welding. The effect of crystallographic surface orientation on the occurrence of different crystals was confirmed and interpreted in terms of different grain angles between $<100>$ (single crystal growth direction) orientation and thermal gradient direction.

Honeywell Laser Technology Service (LTS)[59] stated a successful welds on IN 738LC with using Laser Powder Fusion. The filler powder composition was the same as blade material. Good metallurgical bonding, low dilution and a narrow heat affected zone were obtained on crack-free welds with several porosities. 


\subsubsection{Laser Metal Forming (LMF)}

Laser metal forming is a repair engineering process related to cladding, whereby powder (or wire) material is deposited onto a substrate by local melting and using a high power laser beam. In this way new material can be added onto a bulk body layer by layer by melting and rapidly solidifying, until a desired shape is built up, [Figure 25] [60]. Unlike castings, where solidification is normally controlled by nucleation and growth processes, laser clad exhibit mainly epitaxial growth from the adjacent melted substrate, therefore, the initial solidifying metal expects a crystallographic orientation identical to that of the adjoining solid at the fusion line.

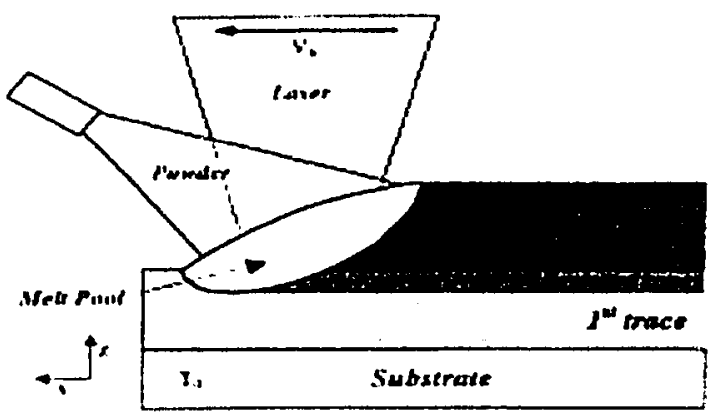

(a)

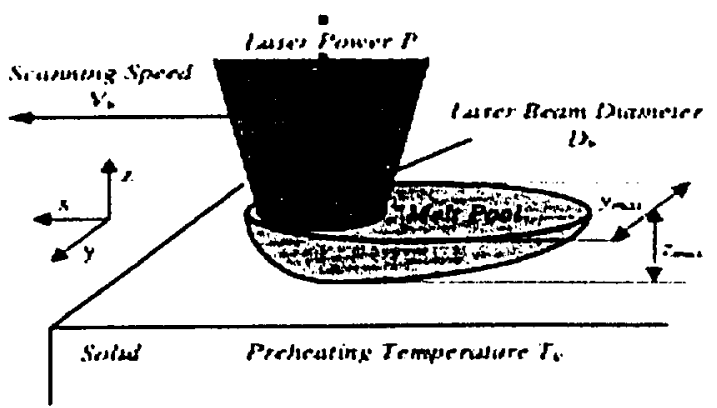

(b)

Figure 25. Schematic representation of

(a) The LMF process (first two deposits only are shown

(b) The laser surface remelting process [60] 
It has been demonstrated [59] hat LMF has such advantages as:

1) Controllable energy input permits low heat input

2) Produces small heat-affected zones and limits the distortion of materials during the process

3) Provides good dimensional control of the welding seam

This welding trail was first studied by M.Gremaud, J.-D. Wagnière, A.Zryd, and W.Kurz [61], Institute of Technology in Switzerland in 1996. The aim of their experimental work was to understand the melt dynamics by varying the laser parameters, feed system, feed materials and material supply geometry with respect to the laser beam and the part. Superalloy IN625, X3CrNi134, Stellite 6, Stellite F and Steel were used in two different systems---wire feed system and powder feed system. They studied the surface quality and found that the thickness of the oxide layer produced during the process and the precise setting of the material injection point with respect to the molten pool are the two fundamental parameters that controlled the process stability. Evidence of epitaxial growth was observed by optical microscopy as well: plates formed by LMF were fully dense and showed no pores or other defects. No porosity exhibited on sample Stellite 6 with a powder feed rate of $12 \mathrm{~g} / \mathrm{min}$ and a beam traverse rate of $1200 \mathrm{~mm} / \mathrm{min}$.

Many works have been done by some research groups in this area in Sivitzerland $[62,63]$ since 1997. Sulzer Innotec illustrated their laser welding tests and metallography research. The automated laser powder welding technology is a combination of welding 
and cladding [Figure 26] technique. The build-up of blade tip was made of Inconel 738.

[Figure 27]

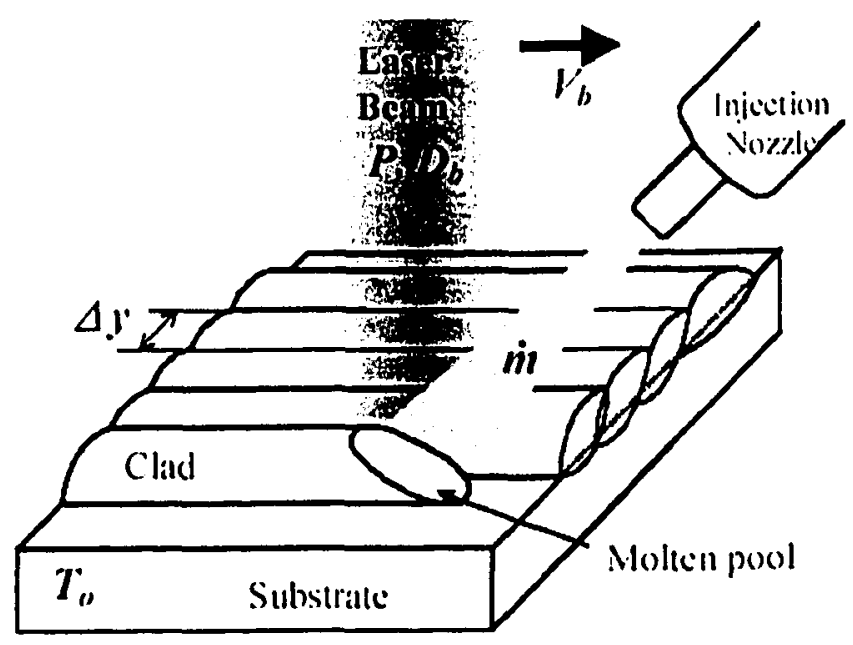

Figure 26 Laser cladding process [62]

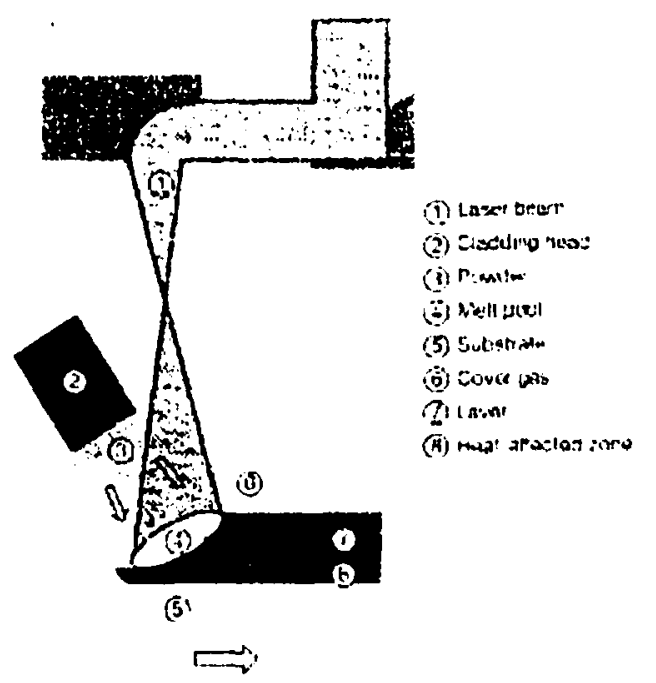

Figure 27 Principle of the laser powder welding process [63]

In laser metal forming, the local solidification conditions and laser surface remelting lead to a dendritic microstructure with columnar or equiaxed growth morphology --- Epitaxial laser metal forming (E-LMF) is a novel branch of LMF, where epitaxial growth of 
columnar dendrites is produced during the solidification of melting pool by selecting proper processing parameters [Figure 28] [64]. During solidification, solute piles up ahead of the interface. This concentration change ahead of the interface will affect the local equilibrium solidification temperature. When the actual temperature is lower than the equilibrium liquidus temperature in a limited zone ahead of the growth front, there is a constitutionally undercooled zone at where nucleation of equiaxed dendrites may occur [65]. Once nucleated, equiaxed grains will take on various volume fractions, and eventually develop to the columnar-to-equiaxed transition (CET) [Figure 29][65]. Since the equiaxed grains lead to crystallographic misorientation, which causes the mechanical defects of the alloy (cracking, porosity, etc.), CET should be avoided as much as possible in the welding process.

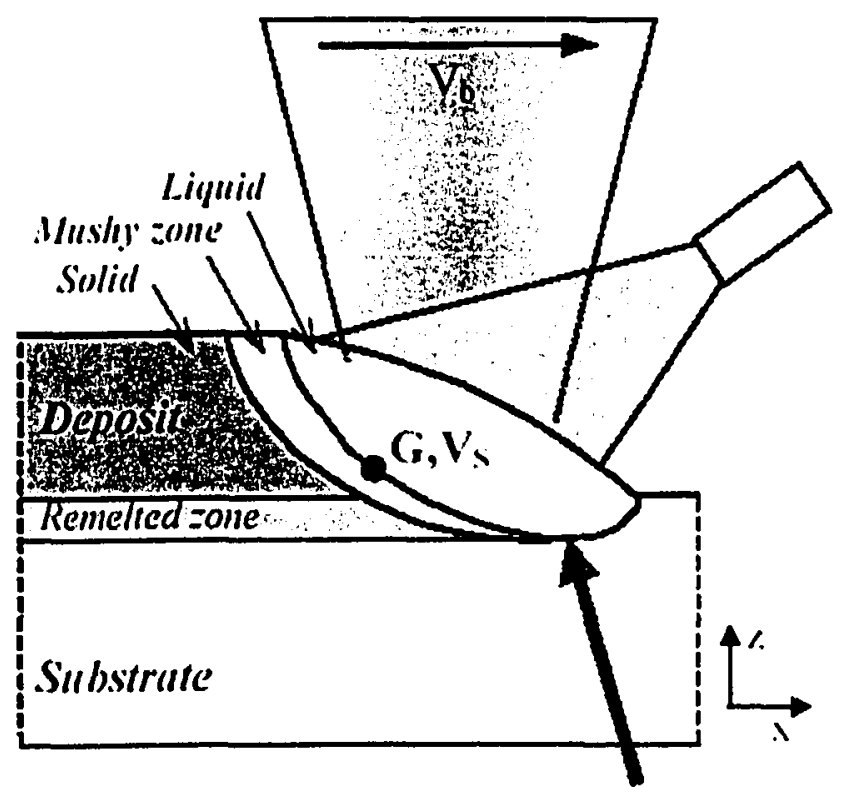

Figure 28 Laser metal forming process and the evolution of the solidification velocity $V$ and temperature gradient $G$ along the solid/liquid interface [64] 

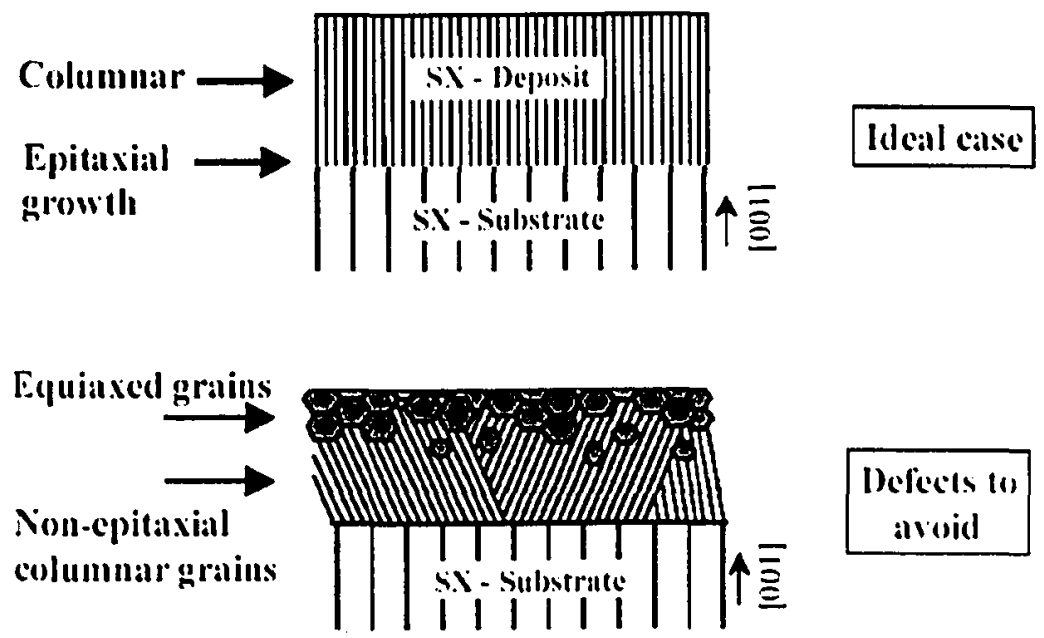

Figure 29 columnar-to-equiaxed transitions [65]

An E-LMF experiment was performed by Gäumann, Henry, Cléton, Wagnière, and Kurtz [66] in 1999 . A $1.7 \mathrm{~kW}$ continuous wave $\mathrm{CO}_{2}$ laser cladding head with a lateral powder jet and a laminar flow of protective gas was utilized. Commercial Ni-based SX CMSX-4 was used for both the substrate and the injected powder. Thanks to the high solidification velocities, precipitation had barely time to take place, and a fine dendritic morphology was formed, thus, the size of residual porosity was reduced in SX. The grain structure of SX was analyzed by electron-backscattered diffraction (EBSD). It was shown that in most regions the crystal orientation of the deposit and of the substrate were identical, no grain boundaries were detected at the interface between the substrate and the deposit, which proved the SX structure of the substrate was reproduced. After laser cladding, two types of heat treatment were applied to characterize the susceptibility to recrystallization and precipitation behavior of SX: the first HT consisted 4 h aging with a peak temperature at $1140^{\circ} \mathrm{C}$, whereas the second one corresponds to a solution heat treatment for $2 \mathrm{~h}$ with maximum of $1290^{\circ} \mathrm{C}$ followed by aging. The SX retained its stability at the first HT while 
a thin recrystallized layer appears at the surface of the deposit after the second heat treatment.

Gäumann, Bezençon, Canalis and Kurtz [67] did the further study in 2000 on E-LMF processing maps for SX CMSX-4 based on solidification microstructures and growth morphologies on various processing conditions. Laser remelting was introduced there to model the solidification phenomena of LMF process and to connect the processing parameters for microstructure control. A microstructure selection map for the superalloy is established to develop the microstructure selection criterion for the CET. Processing parameters such as laser power $P$, beam velocity $V_{b}$, beam diameter $d$, and preheating temperature $T_{h}$ on the solidification were shown in the form of processing microstructure maps [Figure 28]. The local solidification conditions such as thermal gradient $G$ and solidification velocity $\mathrm{V}$ were calculated. As they reported, the formation of equiaxed grains depend on the temperature gradient in the liquid, the solidification velocity of the columnar front and the nuclei density of the alloy. Therefore, the CET could be controlled by properly choosing these parameters [Figure 30]. It was also concluded that in order to obtain a successful SX deposit, the substrate temperature should be as low as possible. Besides, the laser beam power should be reduced since it increases the temperature gradient. Furthermore, they also reported that the laser beam diameter was set very small to ensure sufficient remelting for epitaxial growth. 


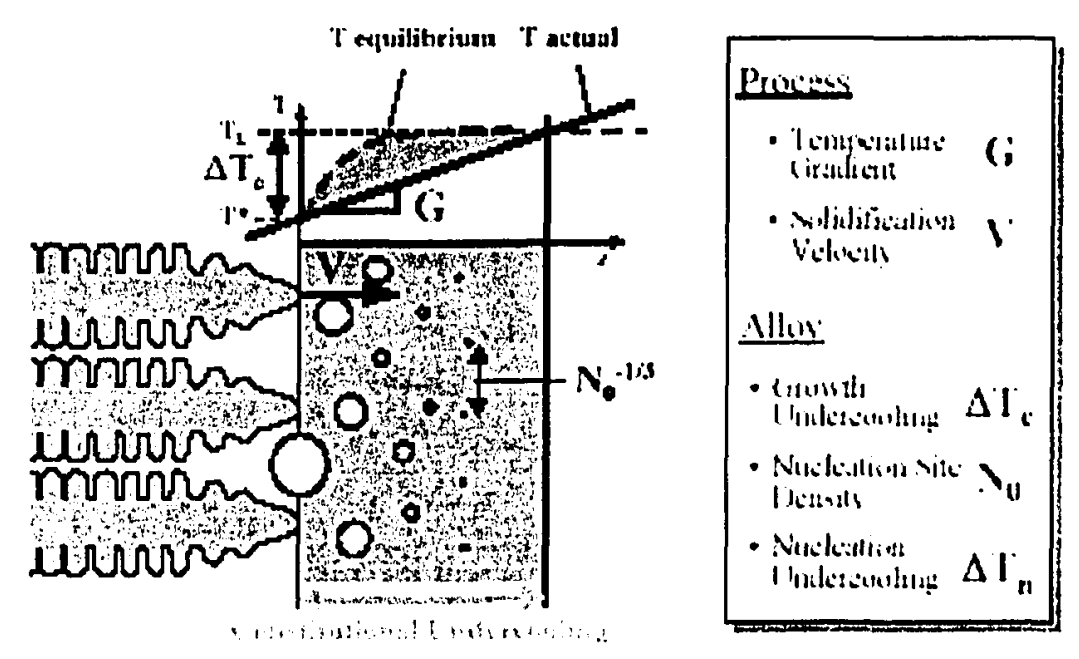

Figure 30 CET can be controlled by choosing the processing parameters [67]

ALSTOM Power Technology Center, Daettwil, $\mathrm{CH}$ [68] currently developed this novel repair procedures. SX blade tips were rebuilt by using fiber coupled high power diode lasers with more than $1000 \mathrm{~W}$ and the robot controlled laser/powder head. The powder and laser beam were combined in a coaxial laser powder head. Microstructure of laser metal-formed single crystal showed fully epitaxial growth through several layers. The higher cooling rate caused the dendrite structure of the deposit to be much finer than that of the substrate, which resulted in a more homogeneous distribution of the coating elements, thus, by properly controlling the process parameters and choosing the substrate-filler, the single crystal nature was extended.

Sulzer Elbar [69] [70] has been working on extending the E-LMF repair limits and improving its quality and reliability. A 3-D model of the component was created to integrate the digitized surface into a workstation. The welding speed and laser energy were controlled by a power control program. Inconel 738 was built up with the same 
material. Microstructure development showed the epitaxial growth formed on the partly melted substrate during the initial solidification, and the planar surface was much stabilized under a higher growth rates. With the growth rates decreasing, the planar morphology changed into cellular, fine dendrite, and then became coarser.

A completely analogous commercial process with a different trademark acronym is the laser engineered net shaping (LENS ${ }^{\mathrm{TM}}$ ) process. The feasibility study was conducted by Glavicic and Michael [71]. The depositions were performed on RENE N5 single crystal turbine blades using Rene N5 powder with $45 \sim 150 \mu \mathrm{m}$ particle size. An Optomec LENS $^{\text {TM }} 750$ system with a $1000 \mathrm{~W}$ Lumonics Nd: YAG laser focused to a spot size of $0.5 \mathrm{~mm}$. Electron-back-scatter-diffraction was used to analyze the microstructure of prepared samples. It was stated that cracks were formed when the equiaxed grain volume fraction reached 0.0066 during the solidification of the deposit, which proved that the transition between a columnar grain structures to equiaxed grains occurred in the deposition of LENS ${ }^{\mathrm{TM}}$ as well. It was also indicated that the crystallographic orientation of the deposit remained same as the substrate since dendrite arms were re-melted and separated from the main dendrite during the process, with the dendrites growth direction parallelled to the [001] crystallographic direction in the substrate. Nevertheless, LENS ${ }^{\text {TM }}$ has some serious stability and reproducibility issues that still need to be understand at present. It may be considered as a feasible repair process for SX turbine blades in the near future once those problems are sorted out. 
Lately, some groups presented their research in International Conference on Joining of Advanced and Specialty Materials VII on October 2004, at Columbus, OH, USA [72,73,74,75] Laser Engineered Net Shaping (LENS) [72] was applied in repair of turbine components to obtain a small heat affected zone to meet the high performance require in a high reliability application. Melt pool geometry on single crystal growth and microstructure development during laser surface melting were studied by means of mathematical modeling and experiments [73]. Results indicate that the melt-pool geometrical parameters have profound influences on the dendrite growth velocity and growth pattern in the melt pool.

\subsubsection{Electron Beam Welding (EBW)}

As an industrial welding process, Electron Beam welding (EBW) is often compared with Laser Beam Welding. First developed in the late 1950's[76], it has been applied in various industrial sectors for many years and is increasingly being implemented in the aerospace industry. Commercially available power levels up to $200 \mathrm{~kW}$ can be used to join materials in the thickness of interest in many fields. This high energy density welding process allows for narrow and controllable depth penetration welds with considerable lower heat input when compared with conventional arc welding.

The basic EBW equipment [Figure 31] consists of a welding chamber (usually a vacuum chamber), electron beam gun, power supply system, a vacuum pumping system and a control system. 


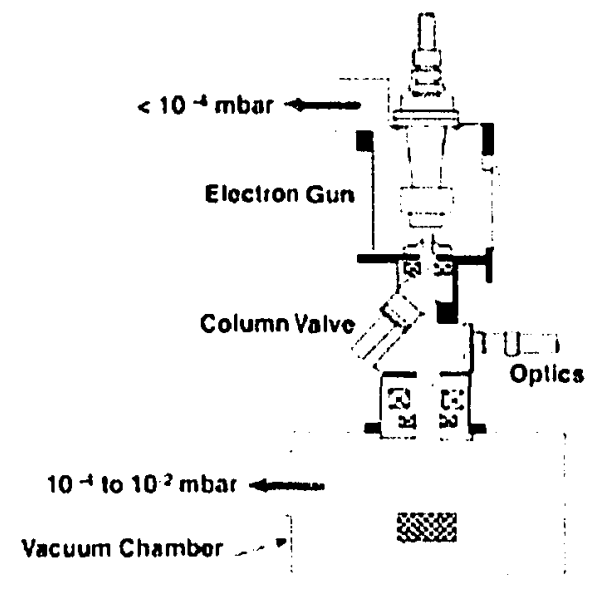

Figure 31 Electron Beam welding facility [77]

High intensity of the electron beam generates welds with small heat affect zone (HAZ) and little distortions of the workpiece. The electron beam used is the heat source used to melt the base materials and thus accomplish the fusion welding operation. The heart of an electron beam system is the generator (electron gun) that produces the clectron beams. The basic arrangement of an electron gun consists of a cathode and anode. The electrons are generated by heating a negatively charged cathode to its thermionic emission temperature and consequently emitting electrons [Figure 32]. Two electron gun designs have been used: a diode gun and triode gun. Most high power EBW machines (up to $200 \mathrm{~kW}$ ) use the triode gun design. When the workpiece is moved relative to the beam, material at the leading edge is melted and flows around the keyhole, solidifying to form a deep narrow weld bead with a characteristic chevron pattern on the surface. Heat conducted into the surrounding material produces a narrow heat affected zone. Deep penetration welding with the "key-hole" mechanism is one of the key features of EBW, which is able to weld relatively thin plate with a high speed and produces a high quality weld. 

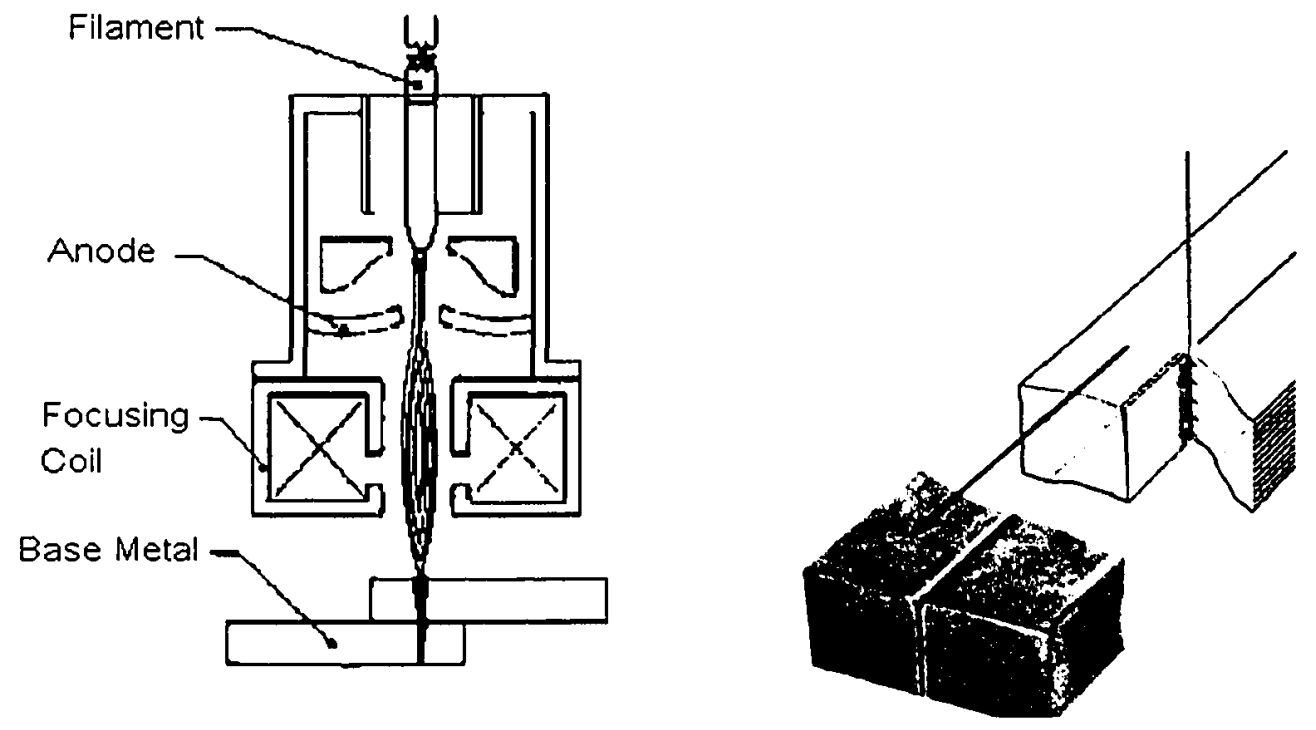

Figure 32. Electron Beam Welding joining process diagram, EBW gun target a weld joint by impinging a beam of high-energy electrons to heat it [78]

The principal processing parameters in the EBW are beam current, beam accelerating voltage, focusing lens current, welding speed and vacuum level. The voltage controls the heat input of the process, and thus influence the residual stresses, distortion and HAZ size. Secondary variables as beam deflection, oscillation frequency, amplitude and gunto-work distance also affect the welding quality.

The advantages of EBW are summarized as follows:

1) High efficiency and high power (up to $200 \mathrm{~kW}$ ) enables EBW to achieve a large range of penetration; high welding speed is attainable due to the high melting rates associated with the concentrated heat source. 
2) Low total heat input per unit length of weld produces a narrow weld bead with high depth-to width ratio and small HAZ, which results in low residual stresses and minimum distortion.

3) As welding takes place under vacuum conditions, contamination of the metal by oxygen, nitrogen and hydrogen is prevented, which gives a high purity weld. Those characters ensure an impurity free of metal oxides and nitrides. Those are beneficial for reactive and refractory metals since they are susceptible to oxidation attack during welding.

4) Basically no filler materials are required, thus complete automatic control can be implemented

5) EBW with filler material can solve problems associated with metallurgical effects for both similar and dissimilar metal welding.

Like any other welding process, EBW has some limitations as:

1) High energy density causes the tendency for spiking, incomplete fusion and root porosity

2) Electron beams require magnetic fields to direct their limited displacements

3) A vacuum environment is normally necessary, and it creates difficulties with metals vaporizing easily; non-vacuum EBW is ineffective

4) Advanced technology leads high capital and running cost, which can not be neglected in industry manufacture

5) Personnel must be protected from the X-rays generated by the electron beam and equipment 
EBW is the most powerful fusion welding process to date. It has many similarities with Laser Beam Welding since they are both high energy density beam processes. Each of them has its own characteristics because of its different working principles and operating conditions. Table 2 shows a comparison of fusion welding processes.

Table 2 Characteristic comparison of conventional fusion weiding, LBW and EBW

\begin{tabular}{llcc}
\hline & $\begin{array}{c}\text { Laser beam } \\
\text { welding }\end{array}$ & $\begin{array}{c}\text { Electron } \\
\text { beam welding }\end{array}$ & $\begin{array}{c}\text { Conventional } \\
\text { fusion welding }\end{array}$ \\
\hline Welding speed & High & High & Low \\
Heat input & Low & Low & High \\
HAZ size & Small & Small & Large \\
Penetration capability & High & very high & Low \\
Weld bead appearance & Good & Good & Fair \\
Welding atmosphere & Air & Vacuum & Air \\
Magnetic effect & No & Yes & Yes \\
Deformation & Small & Small & Big \\
Residual stresses & Low & Low & High \\
Precision welding & Good & Good & Limited \\
Reflective material welding & Not good & Good & Good \\
Fit-up requirement & High & High & Low \\
Equipment costs & High & High & Low \\
Operating costs & Depends & High & Depends \\
\hline
\end{tabular}

Recent decades, a good deal of research has been done on the EB welding of nickel base superalloys, from polycrystalline superalloy to single crystal superalloys. They are summarized below:

F.Pierquin and J.Lesgourges [81] characterized the fusion zone configuration of electron beam welded superalloy. Due to the materials' low ductility, hot cracking problems arise in welding of high strength superalloy. Vertical cracks, horizontal cracks, axial cracks and spike cracks were recognized as welding defects that occurred in the fusion zone. 
Changes in microstructure of EB welded superalloys Udimet 700LC and Inconel 718 was reported by W-B Busch, H.D.Kunze, and U.Draugelates [82]. All weldments were annealed. In some cases shrinkage pores and microcracks took place during the welding. Numerous microscopic cracks were found on Udimet 700LC in the partly melted zone, in another words, liquid and solid interface region. Some of the cracks were visible under optical microscopy [Figure 33], with the morphology of right-angled shape, which called post-weld heat treatment cracks. The tendency of welding crack forming was correlated with the volume fraction of $\gamma^{\prime}$. The $\gamma^{\prime}$ formed rapidly in Udimet 700LC. Thus, residual stresses tended to relax in the partially melted grain boundaries, leading to the microcracks in the heat affected zone region next to the fusion line. Subsequent agehardening was applied to increase the coherency strains of the precipitations. While in the low reactive materials as Inconel 718 , the $\gamma^{\prime}$ precipitation rate is relatively slow, where residual stresses could easily relax in $\mathrm{HAZ}$ and grain boundaries, resulting in the absence of hot cracks or post weld heat treatment cracks.

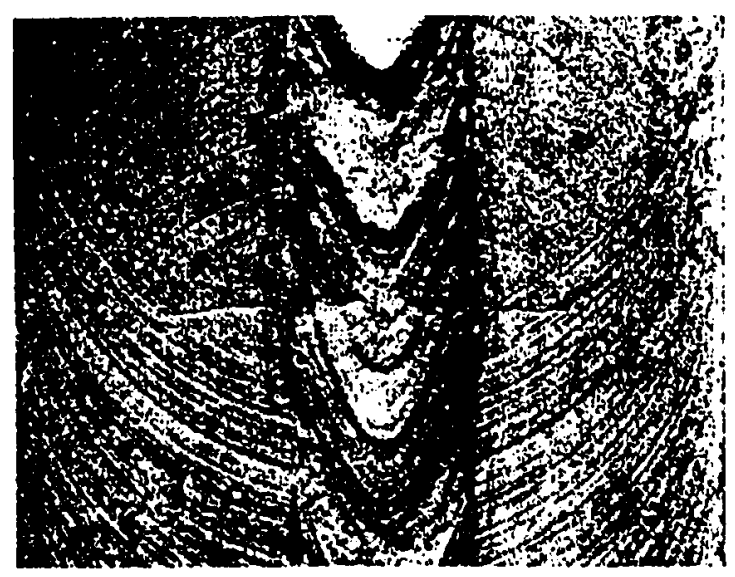

Figure 33 Post weld heat crack in Udimet 700LC welded in the fully heat treated condition, annealed after welding [82]. 
In 1994, National Aeronautics and Space Administration (NASA) [83] investigated the weldability of the nickel-based superalloy Udimet $720 \mathrm{LI}$, a modified form of Udimet 720. Samples were cut into sections and used with different heat treatments to test the susceptibility of welding crack. Full penetration EBW were made in using voltage of $100 \mathrm{kV}, 12.4 \mathrm{~mA}$ current and speed of $76.2 \mathrm{~cm} / \mathrm{min}$. Post-weld heat treatment was applied after welding. Results revealed no surface cracks on the pre-weld annealed specimens, showing that hot cracking does not exhibit in Udimet 720LI during EBW unless it received aging heat treatment. However, severe sub-surface cracking were revealed by optical microscope. It was concluded that the welding of Udimet $720 \mathrm{LI}$ results in residual stresses that can be relieved in one of two ways during aging --- deformation or strain-age cracking. Pre-weld solution annealing heat treatment and rapid heating used for eliminating strain-age cracking were unsuccessful.

Sorokin Li [84] studied EBW of creep-resisting alloys in 1998. Research was carried out on EI868 creep-resisting homogeneous alloy with an austenitic structure of the $\gamma$-solid solution and EP437 and EP718 creep-resisting, dispersion-strengthened, iron-chromiumnickel alloys, as well as E1437B, EP648, EP708, EP693, EP199 and EI698 nickel-based alloys. After quenching, welding and aging, the materials hot cracking tendency was examined. Results showed that the susceptibility increased with increasing thickness of the welded components and welding speed, which resulted in an increase of the welding stresses and an increase of internal strains rate during welding. 
The weldability and microstructure evolution of SX PWA-1480 and CMSX4, the first and second generation SX superalloy was studied in detail by ORNL $[85,85,87]$. Welding was done with a large range of parameters, extensive cracking was observed in the welds [Figure 34]. Detailed microstructure analysis indicated epitaxial growth took place in the weld metal region while the single crystal nature was compromised by stray grain formation. They were more abundant at the top center and near the crown rather than along the weld edges [Figure 34], or at the root of the weld less stray crystals formed with higher speeds and lower pulse rates in laser welds case. Stray grains were found to be more in EB welds than in laser welds. On the other hand, as a continuous process, EB welding produces a steady pool size and shape, which definitely results in a uniform microstructure along the welding length and fewer dendrite zone growth boundaries. Crack free welds was made only over a very narrow range of welding conditions with a preheat of $500^{\circ} \mathrm{C}$. Atom probe field ion microscopy analysis was carried out, revealing that there was no $\gamma / \gamma^{\prime}$ interfacial segregation, and the compositions of $\gamma / \gamma^{\prime}$ phases were similar to those of the base metal. 


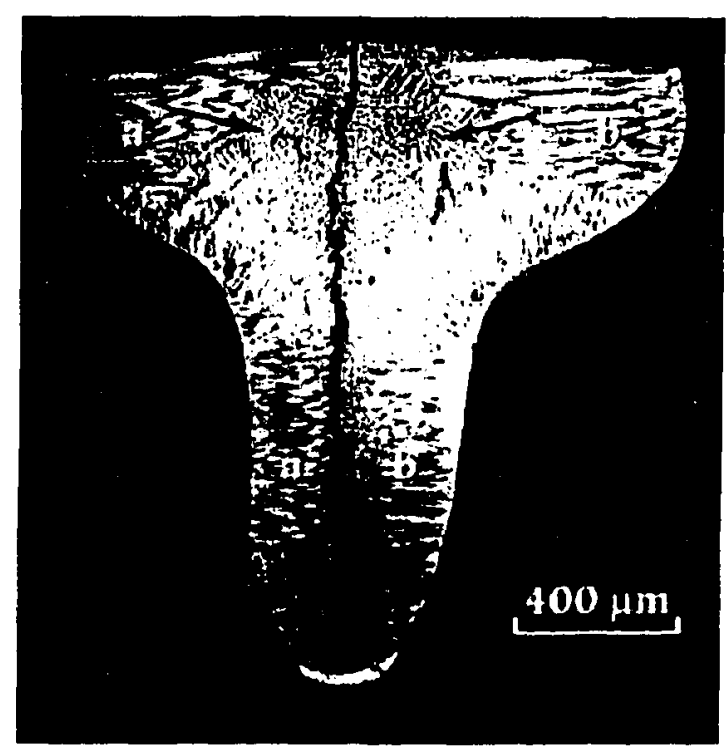

Figure 34 SX PWA1480 is susceptible to hot cracking [85]

They also presented an overview [88] of scientific and technical issues related to joining single-crystal nickel-base superalloys with examples from PWA1480, CMSX-4, TMS-75 and N5, which are materials used in the gas turbine industry. A geometric model was used to describe the interaction between crystallography and dendrite growth directions to interpret the grain structure development in EBW of PWAI480 [Figure 35]. Detailed microstructure characterization illustrated the solid-state decomposition of the $\gamma$ phase on the final $\gamma+\gamma^{\prime}$ microstructure during rapid cooling using atom probe tomography. Computational heat transfer and stress model calculations show that the small amount of liquid along the grain boundary and tensile stress may lead to weld cracking. 


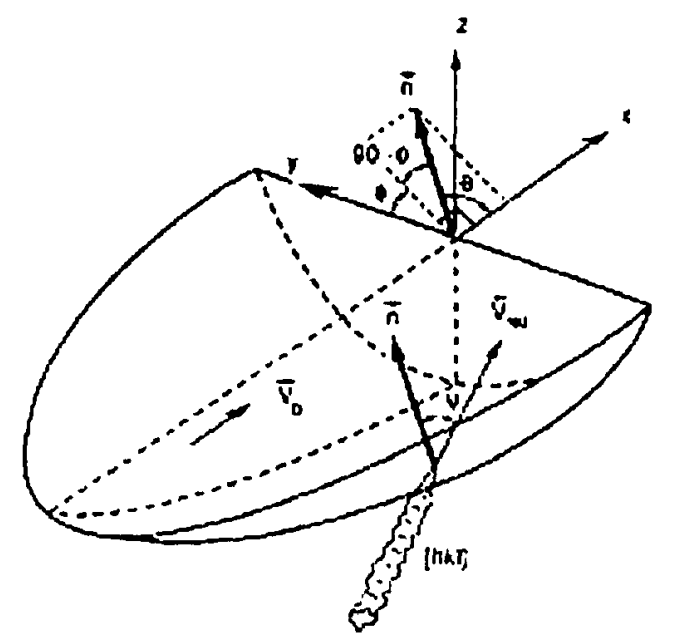

Figure 35 A geometrical model was developed to predict the dendrite microstructure in single crystal welds [88]

ALSTOM Power Sweden AB [90] has made an extensive use of EB welding techniques to manufacture compressor rotors for their gas turbine engines. The process involved the welding of separate steel disc and nickel-based superalloys IN718 and Nimonic901. With a $150 \mathrm{kV}$ EB welding facility that can providing a maximum heat input of $300 \mathrm{~kW} / \mathrm{mm}^{2}$, the high intensity parallel beam of electrons produces much deeper and narrower weld melts. The high quality welding technique enable to join even those dissimilar materials, and it has been proved very reliable.

A.K.Abduljawwad, M.Strangwood and C.L.Davis [91] applied EBW in forged and double heat treated $\left(850^{\circ} \mathrm{C}\right.$ for 4 hours followed by air cooling and $760^{\circ} \mathrm{C}$ for 16 hours followed by AC) WASPALOY. Microstructure, hardness and fatigue initiation for the base metal were characterized. Heat treatments were employed to develop a range of $\gamma$ precipitate sizes and increased the overall strength levels, a greater volume fraction of $\gamma^{\prime}$ was precipitated as well, resulting in higher strength and improved fatigue life at elevated 
temperatures. A post-weld heat treatment at $760^{\circ} \mathrm{C}$ for 5 hours was employed following by vacuum cooling to $260^{\circ} \mathrm{C}$ and then a nitrogen fan cool to room temperature. It was found that grain size increased from the base metal through the full penetration weld to the partial penetration weld metal and being largest at the end of full penetration. Microstructure showed an incomplete dissolution of large TiC particles occurred, and modifications in size volume fraction and type of grain boundary carbides, TiC and $\mathrm{M}_{23} \mathrm{C}_{6}$ developed during EBW.

N.L.Richards, M.C.Chaturvedi, Y.G.Liu and K.Mount [91] did a further study of heataffected zone microfissuring in Incoloy 903 regarding to various welding parameters. EB welding was performed by a $60 \mathrm{KV}, 30 \mathrm{KW}$ machine partially penetrating the specimen. It was concluded that travel speed, beam current and beam focus have a paramount effect on micro-fissuring behavior, a function of the shape of the weld. Those factors were combined into a regression equation interpreting the influence of each independent variable on micro-fissuring behavior.

\subsubsection{Linear Friction Welding}

Unlike fusion welding, pressure welding depends on the application of high pressures and/or high temperatures, resulting in a strong plastic band and a local deformation of the pieces to be joined in the welding area so that a bond between both pieces is made. 
Friction welding [93] is a kind of pressure welding, where metals are joined through mechanical deformation.

Linear Friction Welding (LFW) [Figure 36] is seen a key technology for the aerospace industry as it enables the joining of difficult to bond materials. It is used as a manufacturing process to build the complex structures required for today's gas turbines. Essentially, it is a non-melting fusion process producing high integrity welds with little prior surface preparation required. It is preferred for the joining of turbine shaft and case components.

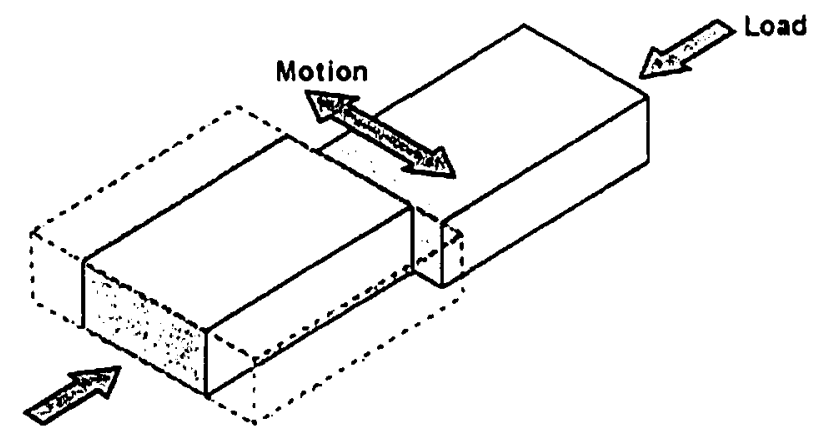

Figure 36 Linear Friction Welding [94]

For linear friction welding one of the components is laterally reciprocated and axially pressed against the stationary component by applying a pre-set friction force. Friction heats up both workpieces in the joint area and softens a finite volume of material. After generating sufficient heat, the oscillation is stopped in the central position and the axial force is increased during the forge phase. Meanwhile the plasticized material (interfacial contaminant) is expelled from the joint and a flash is generated. The process operates below the melting point in the solid phase and achieves fine-grained welds of 
exceptionally high quality. Because the metals are not melted, defects associated with melting solidification phenomena do not develop, and unions as strong as the base material can be made.

It is generally accepted that friction welding can be separated into i) a dry friction stage, followed by ii) an increased asperity contact, and iii) some sort of steady state once the relatively high weld temperature has been acquired. It is not clear how the surface contaminants are removed - especially from the mid-point of the weld.

The main challenge of LFW are heat generation, heat conduction, and more importantly, the representation of the visco-plastic matcrial flow during steady state LFW. It is essential that both these matters be addressed systematically, so that an accurate formulation of an average material extrusion model can be constructed.

\subsection{Summary}

A review was presented above on superalloy fundamentals and welding of superalloys. Various samples were chosen from conventional cast superalloy to commercial single crystal $\left(3^{\text {rd }}\right.$ generation) superalloy. Different fusion welding processes, such as electron beam welding, laser beam welding and laser metal forming were demonstrated. Historical work shows that welding for nickel base superalloys is very difficult because of the following issues: 
- Hot cracking. Known as solidification cracking. This happens during the solidification when the thermal strain causes contraction exceeding the ductility of half-melted alloy. A material's solidification temperature range in large extent influences the hot crack tendency. Larger solidification temperature window gives it more time for stress-related cracking to generate.

- Grain boundary liquation cracking. Also called heat affected zone fissuring, mostly occurs within the HAZ as a consequence of local dissolution of grain boundary phases, such as carbide, Laves phases and $\sigma$-phase. These phases cannot dissolve completely into the surrounding matrix under rapid heating, leading to the formation of low melting point eutectic phases along grain boundaries. Liquated grain boundary has no strength, thus, separation occurs at the liquated grain boundary that results in fissuring. Susceptibility to HAZ fissuring is associated with alloy composition; Boron and sulfur are two elements that form lower melting point eutectics that contribute to $\mathrm{HAZ}$ fissuring. Grain size, grain boundary character and welding conditions also affect the occurrence of grain boundary liquation cracking [95]. Grain boundary liquation cracking does not apply on single crystal superalloys since there is no grain boundary involved.

- Stray grain formation. Refers to single crystal superalloys. Under low speed, the welds are more likely to maintain the single crystal nature while high speed welds tends to form extensive stray grain formation. Previous work shows that stray grain formation is related to cracking behavior. Constitutional undercooling and dendrite fragmentation are the main factors that cause stray grain formation. 
- Strain-age cracking. Precipitation-hardenable nickel-base alloys are often post weld heat treated to relieve the residual stress and develop the maximum strength. To obtain those properties, the welds are usually solution annealed and then aged. Solution annealing helps to relieve the stress, however, aging can occur during heating to the solution annealing temperature. This aging could be very deleterious since it often results in cracking. Such post weld heat treatment cracking is also called strain-age cracking.

Due to the above issues, the following recommendations are given regarding to:

Welding process. Processes with high power density and low heat control are the optimum options. Therefore, laser welding and electron beam welding are more potential and expected to be the focus of future development efforts.

Repair goals. Since single crystal superalloys are prone to easily crack during weld, improving their weldability and obtaining the optimum properties after welding are the primary goals of future welding research. Pre-weld heat treatment and post-weld heat treatment are applied when it is necessary. Control of welding parameters, such as heat input, shape, welding speed, pulse rate, beam diameter etc. play an important role of good weldability; other parameters related to welds (thermal, mechanical and metallurgical parameters) should be considered as well to avoid stray grain formation, which is associated with weld cracking. Proper heat treatment is recommended to improve the phase stability, weldability, constitution and material properties. 
Filler materials. This is recommended for Laser forming welding: powder fillers offer the better flexibility for varying weld composition and the melting of fillers in powder formation has higher heat transfer rates than wire fillers. Overall, developing advanced filler compositions that are stronger and more capable of withstanding both welding and PWHT-induced stresses and they are potential for lower heat input to the weld joint.

Economic benefit. To be successful a repair scheme must be commercially viable as well as technically sound. Thus, engineers should understand the need of customers and the economic consequences of his /her design choice. Methods of welding and its efficiency determines the cost of the repair to the supplier, therefore, it is extremely important to keep production costs as low as possible in order to be competitive in all types of markets. Expensive control systems, excessive inventories, non-value-adding inspection operations and disordered part flow, as the major resource consumers, negatively effect building good quality into the production processes and decrease production cycle time. Therefore, they have to be considered at the same time. Simply stated, good, fast, and low cost are the demanding requirements of Aerospace industrial manufacturing. 


\section{Thesis objectives}

As mentioned above, advanced welding technologies have been used in repairing gas turbine components. Recently, the weldability of gas turbine blade material, particularly Ni-base single crystal superalloy PWA1484, has become an area of great interest in the aerospace industry. This project is part of a collaborative research program between Carleton University, the Structures, Materials and Propulsion Laboratory of the Institute for Aerospace Research, National Research Council Canada and Nu-tech Precision Metals Inc.

The purpose of this project is to develop a Electron Beam Welding process that can be used to repair damaged single crystal turbine blades without unduly affecting the mechanical properties of the base material while maintaining the $\mathrm{SX}$ nature of the component and avoiding welding defects. To help meet this goal, several tasks have been identified and formed the objectives of this thesis:

i) Develop a better understanding of problems associated with the welding repair of SX nickel-base superalloys.

ii) Develop a better understanding of the processing parameter - microstructure formation relationships involved in electron beam welding.

iii) Develop the welding process parameters required to repair SX components with minimum welding defects and maintaining high mechanical properties. 
iv) Characterize the repaired SX components by microstructural analysis and mechanical property testing. 
$4 \quad$ Weldability and microstructure analysis of SX PWA1484

\subsection{Experiment Material -- SX PWA1484}

\subsubsection{Material Compositions}

The material PWA1484 is a commonly used second-generation SX superalloy, developed in the late 1980's [84]. It was supplied in the form of SX cast bars, approximately 180 $\mathrm{mm}$ in length and $19 \mathrm{~mm}$ in diameter [Figure 37] by PCC Airfoils Inc., Minerva, $\mathrm{OH}$. The chemical composition of the alloy, in weight percent, was $\mathrm{Ni}-4.82 \mathrm{Cr}-1.89 \mathrm{Mo}-$ 5.83W-2.91Re-8.53Ta-5.64Al-10.11Co-0.07Hf.

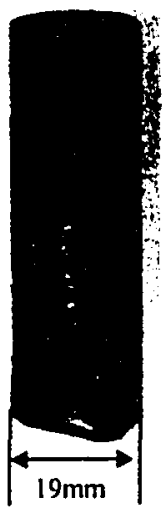

Figure 37 SX PWA1484 Bar 


\subsubsection{Metallographic Results (As-received material)}

The SX PWA1484 superalloy bars were sectioned longitudinally and transversely with an ISOMET 2000 Precision Saw. Conventional metallographic techniques were used to characterize the as-received microstructure of PWA1484 before welding was applied. Samples were mounted with Struers LaboPress-3 and ground automatically by using AutoMet variable speed grinder polisher with the grit range from 180 to 1200 . They were then polished in a diamond abrasives solution with Metadi Fluid. Specimens were chemically etched using a solution of $20 \mathrm{~mL} \mathrm{HCl}, 20 \mathrm{~mL} \mathrm{HNO}_{3}, 30 \mathrm{~mL} \mathrm{H}_{2} \mathrm{O}$, and $0.6 \mathrm{~g}$ molybdic acid. An Olympus PMG3 optical microscope, a Hitachi S-570 and a Philips XL-30S SEM were used to examine the general microstructure of SX PWA1484.

Low-magnification optical images are shown in Figure 38 and Figure 39, which clearly illustrate the dendritic nature of the microstructure of SX PWA1484. Figure 38 is a longitudinal section with the SX growth direction oriented vertically, while Figure 39 is a transverse section with the SX growth direction oriented perpendicularly to the plane of the page. The crosslike morphology is the evidence of dendrite branching. The primary dendrite arm and secondary arm spacing are clearly revealed from the noticeable degree of branching (primary dendrite and secondary dendrite branching). 


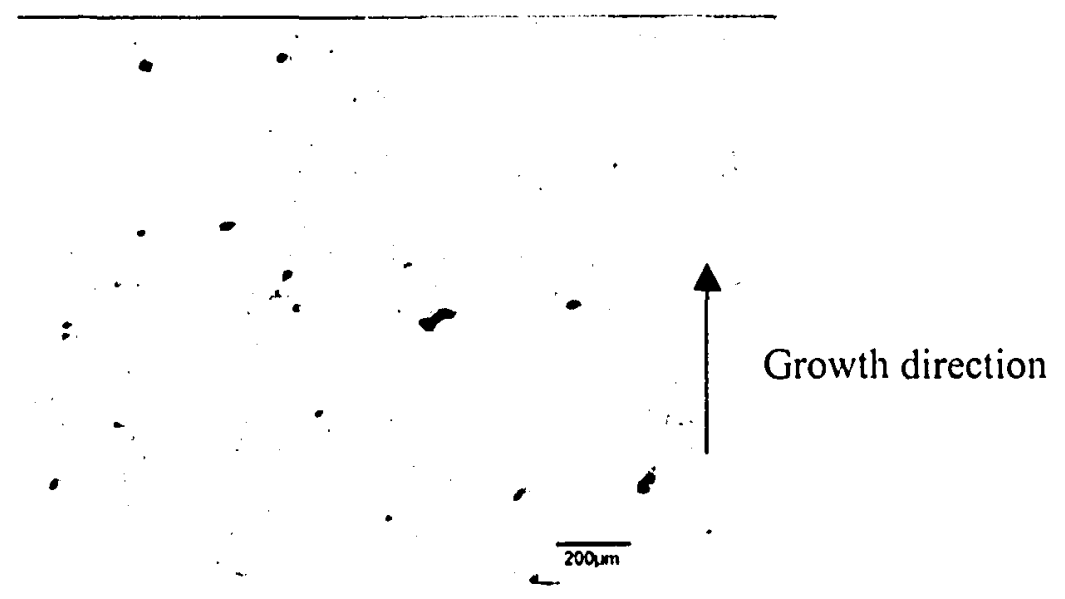

Figure 38 A longitudinal section showing the $S X$ growth direction oriented vertically

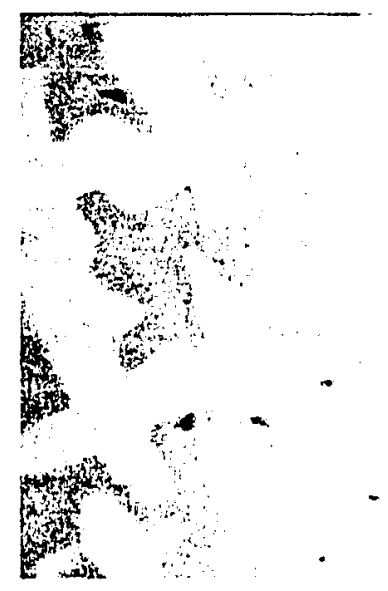

- Growth direction

Figure 39 A transverse section shows the dendrite from the top with the $\mathbf{S X}$ growth direction oriented perpendicularly to the plane of the paper.

Higher magnification image, Figure 40 , demonstrates that $\gamma / \gamma$ 'eutectic phases, seen as light colored spots, distributed randomly in interdendritic zone. The mushy-net-like morphology is known as $\gamma / \gamma^{\prime}$ eutectic phases, surrounded by some leftover $\gamma^{\prime}$, shown as the convex bright chunks. Figure 41 is another optical microstructure of $\gamma^{\prime}$ precipitates and $\gamma / \gamma^{\prime}$ eutectic phase. 


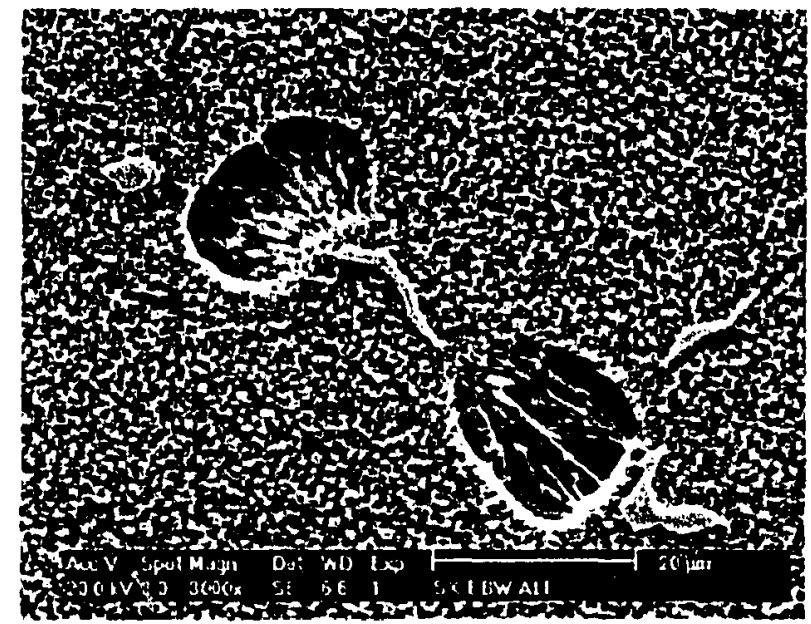

Figure 40 A high magnification SEM image demonstrates the morphology of $y / y^{\prime}$ eutectic phases and $;$

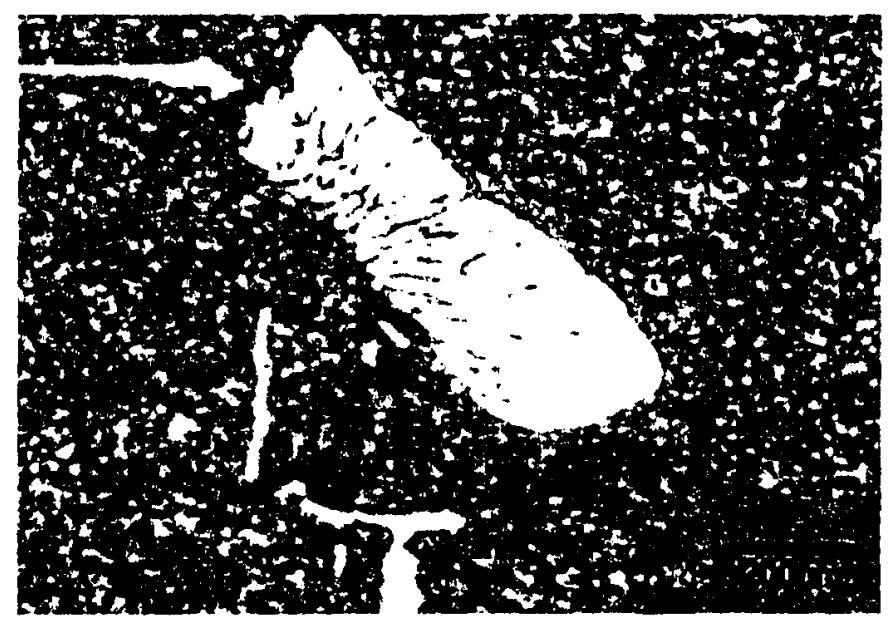

Figure 41 Large amounts of exhibited eutectic phases reveal the microstructure of as-received material in detail

The microstructure of PWA1484 is relatively simple, consisting mainly of a large volume fraction of $\gamma^{\prime}$ precipitates, exhibiting a cubic $\gamma^{\prime}$ morphology, distributed in a $\gamma$ matrix, as shown in Figure 42. 


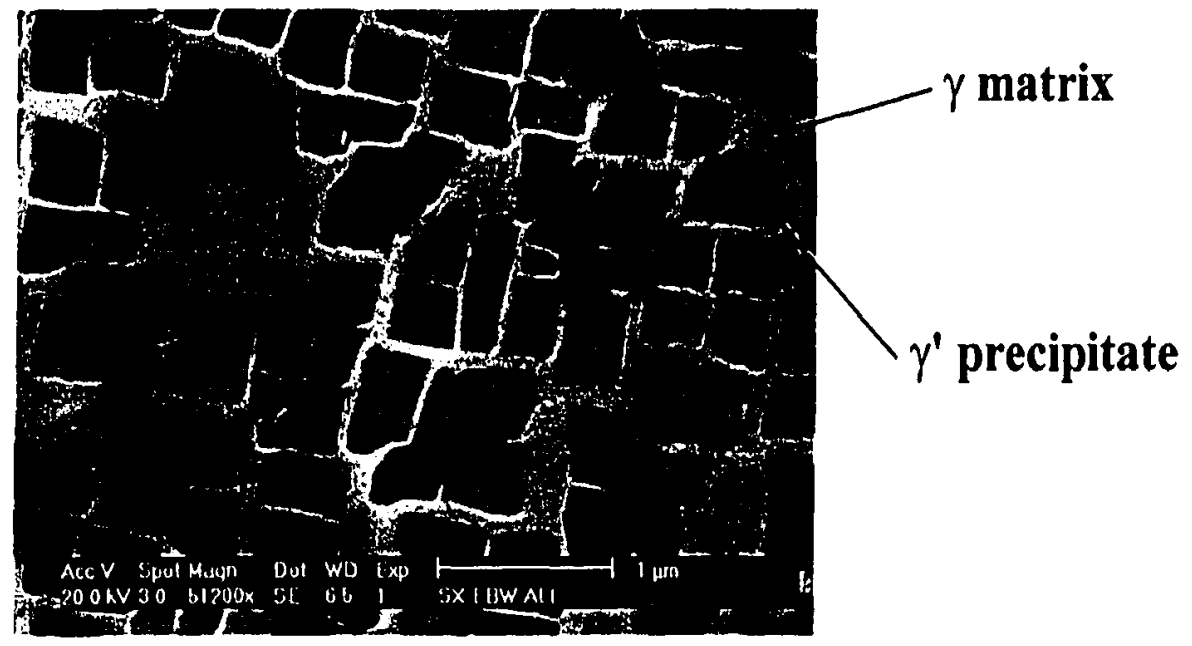

Figure 42 A SEM micrograph of the as-received single crystal PWA1484 bar clearly illustrates the cuboidal nature of the $y^{\prime}$ precipitates in the $y$ matrix.

\subsection{Welding Trials}

\subsubsection{Preparatory work}

Before being welded, small coupons were cut from the cast bars in both transverse and longitudinal directions, as shown in Figure 43. The dimensions of the longitudinal coupons were on the order of $2-3 \mathrm{~mm}$ in thickness, $20 \mathrm{~mm}$ in width, and $50 \mathrm{~mm}$ in length. The transverse coupons were approximately $2-3 \mathrm{~mm}$ thick. It should be noted that the longitudinal direction corresponded to the $<100>\mathrm{SX}$ growth direction. However, the secondary orientation of the coupons was not controlled, i.e. the longitudinal coupons were randomly oriented with respect to the secondary dendrite arm growth direction. 


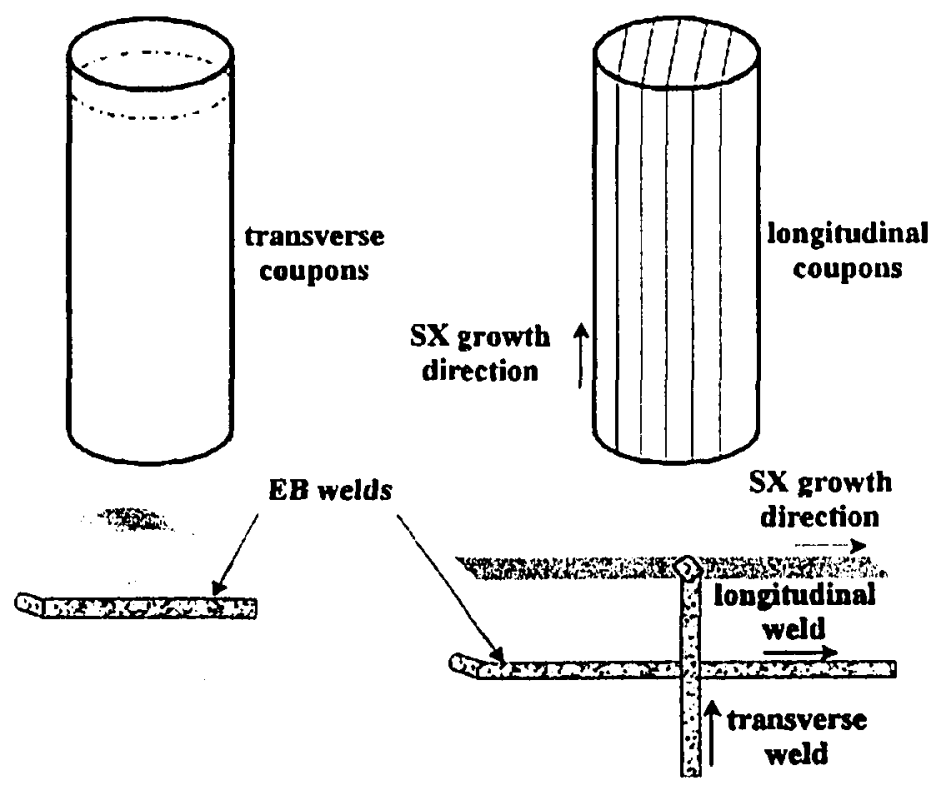

Figure 43 Orientation of the longitudinal and transverse EB welding coupons cut from the as-received SX PWA1484 bars. Also shown are the EB welding directions

\subsubsection{Welding equipment, process and procedure}

\subsubsection{Initial welding trials}

\subsection{Welding parameters}

Welding was done by Nu-Tech Precision Metals. The electron beam welder was a Wentagate Dynaweld DW 604 with maxium power of $60 \mathrm{Kv}$ and $45 \mathrm{~mA}$. A vacuum chamber with level of less than or equal to $1 \times 10^{-4} \mathrm{~mm} \mathrm{Hg}$. The coupons were welded in longitudinal and transverse directions, as shown in Figure 43, to determine if there were any directional issues associated with EB welding. Backing bars were used on some of the samples. A backing bar is a metal bar (usually copper or aluminum because they dissipate heat best) that is clamped to back of the weldment to evenly supporting the 
molten weld metal. This simple technique enables the electron beam to get a full penetration, avoids warping and porosity.

The first three coupons were electron beam welded using different combinations of welding parameters, as detailed in Table 3. The acceleration voltage was $60 \mathrm{kV}$ for all welds, while the beam current was varied from 10 to $11.5 \mathrm{~mA}$. Two different welding speeds of 20 and $25 \mathrm{in} /$ minute $(8.5$ and $10.5 \mathrm{~mm} / \mathrm{s}$ ) were used. In addition, a sharp beam focus was used with a 7" $(180 \mathrm{~mm})$ gun-to-work distance. The EB welds were full penetration and no filler material was used. An as-welded coupon, approximately $50 \mathrm{~mm}$ in the horizontal direction, showing the transverse and longitudinal EB welds is illustrated in Figure 44.

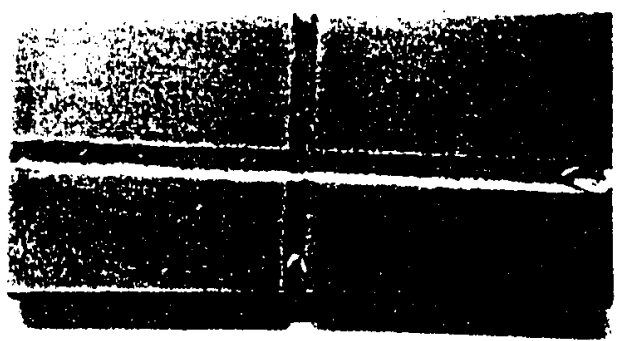

Figure 44 Welding coupon showing the longitudinal and transverse EB welds. The longitudinal weld, in the $S X$ growth direction, is oriented horizontally. 
Table 3 Welding parameters regarding to crack tendency, first patch of specimen

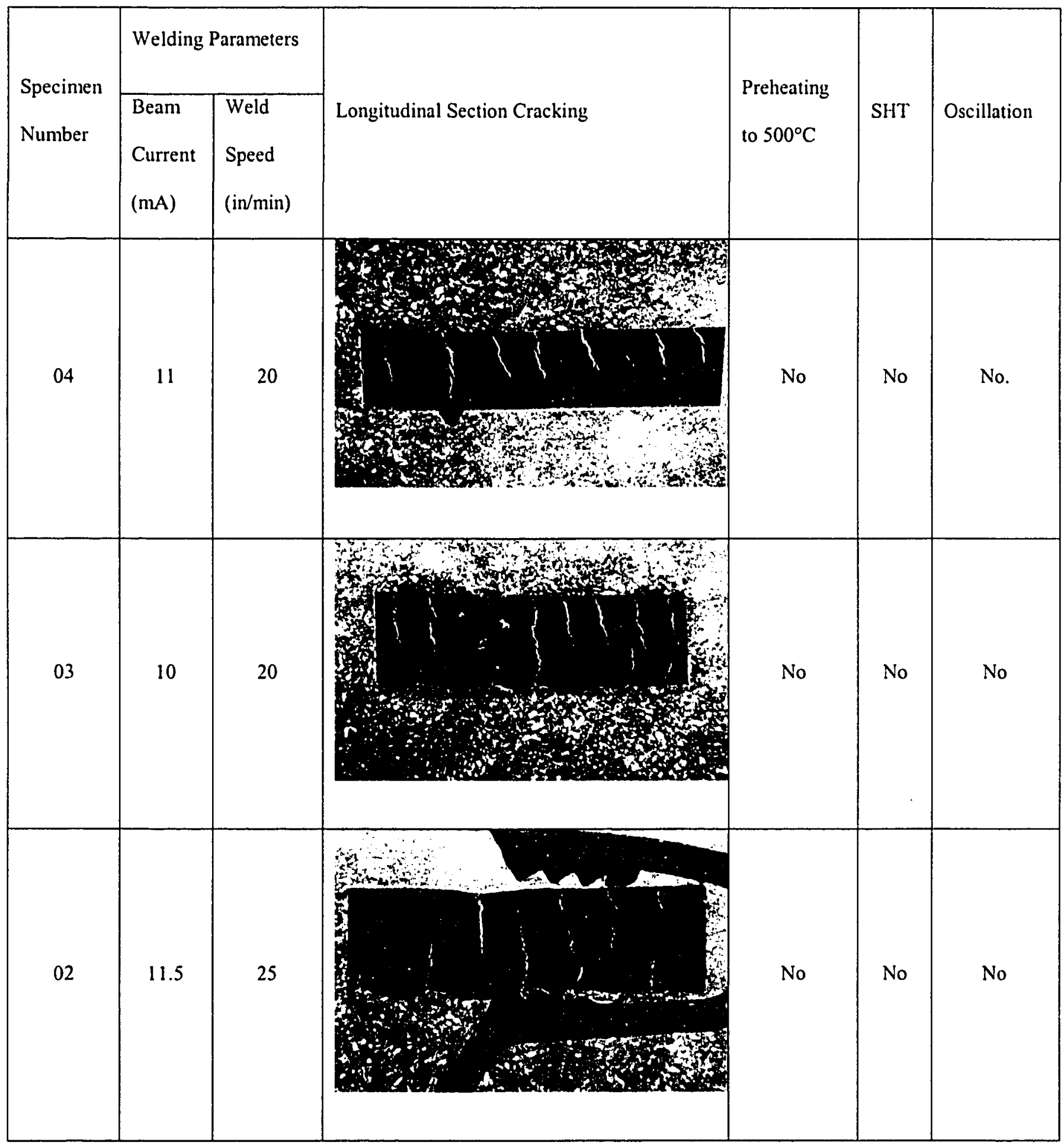




\subsection{Results}

It is usually difficult to study the weld cracking because of the reflection of the weld's brightness. However, using the Olympus Highlight 3000 allows a Kodak DC4800 zoom digital camera to capture any cracks. Images of longitudinal sections reveal that numerous cracks have developed in the welds, as shown in Table 3. Samples 02 and 03 have cracks all the way through, while the cracks on sample 04 only extend from top to the middle region. This is because a backing bar was used on sample 04 .

\subsection{Discussion}

Initial trials were carried out to examine the weldability of SX PWA1484. Results show that the material is very susceptible to cracking under conventional welding conditions. This confirmed with the previous electron beam (EB) welding studies on the high susceptibility to cracking of PWA1480, a first generation SX nickel-base superalloy $[85,87,88,89]$. Further trials were done to analyze the weldability of PWA1484. Welding parameters were optimized at the same time to obtain less cracking. They are discussed in the following sections. 


\subsubsection{Next series of welding trials}

\subsection{Heat treatment and innovated welding conditions}

In order to reduce or eliminate cracking, development of the welding process was undertaken in a second series of welding trials, summarized in Table 4. Welding optimization on PWA1480 was discussed in the literature review (2.2.4.4). The results showed that some crack-free sample were obtained by preheating the specimens up to $500^{\circ} \mathrm{C}$ and using low heat input $(10 \mathrm{~mA})$ and slow travel speed $(4.2 \mathrm{~mm} / \mathrm{sec})$. According to this, the following steps are taken. First, before welding, sample 07 was given a solutionannealing heat treatment at $1315^{\circ} \mathrm{C}$ for 4 hours, followed by a water quench, to obtain finer precipitates and soften the material. Second, preheating was applied to sample 07 . The preheating was applied by clamping the samples to a copper block which was then heated above the preheat temperature by means of a de-focused electron beam. At the same time, the block was cooled down to preheat temperature and heated back up to $1000^{\circ} \mathrm{F}$ three times to allow the heat to soak into the sample. Then the sample was welded the next time when it cooled to the preheat temperature. This temperature was maintained during the entire welding procedure to reduce the thermal stress that is produced during the welding. Third, heat input (beam current) and weld-traveling speed were reduced to $8 \sim 10 \mathrm{~mA}$ and $10 \mathrm{in} / \mathrm{min}$, which were lower than the values used in the first series of welding trials. Oscillation (the welding gun was swung back and force with a steady rhythm to make a stirring motion on the sample's surface) was also utilized on sample $07,3-11,1 \mathrm{~A}$ and $1 \mathrm{~B}$ to see if there is any effect on welded microstructure and to reduce the number of cracks. 
Table 4 Welding parameters related to crack tendency, second patch of specimen

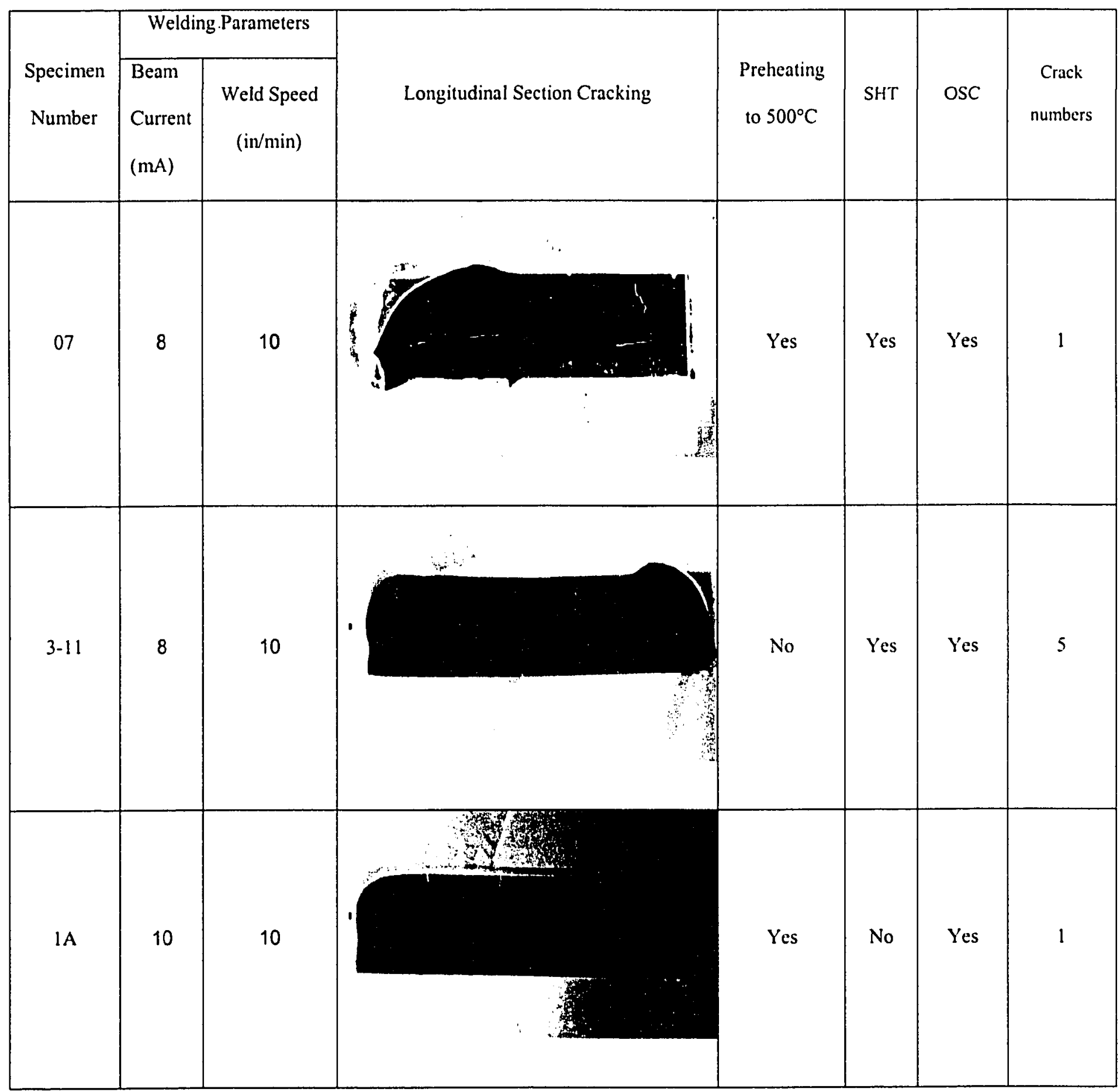




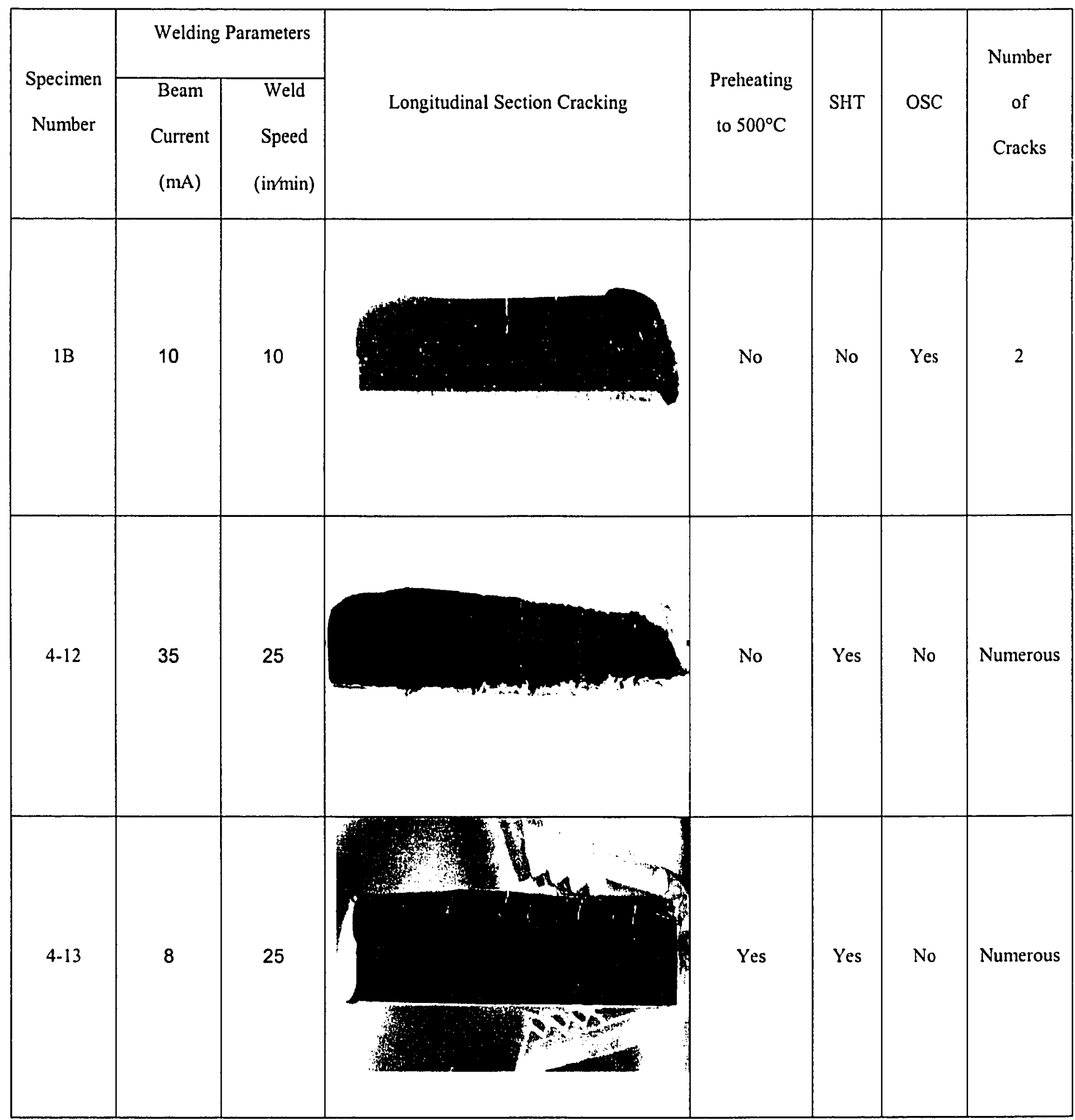




\subsection{Results}

After the welding process, the samples were cut longitudinally, then ground, polished towards the weldment center. Then the longitudinal sections were photographed to determine the number of cracks. Results were shown in Table 4 , the crack trend dramatically reduced once low heat input and slow welding speed are employed on sample $07,3-11,1 \mathrm{~A}$ and $1 \mathrm{~B}$, illustrating that travel speed and beam current are the most significant parameters that influence the weldability.

Sample 07 and sample 3-11 were both welded with the same heat input, travel speed and oscillation. Both were solution heat-treated before welding. Sample 07 was preheated before welding while preheating was not applied on 3-11. Results show that the amount of cracks increases from 1 to 5 , revealing that preheating is especially critical to solutionannealed specimens.

Figure 45 is an SEM image of solution-annealed PWA 1484, which indicates that after the heat-treatment, the gamma prime size dramatically decreased from $0.5 \mu \mathrm{m}$ to $0.1 \mu \mathrm{m}$. Finer $\gamma^{\prime}$ is the result of a faster cooling rate, which is expected to help reduce the cracking tendency since the large amount of coarse solid state $\gamma^{\prime}$ was treated into finer precipitates and eutectic $\gamma^{\prime}$ dissolved, so that the material is softened and contains less constraint during the welding. 


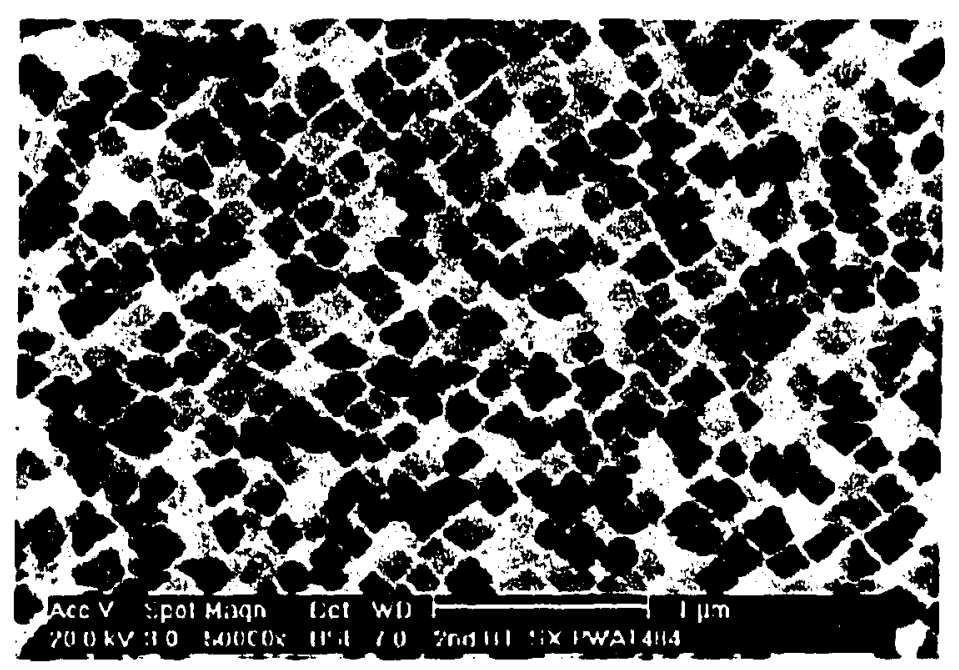

Figure 45 Fine gamma prime is the outcome of solution heat treatment, showing the material is softened

However, non-solution-annealed samples $\mathrm{A}$ and $\mathrm{B}$ were welded under that same condition except for preheating. There is no significant difference in cracking tendency (sample 1A has 1 crack while 1B only has two). This result indicates that for samples that are not solution-treated, preheating does not have a considerable impact on crack propensity.

It should also be noted that nickel has a relatively high thermal conductivity of approximately $75 \mathrm{~W} / \mathrm{m} \cdot \mathrm{K}$. This influences the heat flow and heat required during the welding of Ni-base superalloys. Low heat input avoids high thermal conductivity material conducting heat away when welding is applied. In the case of electron beam welding, it helps the local heat of welding retain, results in smaller heat affected zone than those welded under high heat input. 
Travel speed, plays an important role of controlling the weld quality. Samples with a low welding speed (07, 1A, 1B, 3-11) have fewer cracks, varying from 1 $\sim 5$ cracks (Table 4), while severe cracks appear in those samples with high travel speed (samples 4-12 and 4-13) although the beam current remains low in $4-13$. This is probably because a high welding speed has a certain grain refining effect: new grains have to nucleate to maintain growth along $<100>$ directions, generating more equiaxed, finer grain structure, as shown in Figure 46. This may cause sudden and abrupt changes in growth direction in the welds, making the grain structure weaker under the residual stress produced during the welding. A low speed, on the other hand, tends to produce coarser solidification patterns at which epitaxial growth is maintained from the fusion line towards weld center, as shown in Figure 47. Details of this phenomenon will be discussed below.

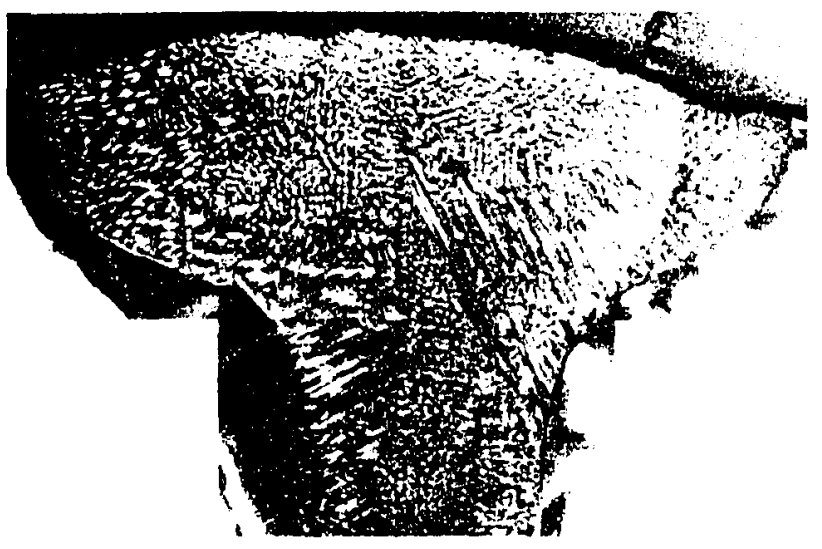

Figure 46 Low speed tends to maintain the epitaxial growth 


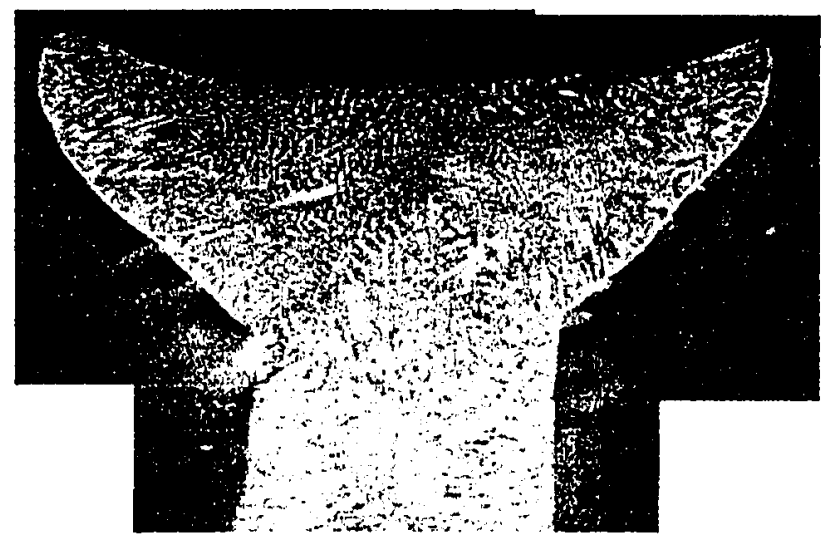

Figure 47 High-speed results in more misoriented grains

Furthermore, high welding speed creates heat faster, causing a thermal expansion combined with an intensive compressive stress. Meanwhile, when the welds solidify and contract very quickly, it generates a contraction with elevated tensile stress. This sequence causes the residual stress to concentrate in certain partially melted areas. Therefore, the stress is relieved by the formation of solidification cracking, as discussed in Ref. 96.

Different combinations of preheating, SHT and oscillation were applied to samples 4-12 and 4-13. Extensive cracks occurred on both samples due to the utilization of high speed. Full penetration of cracks was shown on sample 4-12, whereas partial penetration was observed on the surface of sample 4-13. This difference may stem from the variety of heat input on each. 


\subsection{Discussion}

The second series of welding trials was carried out under various welding conditions. Some signigficant progress has been achieved by optimizing the welding parameters and adding a pre-weld heat treatment. As illustrated above, the correlation of weldability and welding conditions of PWA 1484 has been studied. It has been understood that travel speed and heat input are two major parameters that control the crack tendency. Low beam current and slow travel speed result in less crack tendency than high heat input and high speed welds. However, due to the material constraint, it is quite difficult to better understand the detailed influence of other parameters (pre-heating, SHT and oscillation). More EB welding trials are required once materials are made available.

\subsection{Microhardness Testing}

Microhardness testing was carried out on two EB welded coupons to check for the presence and extent of a heat-affected zone, as well as the localized change of hardness. Testing was performed using an AMH43 automatic Micro/Macro-indentation hardness testing system, shown below in Figure 48. A $500 \mathrm{~g}$ load with a diamond indenter was used. Sample analysis was performed by the system via AMH43 software that operates a microhardness tester, as shown in Figure 49. 


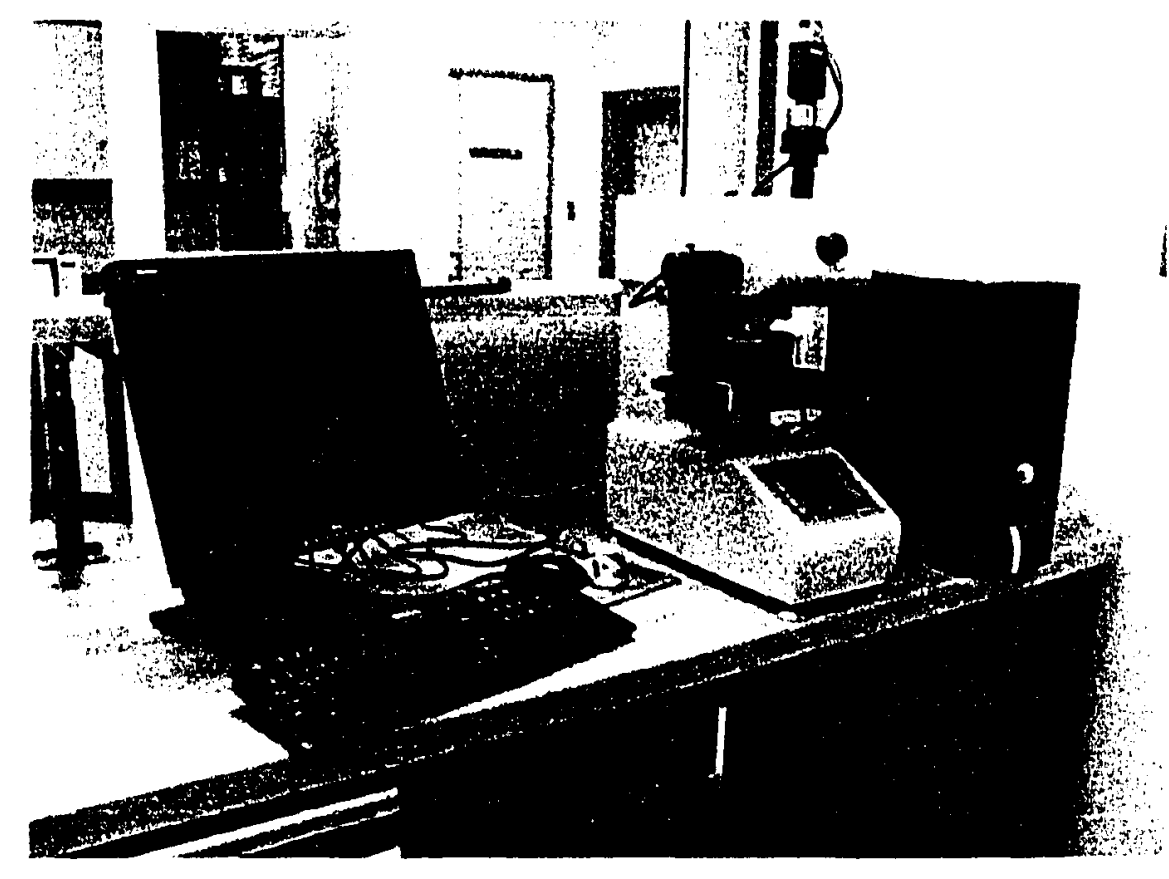

Figure 48 AMH43 automatic Micro/Macro-indentation hardness testing system

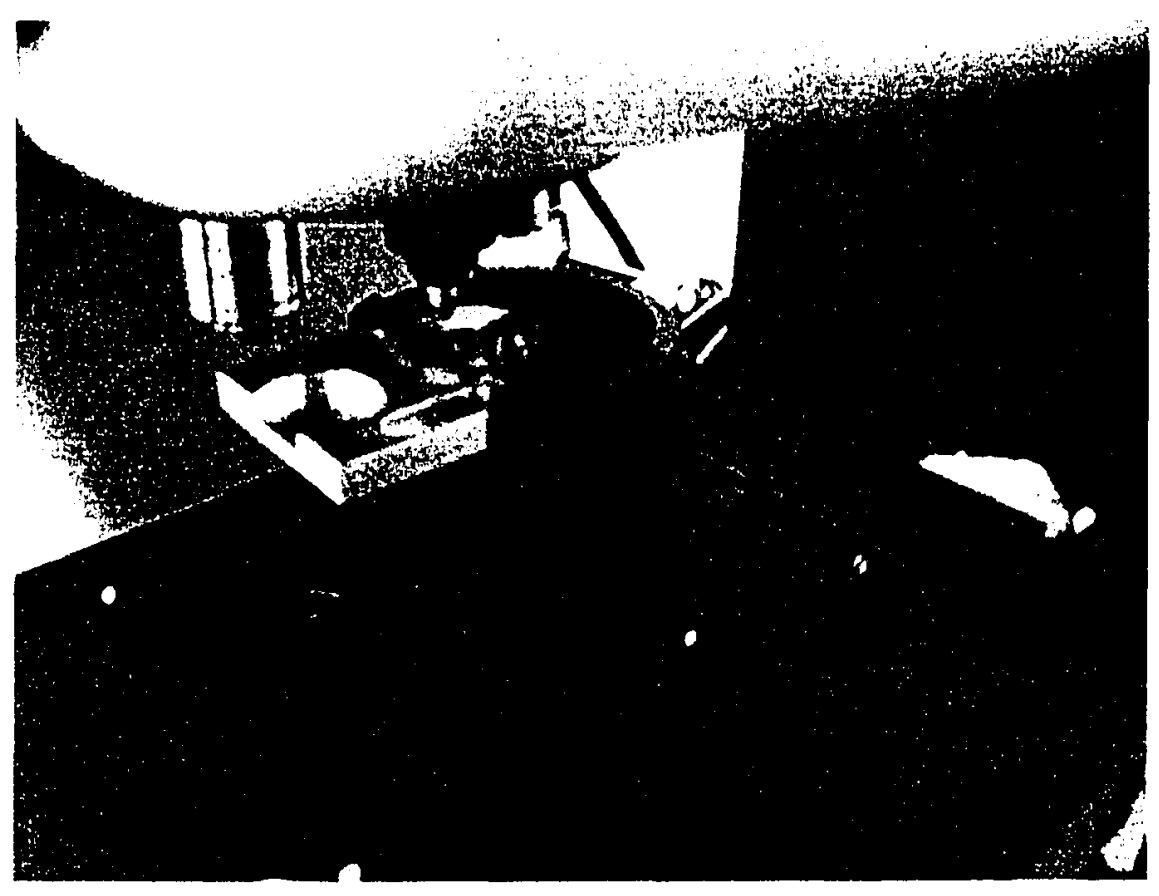

Figure $\mathbf{4 9}$ microhardness tester 


\section{Results}

In most material the heat affected zone (HAZ) appears critical in respect to mechanical properties. Considering electron beam welding provides the high concentrating energy and low heat input, a small heat affected zone is expected to achieve. The microhardness result [Figure 50] shows that there are slimly thin areas adjacent to both sides of fusion line (about $0.1 \mathrm{~mm}$ ), where the hardness is slightly lower than that in fusion zone. This proves that in the case of electron beam welded single crystal superalloy PWA1484, the low heat input minimizes warping and distributes the heat uniformly as possible, which avoids the distortion and the loss of strength in heat affected zone, achieving the integrity and maintaining the materials mechanical properties.

\section{Microhardness of PWA1484}

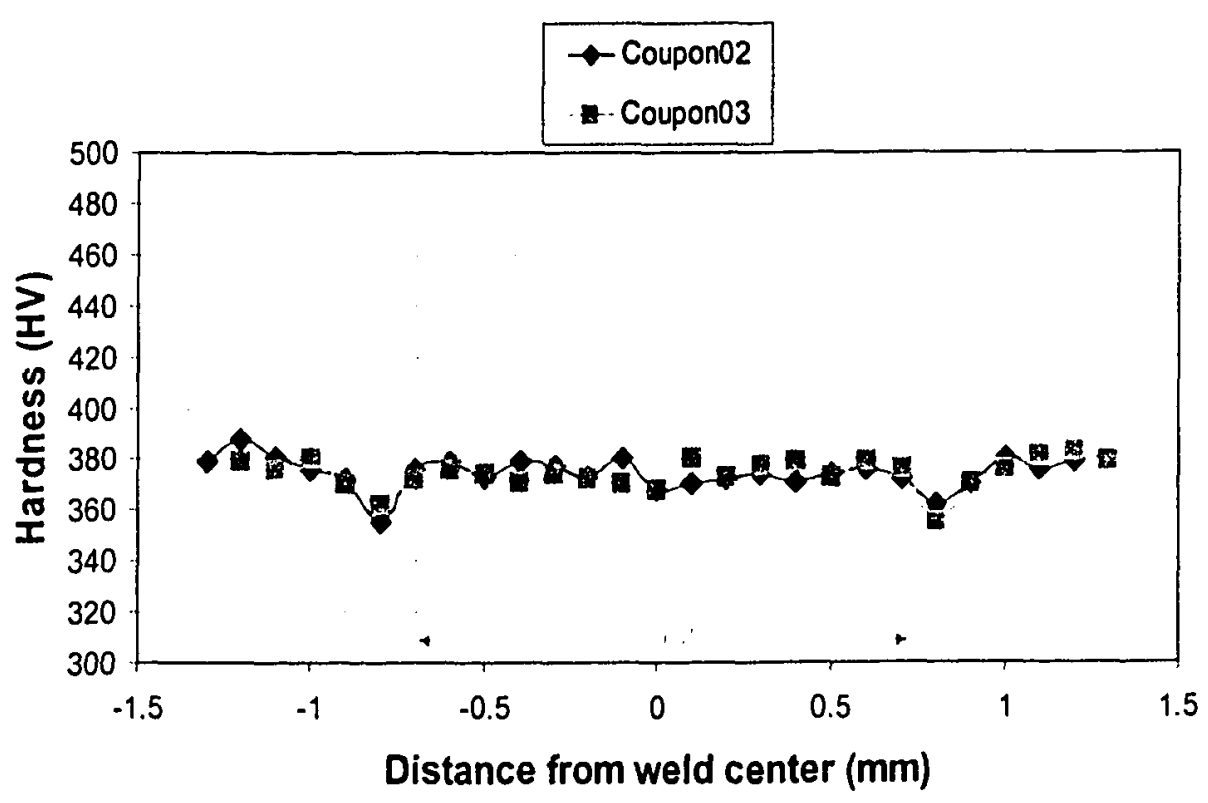

Figure 50 Microhardness result indicates no apparent HAZ in EB welded PWA1484 


\subsection{Orientation Imaging Microscopv (OIM)}

Orientation Imaging Microscopy (OIM) on sample 02 and 04 were done by TSL/EDAX Company to enable a visual representation of the crystallographic microstructure in terms of welding conditions. In OIM mapping, a variety of data and parameters are calculated and recorded, including the orientation of the crystal, a quality factor defining the sharpness of the diffraction pattern (IQ), the "confidence index" (CI - patented by TSL) indicating the degree of confidence that the orientation calculation is correct, Hough data, the phase of the material, and the location (in $x, y$ coordinates) where the data was obtained on the specimen, etc. Each point is assigned a color or gray scale value based on a variety of parameters such as orientation, image quality, confidence index, phase, etc. Each point can be assigned a color or gray scale value based on a variety of parameters such as orientation, image quality, confidence index, and phase.

\section{Results}

OIM results are shown in Figure 51 and Figure 52. The effect of welding conditions on the abundance of stay grains is clearly revealed. The grain boundaries represent misorientations from $7^{\circ}$ to $63^{\circ}$. As it shown in the image, those misorientated grains are more profound at the crown and butt of welds. Though stray grains are visible on both welds, higher speed and higher power weld shows more stray grains [Figure 52]. Unlike PWA1480 where the stray grains are asymmetrically distributed with respect to the centerline $[101,102]$, stray grains are spread throughout the welds of PWA1484. That means they are not just concentrated near the centerline and not absent along the fusion line, as it described in the welds of PWA1480. 

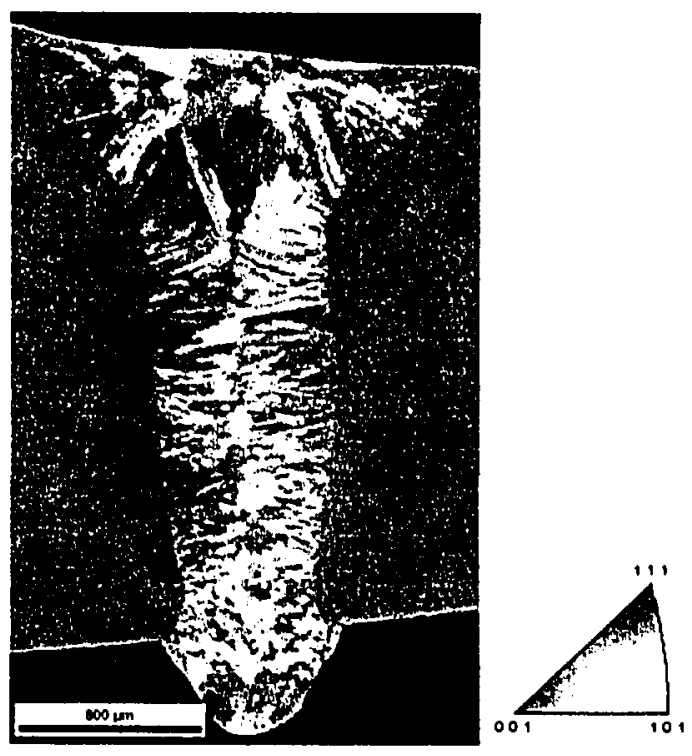

Figure 51 Sample 02-Orientation map (Sample Normal direction). A grain size distribution plot and a misorientation angle distribution plot are also shown. Heat input is $11.5 \mathrm{~mA}$ and weld speed is $25 \mathrm{in} / \mathrm{min}$.
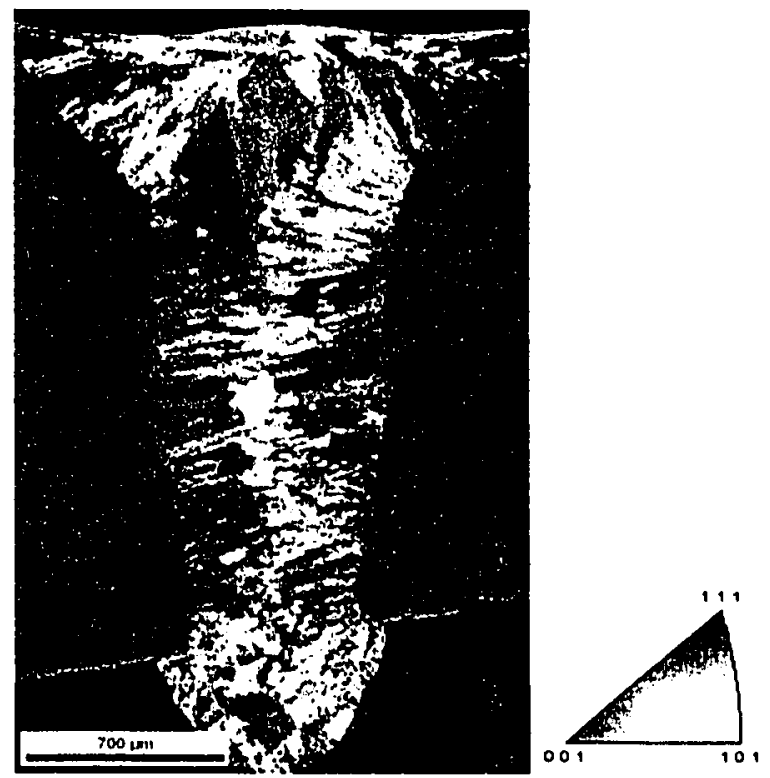

Figure 52 Sample 04-Orientation map (beam current $11 \mathrm{~mA}$, travel speed $20 \mathrm{in} / \mathrm{min}$ ). 


\subsection{Overall Results/Discussion}

Overall results show that PWA1484 has a severe tendency of forming cracks during electron beam welding. Welding parameters not only control the crack tendency, but also the microstructure development in the welds (fusion zone). In this section, the formation of solidification cracking, stray grain formation and their main mechanisms, the correlation of solidification cracking and stray grain formation and the development of weld pool shapes are elaborated in detail.

\subsubsection{Welding direction vs. crack tendency}

Unlike Arc welding and laser beam welding, centerline cracking does not occur in most electron beam welding. Rather the cracks have a "transverse nature" in terms of welding directions. This means that the cracks, without any side branches, are perpendicular to the welding direction [Figure 53]. Note that transverse cracking occurs after solidification, indicating that there must be large longitudinal stresses and weak microstructural features at these areas. All the cracks are confined to the fusion zone and do not extend into the base metal. This proves that in the case of EB welding, the welding direction does not have an impact on the crack tendency. 


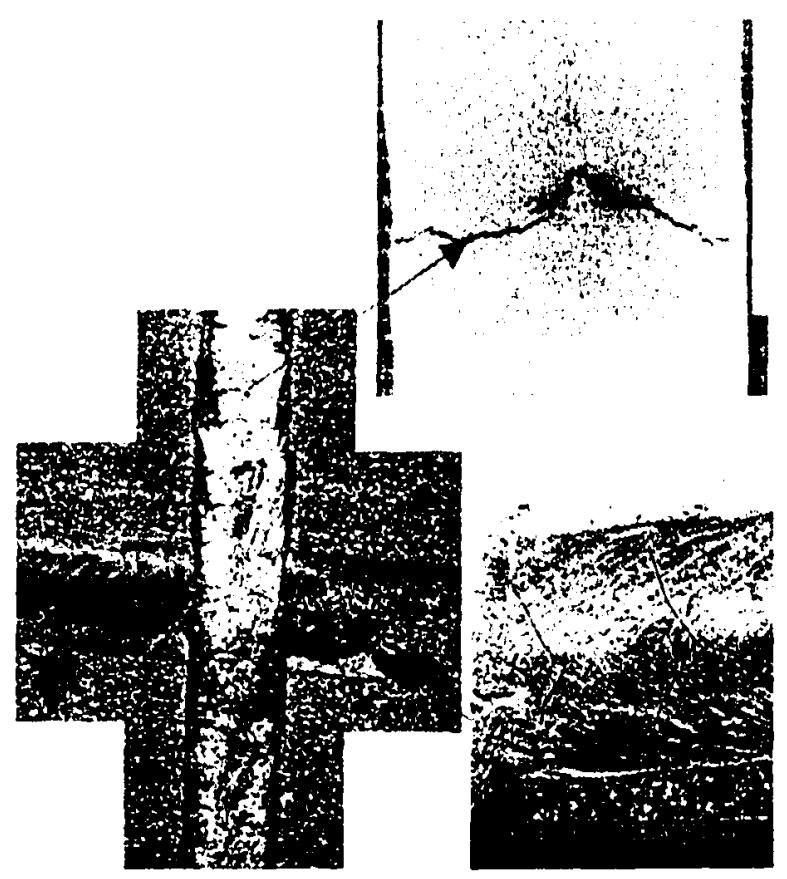

Figure 53 Welding direction does not have an impact on crack tendency

\subsubsection{Solidification cracking}

Solidification cracking has been briefly discussed in the literature review. Nickel base superalloys are prone to weld solidification cracking. In Figure 54, the dendrite morphology with apparent secondary and tertiary dendrite arms is clearly shown on the crack surface. The overlapped layers of these dendrites are shown in the high magnification SEM image (Figure 55). They are the products of continuous solidification motion.

An alloy's solidification cracking tendency is related to the following main factors: stress, large solidification temperature range, low-melting eutectic phases and grain structure. 
In general, two basic approach are usually taken to control this tendency: improving the welds' ductility and improving the thermomechanical conditions during welding. The former way was done via the solution heat treatment on our material (see discussion on 4.2.2.2.1 Heat treatment and innovated welding conditions); the latter approach can be taken by using proper welding parameters, such as welding speed and preheating.

Most cracking formation is caused by thermal shrinkage strains [30]. The two opposing forces existing in the material during the welding are: the thermal stresses developed by the shrinkage of the metal and the surrounding rigidity of the base metal. These two forces can tear the welds apart when the ductility of molten material is insufficient to absorb the strains. Welding parameters, hence, should be carefully selected since they affect cracking formation by the rate of strain. High strain rate that result from rapid solidification and cooling will cause a high risk of rupture. This was shown in our results, where the number of cracks dramatically reduced (sample 07, 1A and 1B) when their travel speed decreased. It is also expected that reducing the heat input would help to control the cracking tendency. However, the effect of beam current on cracking tendency is not clear because of other factors. More trials are required to identify this impact.

Preheating is another effective means of reducing cracking. It brings two major benefits -- retarding the cooling rates in the weld and heat-affected zone and reducing the magnitude of shrinkage stress [103]. The cooling rates are usually faster for the welds without being preheated. Nickel-base superalloys have high thermal conductivity, so their cooling rates are very fast when the welds solidify. By preheating the metal up to $500^{\circ} \mathrm{C}$, 
the temperature gradient is reduced, which ensures slow cooling rate because the heat is transferred from the fusion zone at a lower rate. Slow cooling rate results in lower shrinkage strain, as discussed above, leading to less cracking. Our results also show that preheating has a relatively large influence on solution-treated samples (see the comparison of 07 and 3-11). This is probably because the shrinkage strain retained in the materials became more intense after they were water quenched. So preheating helped relieve the thermal stress greatly.

The local stresses are developed at the solidification crack initiation area. The high longitudinal stress builds up quickly and soon reaches the maximum level at the edge of weld track forms the mechanical condition for formation of transverse cracks. Previous study [51] shows that once the longitudinal stress reaches the maximum, it maintains through the length of the weld except the starting and terminating regions. Since the material resistance in the locations covered by this maximum stress plateau does not vary, it is expected that the samples tend to form transverse cracks as soon as the stress plateau is reached.

An alloy's tendency of forming solidification cracks is directly associated with the difference of solidus and liquidus temperature [98]. The larger this temperature window is, the more susceptible the alloy is to solidification cracking. Former study indicated that this temperature range of SX PWA1480 reaches $35^{\circ} \mathrm{C}[85,99]$, which is fairly large among the superalloys. Hence, PWA1480 is very susceptible to hot cracking. Welding of this alloy is not an easy task. In PWA 1484, the liquidus temperature is $1404^{\circ} \mathrm{C}$ and the 
eutectic reaction drags the effective solidus temperature down to $1340^{\circ} \mathrm{C}$, leading to a $64^{\circ} \mathrm{C}$ solidification temperature range [18]. This shows that PWA1484 should be more prone to crack during the welding, which makes it even tougher to achieve a sound weld.

Our results also show that solidification cracking is more likely to occur in alloys that have high concentration of low-melting eutectic. This was as well discussed in literature review $[48,49]$. When the weld metal begins to solidify, columnar grain substructures grow epitaxially from the fusion line towards the weld's center. In the meantime, many of the alloy elements and impurities are enriched and rejected ahead of the growing crystals and become concentrated as form of eutectic morphology. Figure 56 shows detail of the $\gamma / \gamma^{\prime}$ eutectic phases, these interdendritic features are the result of microsegregation and they develop during the last stage of solidification. This last liquid to solidify causes the low melting phases to wet the grain boundaries (where single crystal nature is not maintained); meanwhile, this mushy liquid-solid mixture leads to low strength and ductility combined with the thermal stresses that develop during welding, while the amount of residual liquid is insufficient to fill the voids, thus solidification cracking is produced. 


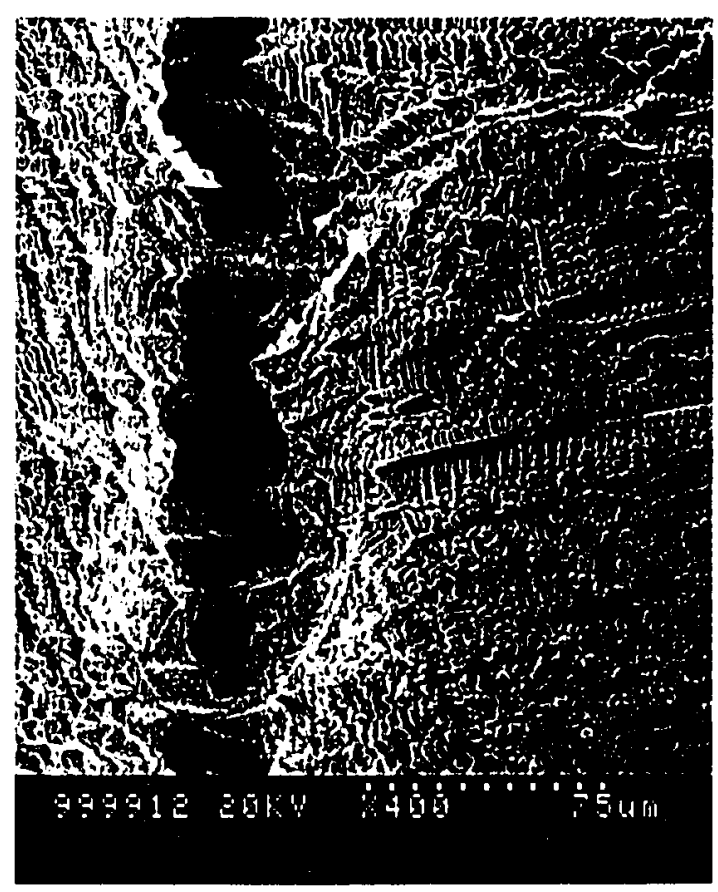

Figure 54 Scanning electron micrographs showing dendritic features on weld crack surface

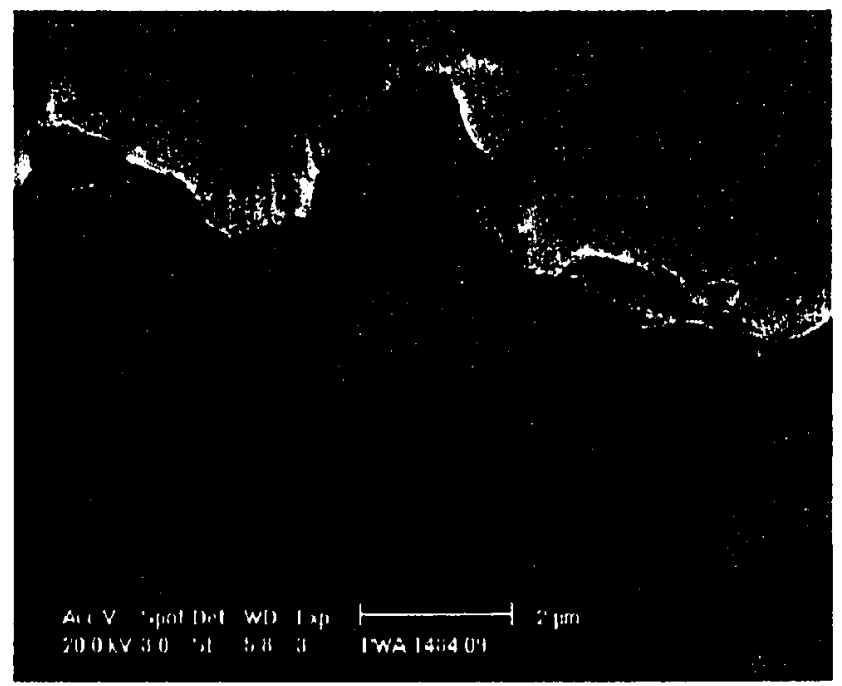

Figure 55 Detailed SEM image reveals the dendrite-solidified layers on crack surface. 


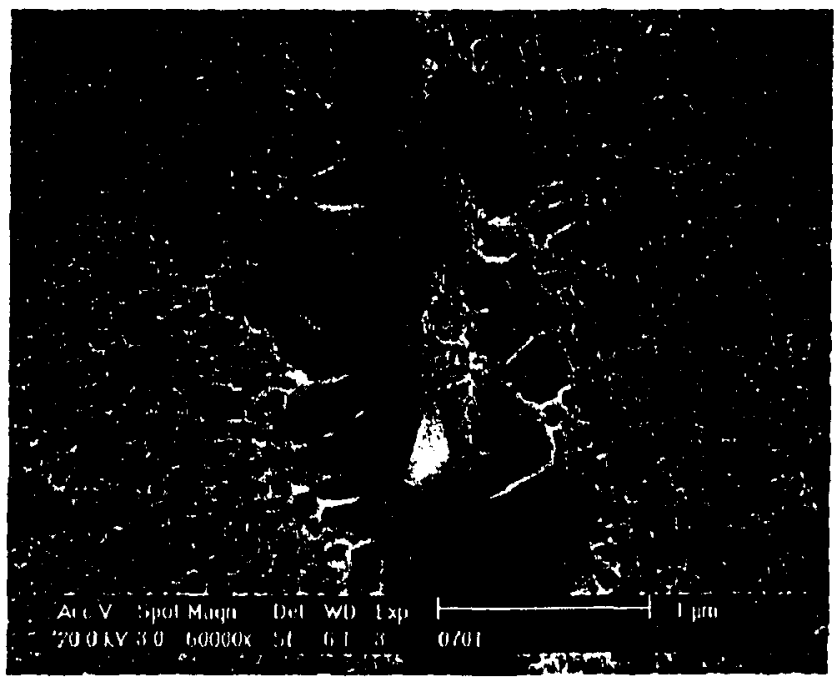

Figure 56 Microstructure of $F Z$ showing cracks are surrounded by $y / \gamma^{\prime}$ eutectic phases

More detailed micrographs such as Figure 57 reveal that shrinkage porosity exists in the interdendritic area, promoting the cracks to propagate along the grain boundaries as shown in Figure 58, which shows the grain boundary area/interdendritic zone is less resistant to solidification cracking.

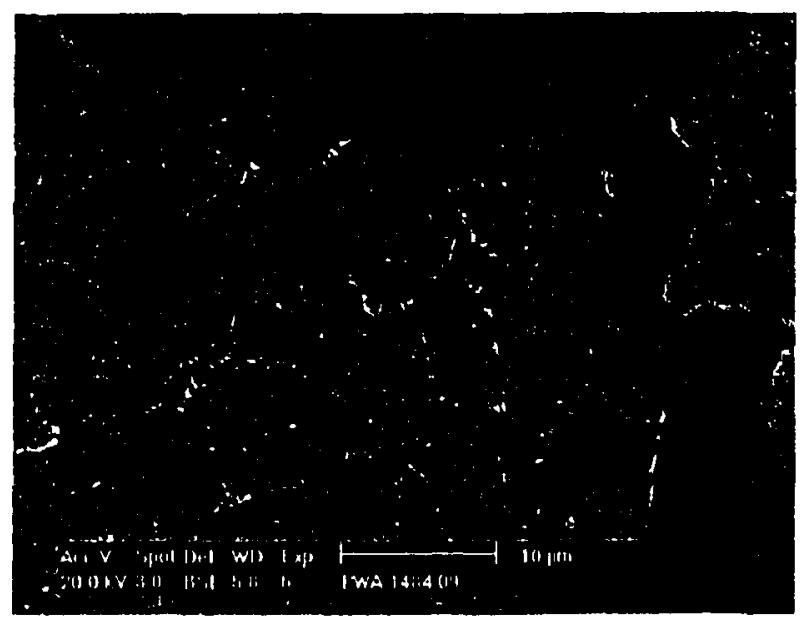

Figure 57 Shrinkage porosities in interdendritic region promote the presence of solidification cracking 


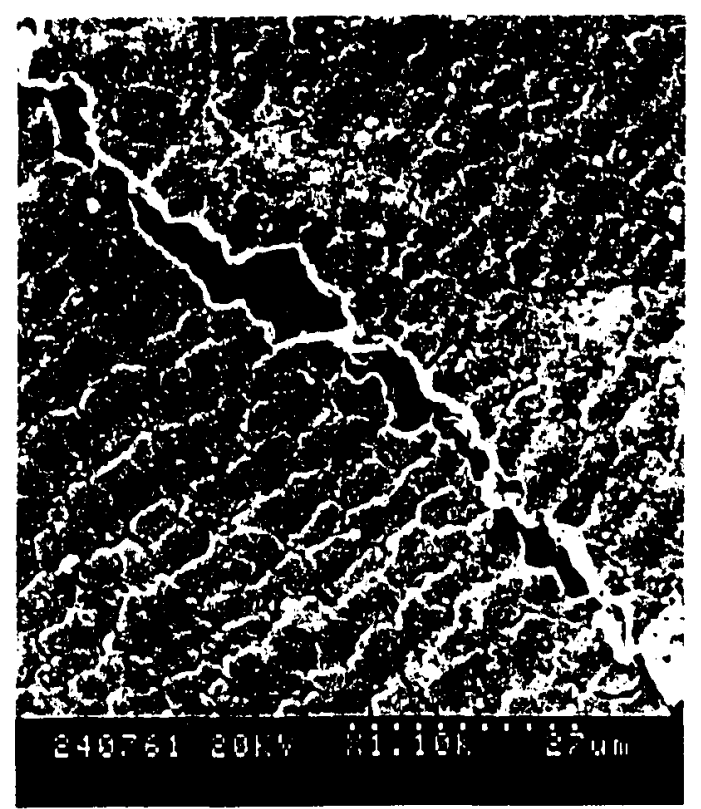

Figure 58 Cracks propagate along the grain boundaries

\subsubsection{Stray grains}

The correlation between welding conditions and microstructure of welds was briefly mentioned above. The fusion-zone microstructure is controlled by the base metal grain structure and welding conditions. At the edge of the fusion zone adjacent to the base metal, the initial solidification occurs epitaxially. The epitaxial growths of dendrites at the fusion boundaries are in $<100\rangle$ directions, the preferred growth direction (Marked as arrow at Figure 59). Since the growth rate in welding is a lot faster than the casting process, the primary dendrite arm spacing in $\mathrm{FZ}$ is notably finer than the parent material. As the welds solidify toward the center, some dendrites do not grow along the favorable $<100>$ variants and develop a few new grains with high angle grain boundary. These misorientated grain are identified as "stray grain" (circled at Figure 59), and their presence indicates that the fusion zone and base metal no longer constitute a perfect 
single crystal. "Stray grains" are also interpreted as equiaxed grains in directional solidification process for single crystal superalloys. They introduce grain boundaries into the crystal, which results in a crystal with low creep strength and ductility at elevated temperatures because of the absence of grain boundary strengthening elements in the alloy. Among the whole welds, the total high angle grain boundary area is relatively small, therefore, in the presence of low melting eutectic phases during solidification, the small amount of grain boundary area leads to full wetting of these high angle grain boundaries. Thus, though the thermal stresses still remains the same, the material gets much weaker and the cracking tendency is largely enhanced.

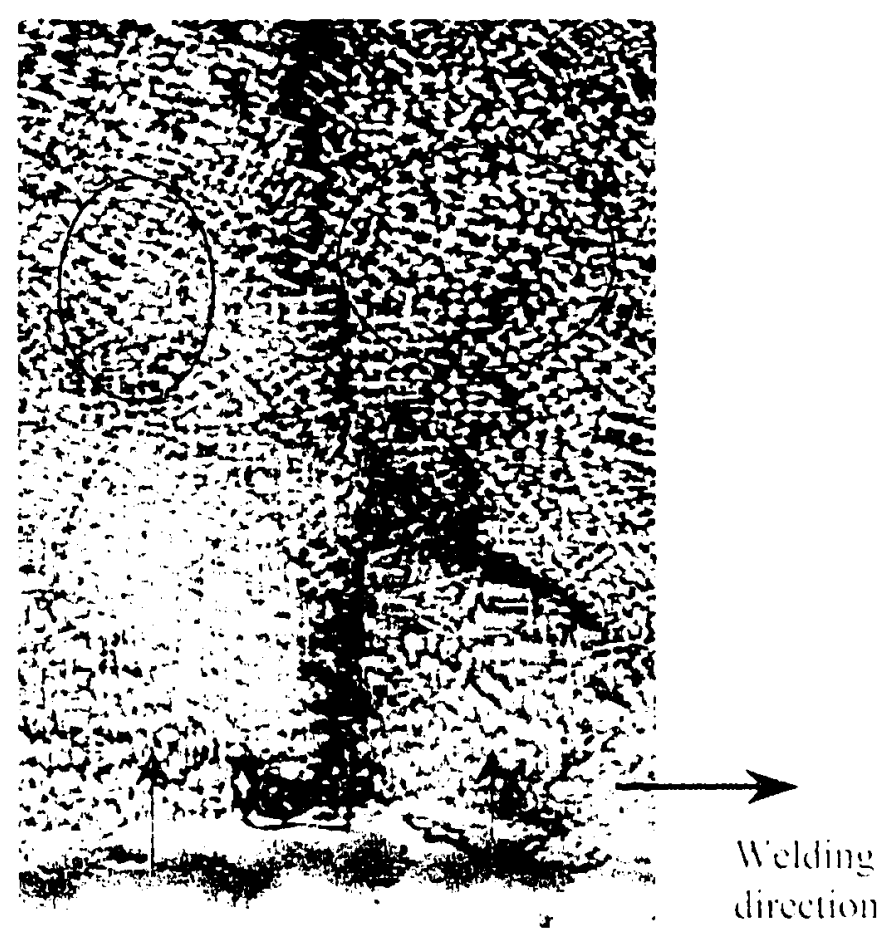

Figure 59 stray grains is defined as misorientated grain with high angle grain boundaries, revealing the loss of single crystallinality

Stray grains tend to be more abundant in the crown and around the centerline of the welds where the local cooling rate is highest, rather than along the edge or the root of the welds 
[Figure 60]. Two main mechanisms that explain the formation of stray grain are constitutional supercooling and dendrite fragmentation [96]. Constitutional supercooling is more likely to explain the formation of stray grains. The degree of constitutional supercooling (CS) interprets the phenomenon of stray grain formation. According to the solidification theory [100], a solidification front is stable if equation:

$$
G_{L} / R \geq-\Delta T / D_{L}
$$

Stray grain formation develops when

$$
G_{L} / R<-\Delta T / D_{L}
$$

is met, where $G_{L}$ is the liquid thermal (temperature) gradient, $\mathrm{R}$ is the growth rate (velocity), $\Delta T$ is the solidification temperature range and $D_{l}$ is the diffusion coefficient in the liquid. As the CS increases, the degree of dendrite branching will increase as well as the nucleation of grains ahead of the solidification front, hence, the tendency of stray grain formation enhances. At the interface of base metal and fusion zone, the $G_{L}$ is the highest and the $R$ is smallest, so $G_{L} / R$ is maximum and no stray grain is observed; on the contrary, at the center of the welds, the temperature gradient $G_{L}$ is the minimum while the growth rate $R$ is the greatest, which results in a minimum $G_{L} / R$. Thus, the criterion of CS is met and corresponds to a large degree of stray grain formation. 

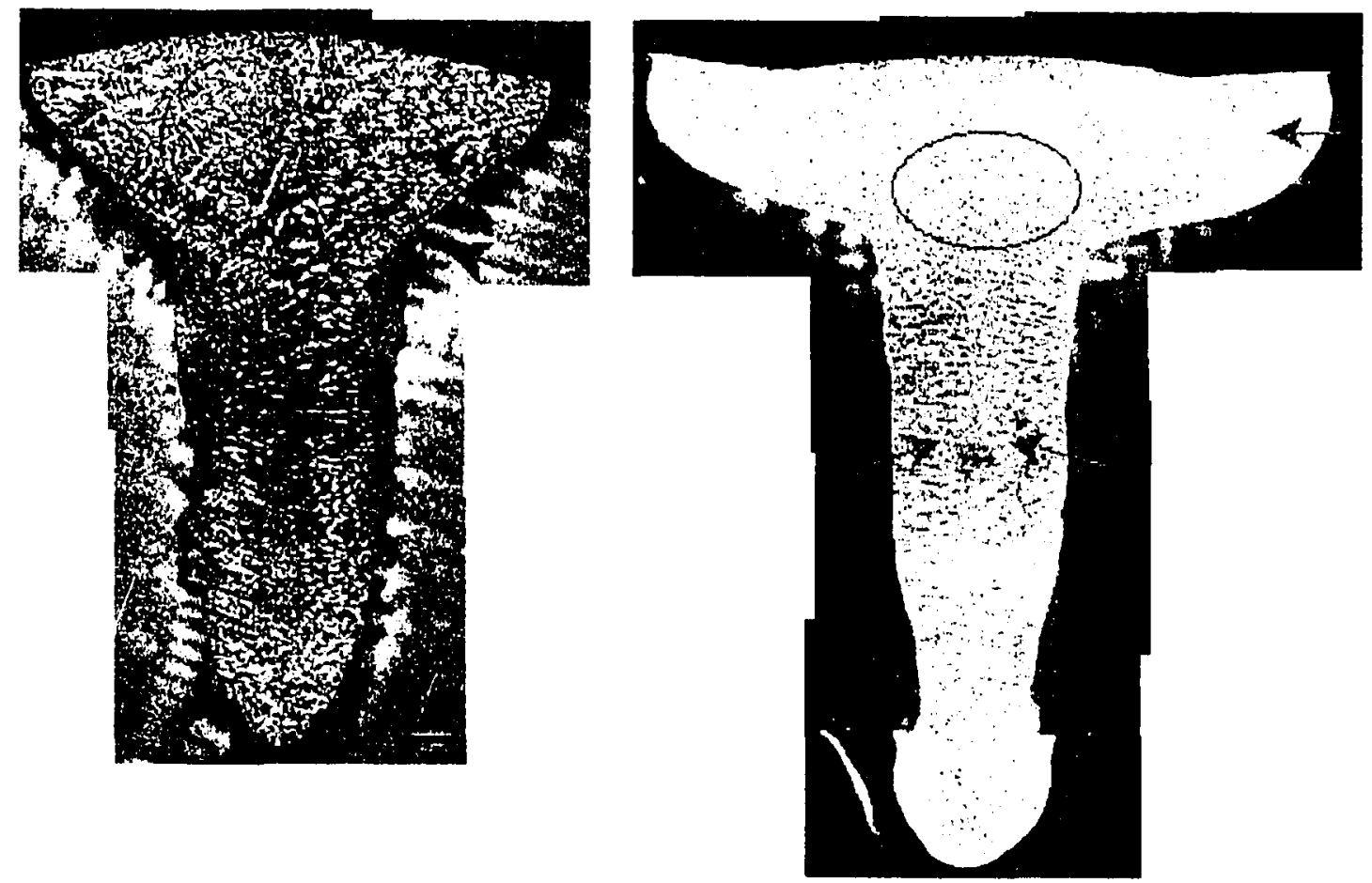

Figure 60 Stray grain are more common in the crown and the center of the welds than at the fusion zone edge

It is also noticed that cracking is associated with the presence of stray grains. Figure 61 shows the crack propagation along grain boundaries where dendrites grow misorientatedly, which corresponds to the phenomenon that cracks are usually adjacent to interdendritic eutectic phases.

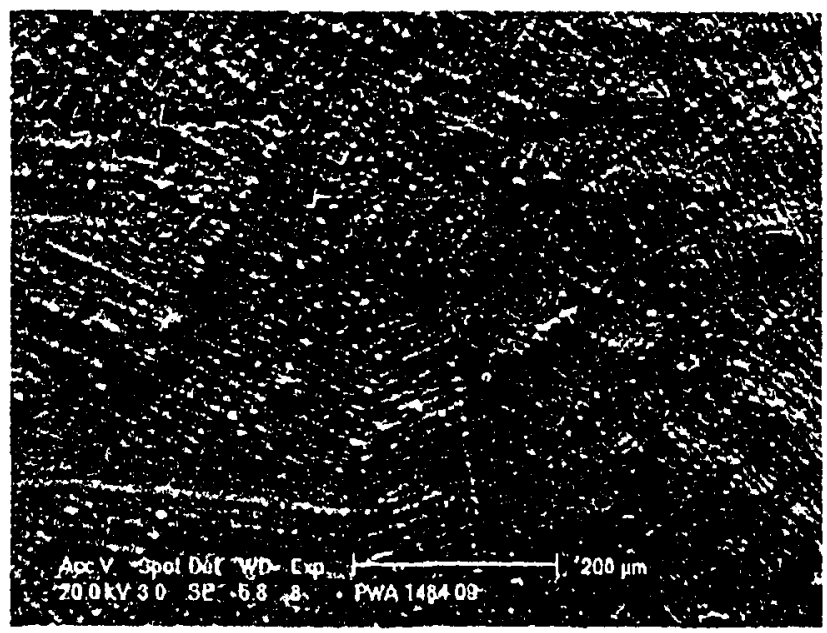

Figure 61 Crack travels along the high angle grain boundaries 
As discussed above, extensive stray grains have been observed when the heat input and welding speed are increased, while low beam current and travel speed has been shown to promote less stray grains [Figure 47 and Figure 46]. However, the use of oscillation makes the occurrence of stray grain more complicated as shown in Figure 62. This can be explained by the second mechanism --- dendrite fragmentation. During this slower solidification process, the growing dendrites are broken, transported in the liquid, and then continue to grow at some other location with an orientation different from the original dendrite. When the beam gun is traveling spirally, it allows for a longer time to develop a wider weld pool with more volume; therefore, the total volume fraction of stray grain is the function of linear specd and rotating speed as well. The stray grain formation of PWA1480 has been studied using a geometry model $(101,102)$. The model calculations predicted that the extent of stray grain formation should be significantly higher in the high speed, high power welds, showing that the conditions leading to the greatest constitutional supercooling corresponded very well with our experimental results on stray grain formation.

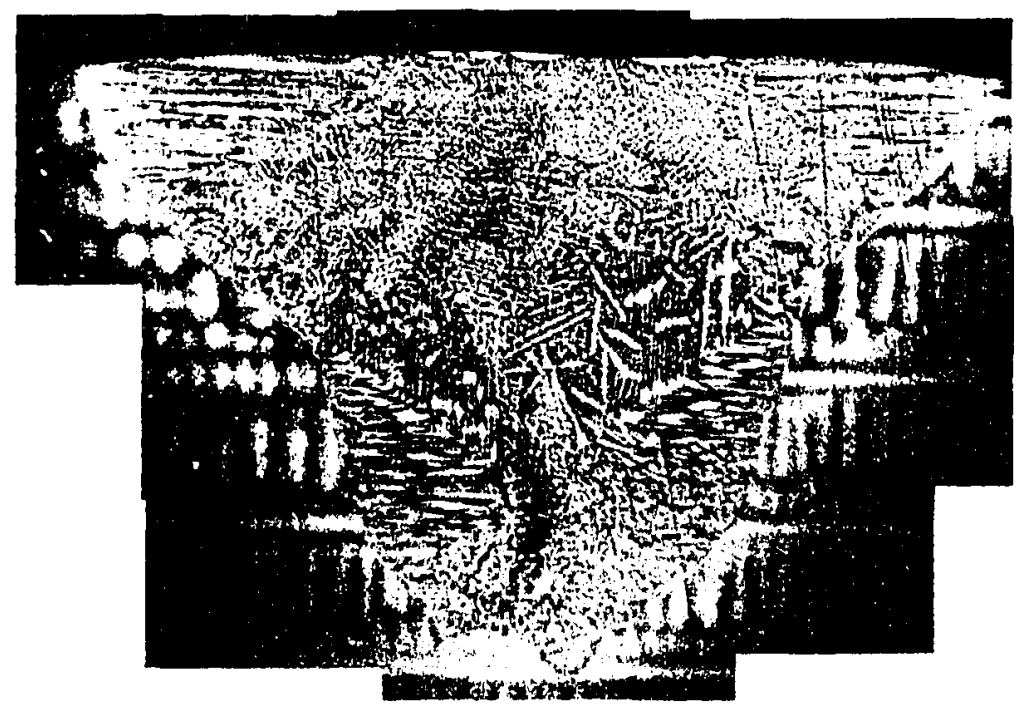

Figure 62 The using of oscillation complicates the occurrence of stray grains 


\subsubsection{Weld pool shape}

The development of weld pool shape is affected by welding conditions, in another words, heat and fluid flow conditions. The use of a backing bar and oscillation also has influence on the pool shape. Figure 63 shows the sample's pool shapes in terms of different welding speeds and heat inputs, indicating that the pool volume is directly proportional to the beam current (heat input) and inversely proportional to the travel speed. The backing bar was held from the bottom flange on sample 4 and 7, while sample 2 and 3 are fully penetration without using the backing bar. Oscillation was also applied on sample7. The stirring action is the combination of rotation and linear motion, giving more time to liquefy the local material and resulting in a wider and more profound pool shape.
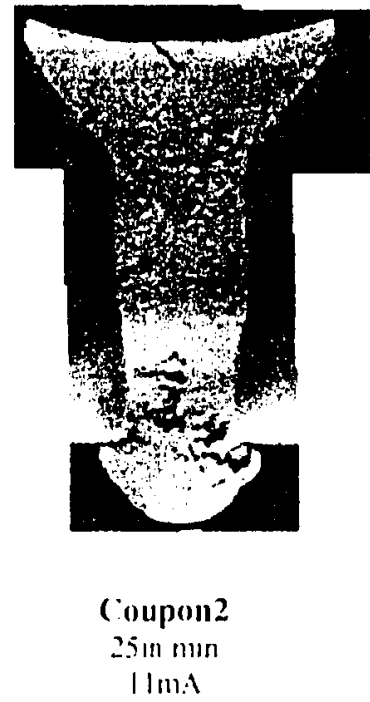

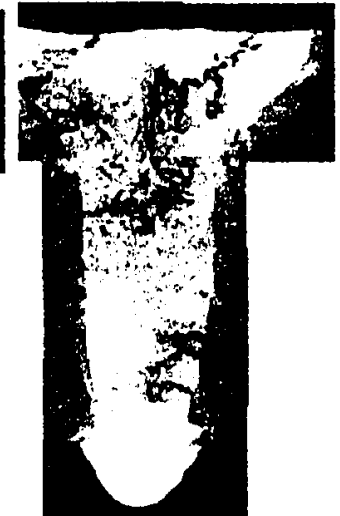

$$
\begin{aligned}
& \text { Coupon3 } \\
& 2 \text { (1) } 11 \text { min } \\
& \text { l(1min }
\end{aligned}
$$

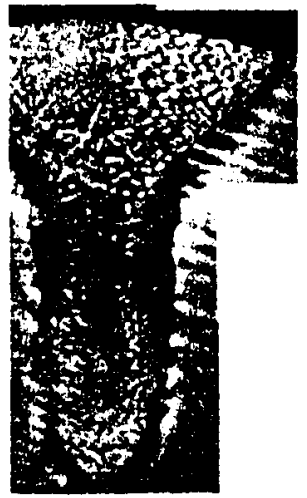

Coupont

20 in mins

$11.5 \mathrm{~mm}$

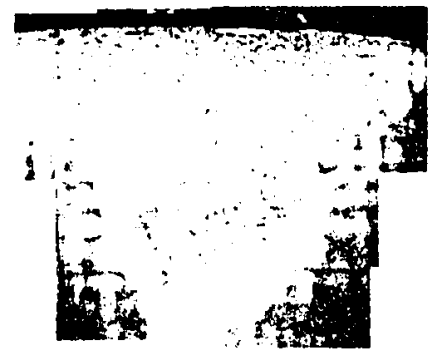

('oupon7

(1) $\mathrm{mm}$

simel

Figure 63 Pool shape vs. welding conditions 


\subsection{Application to turbine blades}

The welding trials on turbine blade material have been undertaken. While applying this technique on gas turbine blades, there are two main factors need to be concerned with: 1) how to deal with the stress in the need-to-be-repaired area and 2) how to ensure the strength of the repair will meet the service requirement.

Figure 64 is a sketch of a freestanding blade showing the types of airfoil damage considered for repair.

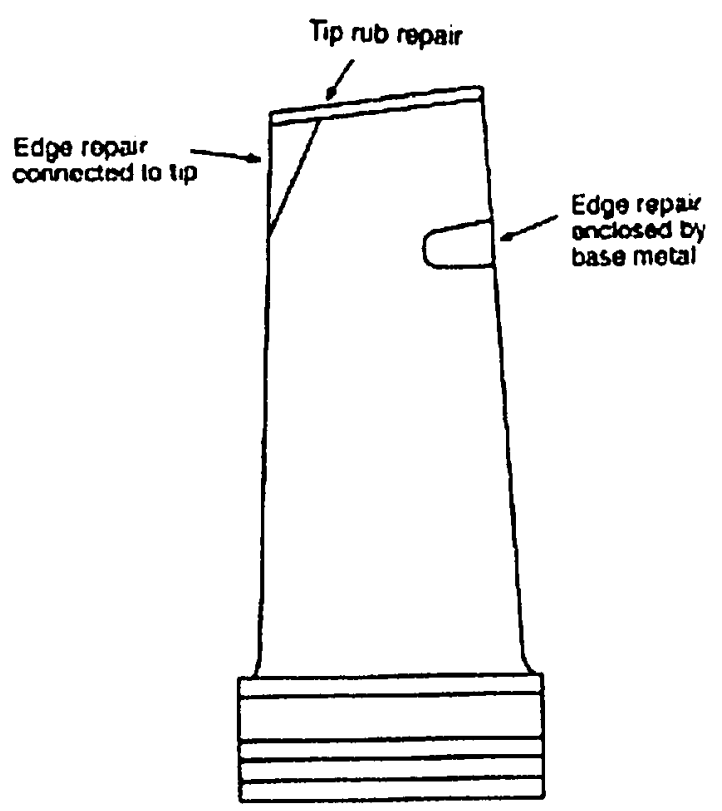

Figure 64 Typical gas turbine repair welds [104]

The stress on a blade varies from a maximum at the platform to zero at the tip. The temperature is highest near the midsection or slightly above. The combination of stress and temperature results in a minimal blade life at its one-third height. 
Welding repair is used mostly for tip rubs which are caused by thermal transient during the service (cool air and hot air cycles); Blades with damage further down the airfoil are normally returned for new ones or scrapped. Typically, about $1 / 4$ inch or less is abraded from the end of the blade. Tip rubs are usually uniform pattern and may be localized or extend across the entire chord. Edge damage is most often caused by foreign object impact. There are significant structural differences between edge repairs that are open to the tip and those that are enclosed by the base metal. Figure 65 shows the stress associated with the repairs shown in Figure 64. The rotational stress at the blade tip repair [Figure 65(a)] is low and the thermal stresses developed in the weld are mainly shear stresses running nearly perpendicular to the rotational stress. Therefore, the shear stress developed during tip rub repairs adds little to the primary (creep) stress component. The samples used in this thesis work are thin enough to simulate the thickness of blade tips. Since there are very low stresses at the tips, electron beam welding repair of them is feasible. Processing can be done by joining a new piece of the same parent material to where the original one was abraded. Figure 65(b) illustrates the stress acting at an edge repair connected to the tip. The weld must carry the same loads in service as the material that it replaced. If the repair interface approximates a straight line as shown, then the thermal stresses will be primarily shear stresses running along the weld. Whenever practical, it is customary to grind and blend this type of damage to produce a relatively straight line to the tip. Setting limits for this type of repair requires the use of the combined loads acting in the area. Fatigue loads should also be considered. The life of the repair in creep must be as great as the design life of the blades. In our case, the single 
crystal nature was lost in the fusion zone during electron beam welding. This implies the dendrites do not grow along the $<001>$ crystallographic orientation parallel to the low modulus orientation corresponding to low thermal loading stress. Therefore, the creep strength in the welds does not maintain as the same as in base metal. This problem should be considered especially when electron beam welding is applied on single crystal turbine blades.

(a) Tip rub repair

Tensile stress due to rotation

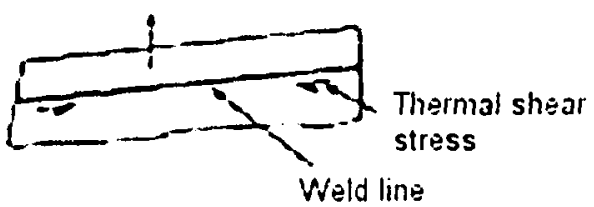

Tensile stress

(b) Edge repair connected to tip

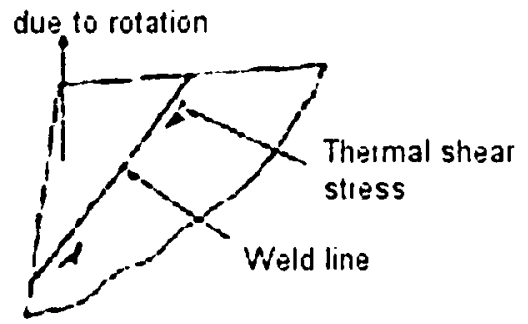

(c) Edge repair

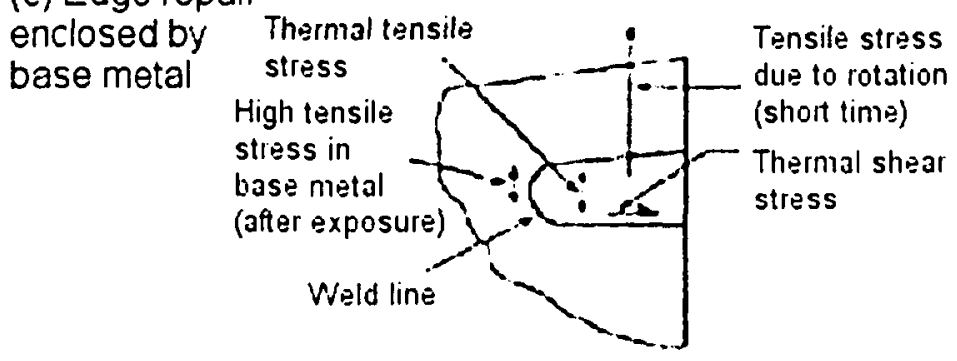

Figure 65 Stress in typical blade repair [104]

The stresses for an edge repair enclosed by base metal are shown in Figure 62(c). This geometry creates a situation much different than in the tip-connected repair. Due to the lower creep strength of the welds, it relaxes over time and the remaining base metal in the section has to carry most of the load. The thermal stress in the radial direction combined 
with the rotational stresses during service makes the joint more sensitive to thermal fatigue than other repairs. Besides, the geometry initiates a notch-effect, which causes a stress concentration in the base metal, making the repair very hard to be employed. Generally, repair of the root of turbine blades is not considered because of high stress concentrations in the blades' root. 


\section{Conclusions}

Electron beam welding has been selected to use on single crystal nickel base superalloy PWA1484. It provides welds that have no significant heat affected zone. However, historical works have proved that weld cracking is common in nickel base superalloys. The first generation single crystal nickel base superalloy PWA1480 is difficult to weld. Our results show the second generation PWA1484 also has poor weldability. The larger solidification temperature range makes this alloy fall into the "hard to weld category" [11, Figure 14]. During the EB welding of PWA1484, extensive cracking was observed in the fusion zone. Detailed microstructure analysis indicated epitaxial growth of the base metal took place. However, in the crown and the center region of the welds, the single crystal nature was compromised by the formation of stray grains, misorientated grains with high-angle grain boundaries. Weld cracking is associated with stray grains, and it was observed that cracks propagate along the grain boundaries. It was also found that cracks are usually surrounded by low-melting eutectic phases, which form at the last stage of solidification. The cracking tendency is largely controlled by carefully selecting

the welding conditions. For example, lower speed plays the most significant role in decreasing cracks, so does low heat input. High speed, however, results in more plentiful stray grains which make the alloy more susceptible to hot cracking. Preheating reduces thermal stresses and therefore attenuates the possibility of cracks forming. Solution annealing followed by a water quench softens the material, refining the $\gamma^{\prime}$ and obtaining a better welding condition. The use of oscillation also makes the alloy more weldable but results in a poorer grain structure because when the beam traces the circle, it stirs the 
weld pool and may lowers the thermal gradients in the it, therefore, dendrite fragmentation is more likely to occur and more equxiated grains may form in the weldment. 


\section{Recommendations and future work}

A number of electron beam welding trials have been made to investigate the weldability and microstructure development of SX PWA1484. Future work should focus on

1. More welding trials are required to further optimize the welding parameters for crack-free welding and investigate microstructure formation. This is because achieving a sound weld is determined by many factors. For instance, the thickness of specimen should be thin enough to simulate the real turbine blades but not too thin to be weldable. The samples' dimensions should be consistent to make comparisons between them. The sample's surface should be thoroughly cleared after heat treatment. And any temperature variations can occur when the preheating is applied. Though those factors seem not to be significant, any of them could lead to a dramatic change in welding result. Due to material constraints and their high cost, enough welding trials could not be done to verify our concerns so far.

2. Other welding techniques, such as laser welding and linear friction welding, should be investigated.

3. Development of required post weld heat treatments to determine if post weld heat treatment cracking is an issue and to determine effects of heat treatment on microstructure formation in the fusion zone.

4. Mechanical property testing, especially creep testing should be carried out to determine the influence of stray grains present in weldments. 
5. Modeling of the weld-cracking tendency, as well as microstructure formation in weldment to determine how microstructure is controlled by the welding conditions. These models can be used to optimize the welding process and process parameters as a function of alloy composition and weld geometry.

6. Application of electron beam process to in-service blades with actual damaged turbine airfoils to reduce the number of trials and error welding experiments required. 


\section{References}

1. Pratt \& Whitney

2. H.Cohen, GFC.Rogers, HIH.Saravanamuttoo, Gas Turbine Theory, $4^{\text {th }}$ edition, Addison Wesley Longman Limited, England, 1996, pp7l

3. http://www.turbocare.com/products/blade_bucket.cfm

4. C.T.Sims and W.C.Hagel, The Superalloys, Wiley-Interscience, New York, 1972, pp15-19

5. G.W.Meetham, ed., The Development of Gas Turbine Materials, John Wiley and Sons, Toronto, 1981.

6. J.Stringer, "The Role of the Coating and Superalloy System in Enabling Advanced Land-Based Combustion Turbine Development", Gas Turbine Materials Technology Proceedings from Materials Solution '98, Otc.12 $15^{\text {th }}$, 1998, Rosement Illinois, ASM International

7. G.Lucas and J.F.Pollock, Gas Turbine Materials, Temple Press Limited, London, UK, 1957, pp3, 106

8. F.L.VerSnyder and M.E.Shank, "The Development of Columnar Grain and Single Crystal High Temperature Materials Through Directional Solidification", Materials Science and Engineering, vol.6, 1970

9. J.J.Jackson, M.J.Donachie, R.J.Henricks and M.Gell, "The Effect of Volume Percent of Fine $\gamma^{\prime}$ on Creep in DS Mar-M200 + Hf', Metallurgical Transactions A, Vol 8A, 1977, pp1615-1620 ' 
10. M.Gell, D.N.Duhl and A.F.Giamel, Superalloys 1980, ed.by J.K.Tien, et al.,ASM. Metals Park, OH, 1980, 205-214.

11. T.S. Piwonka, Directional and Monocrystal Solidification, in Metals Handbook, Ninth Edition, Volume 15: Casting, ASM International, 1988, 319-323

12. J.Matthew, JR.Donachie, Superalloys, American Society for Metals, Metals Park, Ohio pp 103

13. Hillier, Ph.D. Thesis, University of Cambridge, 1984

14. T.M. Pollock, W.H. Murphy, E.H. Goldman, D.L. Uram and J.S. Tu, Superalloys 1992, 125-134, 1992, Warrendale, PA, The Minerals, Metals and Materials Society.

15. M. Durand-Charre, The Microstructure of Superalloys, Gordon and Breach Science Publishers, France, 1997, pp67-69

16. A. Hazotte and A.Simon, "Kinetics and morphology of gamma prime precipitation in single crystal nickel base superalloys", Proc. $I^{\text {st }}$ ASM Europe Tech. Conf. on advanced material and Processing. Techmiques for structural Applications, ed. By T.Khan, A.Lasalmonie, Pub. Onera Paris, 83 90

17. D.N. Duhl, "Single Crystal Superalloys", in Superalloys, Supercomposites and Superceramics, J.K. Tien and T. Caulfield, eds., Academic Press, Inc., Toronto, 1989, pp163.

18. A.D.Cetel and D.N.Duhl, "Second-generation Nickel-base single crystal superalloy", Superalloy 1988, ed. By S.Reichman, D.N.Duhl etc. The Metallurgical Society, 1988, pp235 244 
19. Bradley, E.F., Metallurgy of Superalloys, Superalloys: A Technical Guide, Ed. by E.F. Bradley, ASM International, Ohio, 1990, Chapter 2, p. 43.

20. C.Person and P.O.Persson, "Evaluation of service induced damage and restoration of cast turbine blades", in Superalloys 1992, ed. By S.D.Antolovich, R.W.Stusrud, etc. The Minerals, Metals \& Materials Society, 1992

21. A.C.Lingenfelter, "Nickel Alloys in Gas Turbine Components," Proceedings from Materials Solutions '97 on Joining and Repair of Gas Turbine Components, 1997, pp3-6.

22. C Persson and P-O Persson, "Evaluation of Service Induced Damage and Restoration of Cast Turbine Blades", Superalloys 1992, The Minerals, Metals \& Materials Society, 1992, pp867-876

23. The Jet Engine, Rolls-Royce plc, Derby, England, 1996.

24. http://www.airguard.com/downloads/KA-267.pdf

25. D.B.Doll, "Competitive Requirements for Refurbishment of Gas Turbine Components", Gas Turbine Materials Technology Proceedings from Materials Solution '98, Otc.12 15' ' 1998, Rosement Illinois, ASM International, pp.125

26. Standard Welding Terms and Conditions, ANSI/AWS A3.0-89, American Welding Society, 1989

27. J.F.Lancaster, Metallurgy of Welding, $3^{\text {rd }}$ ed. Pp.6-7

28. Lippold, J.C., "Welding Metallurgy: Nonferrous Alloys, NEMJET Module, Ohio State University, Columbus Ohio, 1999 
29. Haafkens, M.H.and Matthey, J.H.G.Presented at $63^{\text {rd }}$ Meeting of AGARD Structures Materials Panel, Meintenance in Service of High Temp. Parts,Noordwijkerhout, Netherlands, Sept.2-Oct.2, Pp141 143

30. K.Easterling, Introduction to the Physical Metallurgy of Welding, Butterworths \& Co. Publishers, London, 1983

31. G.K.Bouse and J.R.Mihalisin, "Metallurgy of Investment Cast Superalloy Components", in Superalloys, Supercomposites and Superceramics, ed. J.K.Tien and Thomas Caulfield, Academic Press, Boston, 1989, pp99-140

32. J.D.Hunt, Solidification and Casting of Metals, Book 192, The Metals Society, London, 1979, pp3-9

33. H. Jacobi and K.Schwerdtfeger, Metallurgical Transactions, Vol.7A, 1976, pp811-820

34. Hunt J.D. Meterials Science and Engineering 1983 Vol.65, pp75-83

35. M.B. Henderson+, D. Arrellb, M. Heobel*, R. Larssonb and G. Marchantc Nickel-Based Superalloy Welding Practices for Industrial Gas Turbine Applications

36. Keienburg, K. H., W. Esser, and B. Deblon, "Refurbishing Procedures for Blades of Large Stationary Gas Turbines," Materials Science and Technology. Vol. I, August 1985, pp. 620-628

37. Peacock, H. B., Welding Research Council Bulletin (177), 1972.

38. Buchanan, E.R., and R.G. Gullberg, Jr., "A Summary of Factors Affecting Weldability of Nickel Base Turbine Blades' Turbomachinery International, October 1984, pp. 33-36. 
39. Liburdi, J, P. Lowden, and C. Pilcher, "Automated Welding of Turbine Blades," ASME Paper No. 89-GT-307 presented at the Gas Turbine and Aeroengine Congress and Exposition, Toronto, Canada (American Society of Mechanical Engineers, New York, NY, 1989), 6 pp.

40. Swaminathan, V. P. and P. Lowden, "Gas Turbine Blade Life and Assessment Repair Guide," EPRI GS-6544, Project 2775-2 (Electric Power Research Institute, Palo Alto, CA, November 1989), $172 \mathrm{pp}$

41. Gas Tungsten Arc Welding, ASM Handbook, Vol.6, American Society of Metals, Metals Park, OH, pp. 182-203

42. http://wwww.joiningtech.com/laser_services.html

43. Laser Beam Welding, ASM Handbook, Vol.6 (American Society of Metals, Metals Park, OH), pp.647-671

44. Macintype, R.M., "The use of Lasers at Rolls Royce", in conference proceedings Laser Surface Treatment of Metals, San Miniato, Italy, September 1985 (Martinus Nijhoff, Dordrecht, The Netherlands, 1986), pp.545-549

45. Irving,B., "High-powered Lasers Grain Ground for cladding and Hardsurfacing", Welding journal, Vol.70(8), 1991, pp.37

46. Antony, K.C.and G.W.Goward, "Aircraft gas trubine blades and vane repair" Superalloys 1988, from Proceedings of the Sixth International Symposium on Superalloys, Seven Springs Resort, Champion, PA, Sept.1988, The metallurgical Society, pp.745-754

47. Harrison,R.P., "Laser Powder Welding", Turbomachinery International, Vol.35, No.6, 1994, pp.2 
48. S.A.David, J.M.Vitek, S.S.Babu, L.A.Boatner, and R.W.Reed, "Welding of Nickel-Base Superalloy Single Crystals", Sci.Technol.Welding and Joining, Vol. 2, 1997, pp.79-88

49. J.M.Vitek, S.A.David, and L.A.Boatner " Microstructural Development in Single Crystal Nickel-base Superalloy Welds", Sci.Technol.Welding and Joining, Vol. 2, 1997, pp.109-118

50. J.-W.Park, S.S.Babu, J.M.Vitek, E.A.Kenik and S.A.David, "Stray grian formation in sinlge crystal Ni-base superalloy welds", Journal of Applied Physics, Vol.94/06, 2003, pp.4203-4209

51.Z. Feng, S.A.David, T.Zacharia and C.L.Tsai, Science and Technology of Welding and Joining, Vol.2, 1997, 109

52. S.S.Babu, S.A.David, J.M.Vitek and M.K.Miller, "Atom-probe Filed-Ion Microscopy Investigation of CMSX-4 Ni-base Superalloy Laser Beam Welds", $J$. de Physique IV, Vol.6, 1996, pp.C5-253-258

53. S.A.David, S.S.Babu, and J.M.Vitek, "Weldability and Microstructure development in Nickel base superalloys", Mathematical Modeling of Weld Phenomena 4, 1998, pp.269-290

54. M.C. Fleming, Solidification Processing, 1974, New York, NY, Mcgraw Hill, pp.58-66

55. W.Kurz and D.J.Fisher, Fundamentals of Solidification (Aedermannsdorf, Switzerland:TransTech, Publications, 1986).)

56. J.D.Stover,G.Frederick, A.Peterson, "Development of a laser-based/high strength weld filler process to extend repair limites on IN738 gas turbine blades", 
Proceedings of the Fourth RRAC International Welding and Repair Technology for Power Plants Conference, Marco Island, FL June 2000.

57. Y.Hu,V.Reynal,F.Ramundo, and G.Daniak, "Laser Powder repair of Industrial Gas Turbine Blades using IN738LC Nickel-based superalloy", Proceedings of the fourth RRAC international welding and repair technology for power plants conference, Marco Island, FL June 2000.

58. S.Katayama, M.Sakamoto, "Weldability of Ni-Base Single Crystal Superalloys", ASM Material Solutions Conference \& Show, Session 7: Joining and Repair for Engine Components, Oct 18-21, 2004, Columbus, OH, USA

59. J.L.KOCH and J.Mazumder, Proc. ICALEO 1993, Orlando, FL. USA, (ed.P.Denny et al.) Laser Mater. Proc., Vol.2306, pp.556.

60. M.Prager and C.S.Shira, "Welding of Precipitation Hardening Nickel-based Alloys", Welding Research Council Bulletin 128, February 1968

61. M.Gremaud, J.-D. Wagniere, A.Zryd, and W.Kurz, "Laser metal forming: process fundamentals", Surface engineering, Vol.12, No.3

62. H.-W.Bieler, R.Baumann, B.Fritsche ET M.Gaumann, "Repairing Single Crystals", Sulzer Technical Review, Vol.2, 1997, pp.38-41

63. Krause.S, "An advanced repair technique: laser powder build-up welding", Sulzer Technical Review, Vol.83 (4), Dec 2001, pp4039-4041

64. W.Kurz, D.J.Fisher, Fundamentals of Solidification, $4^{\text {th }}$ edition, Trans Tech Publications, Zurich, 1998 
65. W.KurzR. Trivedi "Rapid solidification processing and microstructure formation", Materials Science and Engineering A, Vol. 179-180, Part 1, May 1994, pp.45-61

66. Gäumann-M, Henry-S, Cléton-F, Wagnière-JD, and Kurz-W. “Epitaxial Laser Metal Forming: Analysis of microstructure formation" Materials Science and Engineering A, Vol. 271, N.1-2, 1 November 1999, pp. 232-241

67. M. Gäumann, C. Bezençon, P. Canalis and W. Kurz, "Single-crystal laser deposition of superalloys: processing-microstructure maps", Acta Materialia, Vol. 49, N. 6, 2001, pp. 1051-1062

68. M.B. Hendersont, D. Arrellb, M. Heobel*, R. Larssonb and G. Marchantc, "Nickel-Based Superalloy Welding Practices for Industrial Gas Turbine Applications",

69. Stefan Krause, "An advanced repair technique: Laser powder build-up welding", Sulzer Tech. Review, Vol.83, No.4, Dec 2001, pp.4-6

70. S.Mattheij, "Turbine repairs now possible with laser powder build-up welding technique", Eng. Technol., Vol.5, No.4, May 2002, pp.26-27

71. G.Michael, Glavicic, K.A.Sargent, "The repair of single crystal Nickel superalloy turbine blades using laser engineered net shape (LENS ${ }^{\mathrm{TM}}$ ) technology", UES, Inc. Dayton, ON, 2003, pp.1-18

72. R. J. Grylls, Optomec, Inc., Albuquerque, NM, "Repair of Unrepairable Components by Laser Deposition", ASM Material Solutions Conference \& Show, Session 7: Joining and Repair for Engine Components, Oct 18-21, 2004, Columbus, OH, USA 
73. J. DuPont, W. Liu, "Effect of Melt Pool Geometry on Crystal Growth and Microstructure Development in Laser Surface-Melted Superalloy Single Crystals", ASM Material Solutions Conference \& Show, Session 7: Joining and Repair for Engine Components, Oct 18-21, 2004, Columbus, OH, USA

74. A. Dodd, J. Bialach, Liburdi, "Repair of Turbine Components Using Laser and Filler Wire", ", ASM Material Solutions Conference \& Show, Session 7: Joining and Repair for Engine Components, Oct 18-21, 2004, Columbus, OH, USA

75. L. Li, M. J. Harrison, T. Tang, "Microstructure of Laser Deposited Superalloy Rene-80 on GTD-111", ASM Material Solutions Conference \& Show, Session 7: Joining and Repair for Engine Components, Oct 18-21, 2004, Columbus, OH, USA

76. B.E.Paton, "Eletron Beam Welding: Achievements and Problems: A Review", Soviet technology reviews, Section c, Welding and Surfacing Reviews; Vol.1, PT.1, 1989

77. http://www.globalspec.com/FeaturedProducts/Detail?ExhibitID=14563

78. http://www.weldingengineer.com/1\%20Electron\%20Beam.htm

79. Z.Sun, "Electron beam welding: process and industrial applications", International Journal of Materials and Product Technology, Vol. 10, No. 3-6, $1995, \mathrm{pp} 213$.

80. V.A.Kazakov, "Current state and prospects of the development fo electron beam welding in aerospace technology", Welding International, Vol.9, No.6, 1995, pp471 
81. F.Pierquin and J.Lesgourges, "Study of the electron beam weldability of superalloys through the analysis of melt zone morphology", AGARD Advanced Joining of Aerospace Metallic Material, International Organization, 1986, pp22

82. W-B Busch, H.D.Kunze,U.Draugelates, "Electron Beam Welding of Nickel-based Superalloys-Changes in Microstructure", High temperature materials or power engineering1990: Proceedings of the $4^{\text {th }}$ conference, Liege, Belgium, Sep. 1990 PT.2 (A91-52501 22 26)

83. M.Joseph, Kalinowski, "Weldability of a Nickel-based Superalloy (Final Report)", NASA Contractor Report 195376, Aug. 1994

84. Sorokin. Li, "Electron Beam Welding creep-resisting alloys", Welding Research abroad, Vol.45, No.11, 1999

85. S.S. Babu, S.A.David, M.K.Miller, "Microstructural development in PWA-1480 electron beam welds-An atom probe field ion microscopy study", Applied Surface Science, Vol.94, 1996, pp280

86. S.A.David, J.M.Vitek, S.S.Babu, L.A.Boatner, and R.W.Reed, "Welding of Nickel-Base Superalloy Single Crystals", Sci.Technol.Welding and Joining, Vol. 2, 1997, pp.79-88

87. J.M.Vitek, S.A.David, and L.A.Boatner " Microstructural Development in Single Crystal Nickel-base Superalloy Welds", Sci.Technol.Welding and Joining, Vol. 2, 1997, pp.109-118

88. S.S.Babu, S.A.David, J.W.Park and J.M.Vitek, "Joining of nickel-base superalloy single crystals", unpublished research, Metals and Ceramics Division, Oak Ridge, TN37831-6096, USA 
89. S.S.Babu, S.A.David, and M.K.Miller, "Microstructural Development in PWA1480 Electron Beam Welds---An Atom-probe Filed-Ion Microscope Study", Applied Surface Science, Vol. 94/95, 1996, pp.280-287

90. M.B. Henderson+, D. Arrellb, M. Heobel*, R. Larssonb and G. Marchantc, "Nickel-Based Superalloy Welding Practices for Industrial Gas Turbine Applications"

91. A.K.AbdulJawwad, M.Strangwood and C.L.Davis, "The Role of the Slope Out Region on Fatigue Crack Initiation in Electron Beam Welded Waspaloy", Metallurgical and Materials Transactions A, Vol. 34A, Aug, 2003, pp.1637-1645

92. N.L.Richards, M.C.Chaturvedi, Y.G.Liu and K.Mount, "Optimization of electron beam welding parameters for Incoloy 903", International Journal of Materials and Product Technology, Vol.11, No.3, 1996, pp284 300

93. Philip Threadgill, "Linear Friction Welding", Cambridge Scientific Abstracts, TWI Limited, Granta Park, Great Abington, Cambridge, CBI 6AL, UK. Resource Location---http://www.twi.co.uk/j32k/protected/band_3/ksplt001.html

94. http://www.twi.co.uk/j32k/protected/band_3/ksplt00l.html

95. M.Gaumann, R Trivedi, and W Kurz, "Nucleation ahead of the advancing interface in directional solidification", Mat. Sci. Eng., Vol. A226-228, 1997, pp.763 769

96. J.M.Vitek, S.A.David, "correlation between solidification parameters and weld microstructures", International Materials Reviews, 1989, Vol.34, No.5, pp213245 
97. K.E.Easterling, Introduction to the Physical Metallurgy of Welding, Butterworths Monographs in Materials, Sweden, 1983, pp164

98. J.C.Borland, Br.Weld.J., 1960, Vol.7, pp508-512

99. S.M.Tewari, M.Vijayakumar, J.E.Lee and P.A.Curreri, Mater.Sci.Eng.(A), 1991, Vol.A141, pp97-102

100. W.F. Savage, Weld.World, Vol.18, 1980, pp89

101. J.-W.Park, S.S.Babu, J.M.Vitek, E.A.Kenik and S.A.David, "Stray grain formation in single crystal Ni-base superalloy welds", Journal of Applied Physics, Vol.94 (6), pp4203 4209

102. J.M.Vitek, S.S.Babu, J.-W.Park and S.A.David, "Analysis of stray grain formation in single crystal nickel-based superalloy welds", Superalloys 2004, TMS, ed. K.A.Green, T.M.Pollock pp459 465

103. ASM International Handbook Committee. 1997. ASM Handbook, Vol.6, Welding, brazing, and soldering. ASM International, Materials Park, Ohio 104. V.P.Swaminathan and P.Lowden, "Gas turbine blade life and assessment repair guide", EPRI GS-6544, Project2775-2 (Electric Power Research Institute, Palo Alto, CA. 1989), pp 172 